\title{
Guidelines on the use of iodinated contrast media in patients with kidney disease 2012: digest version
}

\author{
JSN, JRS, and JCS Joint Working Group
}

\author{
Iwao Ohno • Hiromitsu Hayashi $\cdot$ Kazutaka Aonuma - Masaru Horio • Naoki Kashihara • Hirokazu Okada • \\ Yasuhiro Komatsu - Shozo Tamura - Kazuo Awai $\cdot$ Yasuyuki Yamashita $\cdot$ Ryohei Kuwatsuru •

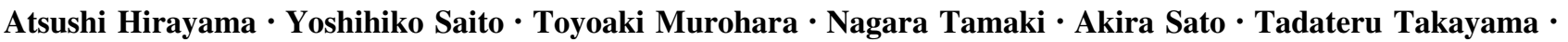 \\ Enyu Imai · Yoshinari Yasuda • Daisuke Koya • Yoshiharu Tsubakihara - Shigeo Horie $\cdot$ Yukunori Korogi \\ Yoshifumi Narumi · Katsumi Hayakawa $\cdot$ Hiroyuki Daida $\cdot$ Koichi Node $\cdot$ Isao Kubota
}

Published online: 25 July 2013

(C) Japanese Society of Nephrology, Japan Radiological Society, and the Japanese Circulation Society 2013

\section{Table of Contents}

1 Outline of the digest version of guidelines on the use of iodinated contrast media in patients with kidney disease................... 549

1.1 Purpose of the guidelines ........................................... 549

1.2 A cautionary note on the use of the present guidelines 549

1.3 Selection of literature, levels of evidence, and grades of recommendations................................................. 549

1.4 Independent assessment .............................................. 550

1.5 Future plans........................................................ 550

1.6 Conflict of interest............................................... 550

1.7 Digest version ...................................................... 550

This guideline was developed in collaboration with the Japanese Society of Nephrology, the Japan Radiological Society, and the Japanese Circulation Society.

This document was approved by the Japanese Society of Nephrology, the Japan Radiological Society, and the Japanese Circulation Society Science Advisory and Coordinating Committee in April 26, 2013.

This article has been copublished in the Clinical and Experimental Nephrology and Circulation Journal.

Permission: Multiple copies, modification, alteration, enhancement, and/or distribution of this document are not permitted without the express permission of the Japan Radiological Society.

The affiliations of the members are as of December 2012.

\section{Ohno}

Chair, Japanese Society of Nephrology, Division of Kidney and Hypertension, Department of Internal Medicine, Jikei University School of Medicine, Tokyo, Japan

\section{H. Hayashi ( $\square)$}

Chair, Japan Radiological Society, Department of Clinical Radiology, Graduate School of Medicine, Nippon Medical School, Tokyo, Japan

e-mail: hhayashi@nms.ac.jp

\section{K. Aonuma}

Chair, Japanese Circulation Society, Cardiovascular Division, Institute of Clinical Medicine, Graduate School of Comprehensive Human Sciences, University of Tsukuba,

Tsukuba, Japan
2 Definition of contrast-induced nephropathy ....................... 550

2.1 CQ 2-1 What is the definition of CIN? .................... 550

3 Risk factors and patient assessment …............................... 552

3.1 CQ3-1 Does CKD increase the risk for developing CIN? 552

3.2 CQ 3-2 Does aging increase the risk for developing CIN? 552

3.3 CQ 3-3 Does diabetes increase the risk for developing CIN? ......................................................... 552

3.4 CQ3-4 Does the use of renin-angiotensin system (RAS) inhibitors increase the risk for developing CIN? ........ 553

3.5 CQ3-5 Does the use of diuretics increase the risk for developing CIN? ........................................................... 553

3.6 CQ3-6 Does the use of non-steroidal anti-inflammatory drugs (NSAIDs) increase the risk for developing CIN? 553

3.7 CQ3-7 Does the use of iodinated contrast media increase the risk of lactic acidosis in patients receiving biguanide antihyperglycemic drugs?.......................................... 553

$3 . 8 \longdiv { \text { CQ3-8 } }$ Does the development of CIN worsen vital prognosis of patients with CKD?................................................ 554

3.9 CQ3-9 Does the use of contrast media increase the risk of a decline of residual kidney function in patients undergoing peritoneal dialysis?.......................................... 556

3.10 CQ3-10 Are risk scores useful as predictors of developing

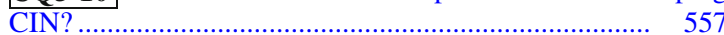

4 Type and volume of contrast media.................................. 558

4.1 CQ4-1 Does the use of a smaller volume of contrast media reduce the risk for developing CIN? (see CQ5-2).... 558

M. Horio

Member, Japanese Society of Nephrology, Department of

Functional Diagnostic Science, Osaka University Graduate

School of Medicine, Suita, Japan

N. Kashihara

Member, Japanese Society of Nephrology, Department of

Nephrology and Hypertension, Kawasaki Medical School,

Kurashiki, Japan

H. Okada

Member, Japanese Society of Nephrology, Department of

Nephrology, Faculty of Medicine, Saitama Medical University,

Saitama, Japan 
4.2 CQ4-2 Is the risk for developing CIN lower in patients receiving low-rather than high-osmolar contrast media? 558

4.3 CQ4-3 Does the risk for developing CIN differ between isoand low-osmolar contrast media? .............................. 558

4.4 CQ4-4 Does the risk for developing CIN differ among different low-osmolar contrast media? ........................... 558

4.5 CQ4-5 Is the risk for developing CIN higher in patients receiving contrast media via invasive (intra-arterial) administration than in those receiving contrast media via noninvasive (intravenous) administration?

5 Invasive diagnostic imaging including cardiac angiography or percutaneous catheter intervention .................................. 560

5.1 CQ5-1 Does CKD increase the risk for developing CIN after CAG? ................................................................. 560

5.2 CQ5-2 Does the use of a smaller volume of contrast medium decrease the risk for developing CIN? ...................... 560

5.3 CQ5-3 Does repeated CAG at short intervals increase the risk for developing CIN? ..................................... 562

5.4 CQ5-4 Does CKD increase the incidence of CIN after PCI?

5.5 CQ5-5 How can CIN be differentiated from kidney injury due to cholesterol embolism?.................................... 564

6 Intravenous contrast media imaging including contrast-enhanced

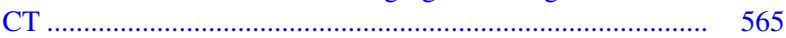

6.1 CQ6-1 Does CKD increase the risk for developing CIN after contrast-enhanced CT?...................................... 565

6.2 CQ6-2 Does the use of a smaller volume of contrast media reduce the risk for developing CIN after contrast-enhanced $\mathrm{CT}$ ?

6.3 CQ6-3 Does repeated contrast-enhanced CT at short intervals increase the risk for developing CIN? ............................ 567

6.4 CQ6-4 Is the risk for developing CIN after contrastenhanced CT higher in outpatients than inpatients?... 567

7 Prevention of contrast-induced nephropathy: fluid therapy. 567

7.1 CQ7-1 Does physiological saline hydration decrease the risk for developing CIN?

567

\section{Y. Komatsu}

Member, Japanese Society of Nephrology, Department of Nephrology, Division of Internal Medicine, St. Luke's International Hospital, Tokyo, Japan

\section{S. Tamura}

Member, Japan Radiological Society, Department of Radiology, Miyazaki Medical College, Miyazaki, Japan

K. Awai

Member, Japan Radiological Society, Department of Diagnostic Radiology, Graduate School of Biomedical Sciences, Hiroshima University, Hiroshima, Japan

\section{Y. Yamashita}

Member, Japan Radiological Society, Department of Diagnostic Radiology, Graduate School of Medical Sciences, Kumamoto University, Kumamoto, Japan

\section{R. Kuwatsuru}

Member, Japan Radiological Society, Department of Radiology, Juntendo University Faculty of Medicine, Tokyo, Japan

\section{A. Hirayama}

Member, Japanese Circulation Society, Division of Cardiovascular Medicine, Department of Medicine, Nihon University School of Medicine, Tokyo, Japan
7.2 CQ7-2 Does oral water intake decrease the risk for developing CIN as much as administration of fluid therapy does? 568

7.3 CQ7-3 Does sodium bicarbonate-based hydration decrease the risk for developing CIN? .................................... 569

7.4 CQ7-4 Is short-term intravenous hydration as effective as standard intravenous hydration in preventing CIN? 570

8 Prevention of contrast-induced nephropathy: pharmacologic ther-

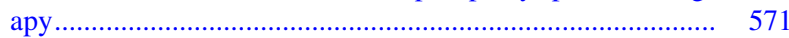

8.1 CQ8-1 Does NAC decrease the risk for developing CIN? 571

8.2 CQ8-2 Does hANP decrease the risk for developing

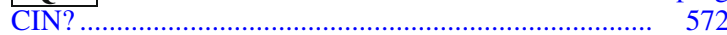

8.3 CQ8-3 Does ascorbic acid decrease the risk for developing CIN? ................................................................. 572

8.4 CQ8-4 Do statins decrease the risk for developing CIN? 572

9 Prevention of contrast-induced nephropathy: dialysis ........ 572

9.1 CQ9-1 Does hemodialysis conducted after contrast exposure as a measure to prevent CIN decrease the risk for developing

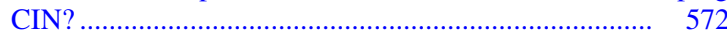

9.2 CQ9-2 Is hemofiltration superior to hemodialysis in decreasing the risk for developing CIN? ............................... 573

10 Treatment of contrast-induced nephropathy ....................... 573

10.1 CQ10-1 Does the treatment of CIN with loop diuretics improve the recovery from AKI? ............................... 573

10.2 CQ10-2 Does fluid therapy prevent the progression of kidney dysfunction in patients with CIN? ........................ 573

10.3 CQ10-3 Does the low-dose dopamine prevent the progression of kidney dysfunction in patients with CIN? ..... 573

10.4 CQ10-4 Does the treatment of CIN with hANP improve recovery from AKI? ................................................... 574

10.5 CQ10-5 Does early renal replacement therapy (RRT) improve the outcome of kidney function in patients with CIN?............................................................... 574

11 Appendix ...................................................................... 575

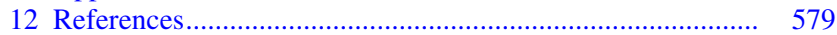

Y. Saito

Member, Japanese Circulation Society, First Department of

Internal Medicine, Nara Medical University, Kashihara, Japan

T. Murohara

Member, Japanese Circulation Society, Department of

Cardiology, Nagoya University Graduate School of Medicine,

Nagoya, Japan

N. Tamaki

Member, Japanese Circulation Society, Department of Nuclear Medicine, Hokkaido University Graduate School of Medicine, Sapporo, Japan

A. Sato

Collaborator, Japanese Circulation Society, Cardiovascular Division, Institute of Clinical Medicine, Graduate School of Comprehensive Human Sciences, University of Tsukuba,

Tsukuba, Japan

T. Takayama

Collaborator, Japanese Circulation Society, Division of Cardiovascular Medicine, Department of Medicine, Nihon University School of Medicine, Tokyo, Japan 


$\begin{array}{ll}\text { Abbreviations } & \\ \text { ACC(F) } & \text { American College of Cardiology (Foundation) } \\ \text { ACR } & \text { American College of Radiology } \\ \text { AHA } & \text { American Heart Association } \\ \text { AKI } & \text { Acute kidney injury } \\ \text { AKIN } & \text { Acute kidney injury network } \\ \text { AP } & \text { Angina pectoris } \\ \text { BNP } & \text { B-type natriuretic peptide } \\ \text { BUN } & \text { Blood urea nitrogen } \\ \text { CAG } & \text { Coronary angiography } \\ \text { CCr } & \text { Creatinine clearance } \\ \text { CHF } & \text { Congestive heart failure } \\ \text { CI } & \text { Confidence interval } \\ \text { CIN } & \text { Contrast-induced nephropathy } \\ \text { CKD } & \text { Chronic kidney disease } \\ \text { CQ } & \text { Clinical question } \\ \text { CT } & \text { Computed tomography } \\ \text { CTA } & \text { Computed tomography angiography } \\ \text { CVVH } & \text { Continuous venovenus hemofiltartion } \\ \text { DSA } & \text { Digital subtraction angiography } \\ \text { eGFR } & \text { Estimated glomerular filtration rate } \\ \text { ESKD } & \text { End-stage kidney disease } \\ \text { ESUR } & \text { European Society of Urogenital Radiology } \\ \text { GFR } & \text { Glomerular filtration rate } \\ \text { hANP } & \text { Human atrial natriuretic peptide } \\ \text { IABP } & \text { Intra-aortic balloon pumping } \\ \text { ICU } & \text { Intensive care unit } \\ & \end{array}$

E. Imai

Executive Office, Japanese Society of Nephrology, Department of Nephrology, Nagoya University Graduate School of Medicine, Nagoya, Japan

Y. Yasuda

Executive Office, Japanese Society of Nephrology, Department of CKD Initiatives Regional Cooperative System, Nagoya University Graduate School of Medicine, Nagoya, Japan

\section{Koya}

Independent Assessment Committee, Japanese Society of Nephrology, Division of Diabetes and Endocrinology, Kanazawa Medical University, Ishikawa, Japan

\section{Y. Tsubakihara}

Independent Assessment Committee, Japanese Society of Nephrology, Department of Comprehensive Kidney Disease Research, Osaka University Graduate School of Medicine, Suita, Japan

\section{S. Horie}

Independent Assessment Committee, Japanese Society of Nephrology, Department of Urology, Teikyo University School of Medicine, Tokyo, Japan

\section{Y. Korogi}

Independent Assessment Committee, Japan Radiological Society, Department of Radiology, University of Occupational and Environmental Health, Kitakyushu, Japan
LVEF Left ventricular ejection fraction

MACD Maximum allowable contrast dose

MHLW Ministry of Health, Labour and Welfare

Minds Medical Information Network Distribution Service

NAC $\quad N$-acetylcysteine

NHI National Health Insurance

NRD Nephropathy requiring dialysis

NS Not significant

NSAIDs Non-steroidal anti-inflammatory drugs

OR Odds ratio

PCI Percutaneous catheter intervention

PREPARED Preparation for Angiography in Renal Dysfunction

PREVENT Preventive strategies of renal insufficiency in patients with diabetes undergoing intervention or arteriography

RAS Renin-angiotensin system

RCT Randomized controlled trial

REMEDIAL Renal Insufficiency Following Contrast Media Administration Trial

RIFLE Risk, Injury, Failure, Loss of kidney function and End stage kidney disease

RR Relative risk

RRT Renal replacement therapy

SCAI Society for Cardiovascular Angiography and Interventions

$\mathrm{SCr} \quad$ Serum creatinine

Scys Serum cystatin C

STEMI ST-elevation myocardial infarction

UAP Unstable angina pectoris

Y. Narumi

Independent Assessment Committee, Japan Radiological

Society, Department of Radiology, Osaka Medical College,

Takatsuki, Japan

K. Hayakawa

Independent Assessment Committee, Japan Radiological

Society, Department of Radiology, Kyoto City Hospital, Kyoto, Japan

H. Daida

Independent Assessment Committee, Japanese Circulation Society, Department of Cardiovascular Medicine, Juntendo University School of Medicine, Tokyo, Japan

K. Node

Independent Assessment Committee, Japanese Circulation Society, Department of Cardiovascular Medicine, Saga

University, Saga, Japan

I. Kubota

Independent Assessment Committee, Japanese Circulation

Society, Department of Cardiology, Pulmonology, and

Nephrology, Yamagata University School of Medicine,

Yamagata, Japan 
1 Outline of the digest version of guidelines on the use of iodinated contrast media in patients with kidney disease

\subsection{Purpose of the guidelines}

Diagnostic imaging using iodinated contrast media is an essential procedure in the clinical setting, and provides a large amount of beneficial information. However, the use of iodinated contrast media may cause contrast-induced nephropathy (CIN) in patients with chronic kidney disease (CKD), and guidelines on the use of contrast media in this patient population have long been awaited. Although international societies such as the European Society of Urogenital Radiology (ESUR) and the American College of Radiology (ACR) have published guidelines on this matter, no guidelines have been proposed in Japan. Therefore, the Japan Radiological Society (JRS), the Japanese Circulation Society (JCS), and the Japanese Society of Nephrology (JSN) decided to collaborate to establish guidelines on the use of iodinated contrast media in patients with kidney disease.

The aim of the guidelines is to ensure the prevention of kidney injury induced by iodinated contrast media by promoting the appropriate use of contrast media and the standardization of kidney function testing in patients undergoing contrast radiography. The target audience of the present guidelines includes physicians who are using contrast media and physicians who order contrast radiography, as well as other healthcare professionals such as radiation technologists and nurses involved in contrast radiography.

The present guidelines have been prepared to provide recommendations for patients with CKD who are at high risk for developing CIN.

The classification of CKD is evaluated on the basis of the cause, kidney function (glomerular filtration rate [GFR]), and presence and severity of albuminuria, patients with CKD may include those in CKD stages G1 and G2 with a GFR of $\geq 60 \mathrm{~mL} / \mathrm{min} / 1.73 \mathrm{~m}^{2}$.

However, readers should be aware that patients with CKD are defined as those with a GFR of $<60 \mathrm{~mL} / \mathrm{min} /$ $1.73 \mathrm{~m}^{2}$ in the present guidelines.

\subsection{A cautionary note on the use of the present guidelines}

The present guidelines have been prepared for use according to the National Health Insurance (NHI) regulations in Japan. The present guidelines provide direction on using contrast media in the clinical setting. Physicians have the final responsibility to maximize the benefits for their patients by deciding, on the basis of their patients' physical and pathological conditions, whether contrast media should be given and whether measures to prevent CIN are necessary. Any use of contrast media that is not consistent with the present guidelines reflects the decisions made by the attending physicians on the basis of conditions specific to their patients, and their decisions should be prioritized. The present guidelines do not provide any legal basis for prosecuting physicians who do not use contrast media according to the guidelines.

\subsection{Selection of literature, levels of evidence, and grades of recommendations}

The present guidelines were prepared according to the procedures proposed by the Medical Information Network Distribution Service (Minds) of the Japan Council for Quality Health Care. The guideline writing committee selected a total of 9 themes regarding CIN. Working groups for the 9 themes, each of which consists of at least 1 representative from 1 of the 3 societies, drafted clinical questions (CQs) for the relevant theme, and selected the CQs to be addressed in the guidelines by using the Delphi method.

The working groups addressed the CQs by critically reviewing literature published from 1960 to August 31, 2011 by using major literature databases (e.g., PubMed, MEDLINE, the Cochrane Library, and the Japana Centra Revuo Medicina [Ichushi]). All documents used as evidence are listed with a level of evidence, and a table of abstracts was prepared (not included in the digest version).

The level of evidence and the grade of recommendation were assigned to the answers to CQs.

The levels of evidence and grades of recommendation are as follows:

\section{Level of evidence}

Level I: Data obtained from a systematic review or a meta-analysis of randomized clinical trials

Level II: Data obtained from at least one randomized comparative clinical trial

Level III: Data obtained from non-randomized comparative clinical trials

Level IVa: Cohort studies

Level IVb: Case-control studies, or cross-sectional studies

Level V: Case reports, or case series

Level VI: Opinions of special committees or specialists with no basis of patient data

\section{Grade of recommendation}

Grade A: A given treatment or procedure is recommended based on robust scientific evidence

Grade B: A given treatment or procedure is suggested based on scientific evidence

Grade C1: A given treatment or procedure may (/might) be considered although scientific evidence is not available 
Grade C2: A given treatment or procedure may (/might) be not considered because scientific evidence is not available

Grade D: A given treatment or procedure is not recommended because scientific evidence indicating the inefficacy or harm of the treatment/procedure is available

The Delphi method was used to finalize the answer to each CQ and determine its grade of recommendation. The reader should give a higher priority to the grade of recommendation of the answer than to the level of evidence. The grade of recommendation has been decided not only based on the level of evidence, but also on the quality and clinical significance of the evidence, extent and conclusions of data on harmful effects and cost effectiveness, depth of coverage by the NHI system, and availability in Japan.

\subsection{Independent assessment}

The present guidelines were reviewed by the independent assessment committee consisting of 3 representatives each from the JSN, JRS, and JCS. The final draft of the guidelines was published on Web pages of the 3 societies along with a request for public comments. The guideline writing committee discussed the comments, used them to revise the guidelines when appropriate, and finalized the guidelines.

\subsection{Future plans}

After the publication as a printed book from Tokyo Igakusha, the Japanese version of the guidelines will be published in the Japanese Journal of Nephrology, and as a JCS guideline document, and then will be published on-line on the Web sites of the member societies. An English version will be prepared and published on the English journals of member societies. The guidelines will also be published on the Minds of the Japan Council for Quality Health Care.

The full and digest versions of the guidelines are planned to be revised every 5 years. A new writing committee will be established by representatives of member societies to maintain unbiased appropriate guidelines.

\subsection{Conflict of interest}

Expenses for the meetings of the guideline writing committee were covered with a Health Labour Sciences Research Grant for the early detection, prevention, treatment standardization, and prevention of progression of CKD by the Ministry of Health, Labour and Welfare (MHLW) research project chaired by Enyu Imai, and supported by the JSN. Transportation expenses of committee members were covered by the JSN, JRS, and JCS.

Conflict of interest statements were provided by all committee members involved in the preparation or review of the guidelines, and managed by the relevant societies.

\subsection{Digest version}

The digest version does not contain the abstract table. The body texts such as background were deleted or modified to simplify the document. All tables and figures of the full-text version are used in the digest version. Additional tables were prepared to summarize the body text (see Appendix). The reader should refer to the full-text version to understand the guidelines in depth.

\section{Definition of contrast-induced nephropathy}

\subsection{CQ 2-1 What is the definition of CIN?}

\section{Answer:}

CIN is defined as an increase in serum creatinine ( $\mathrm{SCr}$ ) levels by $\geq 0.5 \mathrm{mg} / \mathrm{dL}$ or $\geq 25 \%$ from baseline within $72 \mathrm{~h}$ after a contrast radiography using iodinated contrast media.

\section{Rationale CQ 2-1}

Because the risk for developing CIN increases as kidney function decreases, it is important to evaluate kidney function on the basis of the latest SCr levels prior to contrast radiography. According to the classification of the severity of CKD, which is based on the cause, GFR, and presence and severity of albuminuria (Table 1) [1], patients with a GFR of $<60 \mathrm{~mL} / \mathrm{min} / 1.73 \mathrm{~m}^{2}$ (G3a-G5) are considered to have CKD in this guideline. In another words, CKD is also diagnosed in patients with a GFR of $\geq 60 \mathrm{~mL} /$ $\min / 1.73 \mathrm{~m}^{2}$ and albuminuria, in the present guidelines only patients with a GFR of $<60 \mathrm{~mL} / \mathrm{min} / 1.73 \mathrm{~m}^{2}$ are defined as having CKD.

The following formula is used to calculate estimated GFR (eGFR).

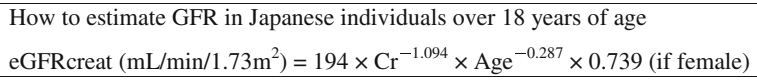

CIN is a form of acute kidney injury (AKI) that occurs after exposure to iodinated contrast media, and is diagnosed on the basis of reducing kidney function after contrast radiography when other causes such as cholesterol embolism are ruled out. AKI due to CIN is generally reversible. Usually, SCr levels increase to a peak 3-5 days after onset, and return to normal in 7-14 days. However, kidney injury may worsen to the point that hemodialysis is required in some patients.

The criteria for the diagnosis of CIN used in clinical research of this condition vary among studies. The minimum increment of SCr levels that defined CIN included $0.5 \mathrm{mg} / \mathrm{dL}$, $1.0 \mathrm{mg} / \mathrm{dL}$, and $25 \%$ or $50 \%$ from baseline, and the duration of monitoring for CIN included $24 \mathrm{~h}, 48 \mathrm{~h}, 72 \mathrm{~h}, 4$ days, and 7 days after contrast radiography. The most commonly used criteria for $\mathrm{CIN}$ in clinical research is an increase in $\mathrm{SCr}$ levels by $\geq 0.5 \mathrm{mg} / \mathrm{dL}$ or $\geq 25 \%$ from baseline within $72 \mathrm{~h}$ after 
Table 1 Classification of severity of CKD (2012)

\begin{tabular}{|c|c|c|c|c|c|c|}
\hline \multicolumn{2}{|c|}{ Underlying disease } & \multicolumn{2}{|c|}{$\begin{array}{l}\text { Albuminuria categories, } \\
\text { description, and range }\end{array}$} & A1 & A2 & A3 \\
\hline \multirow{2}{*}{\multicolumn{2}{|c|}{ Diabetes }} & \multicolumn{2}{|c|}{ Urine albumin (mg/day) } & Normal & Microalbuminuria & Macroalbuminuria \\
\hline & & \multicolumn{2}{|c|}{$\begin{array}{l}\text { Urine albumin/Cr ratio } \\
(\mathrm{mg} / \mathrm{gCr})\end{array}$} & $<30$ & $30 \sim 299$ & $\geq 300$ \\
\hline \multirow{2}{*}{\multicolumn{2}{|c|}{$\begin{array}{l}\text { Nephritis } \\
\text { Hypertension } \\
\text { Polycystic kidney disease } \\
\text { Renal transplantation } \\
\text { Unknown } \\
\text { Others }\end{array}$}} & \multicolumn{2}{|c|}{ Urine protein (g/day) } & Normal & Mild proteinuria & Severe proteinuria \\
\hline & & \multicolumn{2}{|c|}{$\begin{array}{l}\text { Urine protein/Cr ratio } \\
\qquad(\mathrm{g} / \mathrm{gCr})\end{array}$} & $<0.15$ & $0.15 \sim 0.49$ & $\geq 0.50$ \\
\hline \multirow{6}{*}{$\begin{array}{c}\text { GFR categories } \\
\left(\mathrm{mL} / \mathrm{min} / 1.73 \mathrm{~m}^{2}\right), \\
\text { description and } \\
\text { range }\end{array}$} & G1 & Normal or high & $\geq 90$ & & & \\
\hline & G2 & $\begin{array}{c}\text { Normal or mildly } \\
\text { decreased }\end{array}$ & $60 \sim 89$ & & & \\
\hline & G3a & $\begin{array}{l}\text { Mildly to } \\
\text { moderately } \\
\text { decreased }\end{array}$ & $45 \sim 59$ & & & \\
\hline & $\mathrm{G} 3 \mathrm{~b}$ & $\begin{array}{c}\text { Moderately to } \\
\text { severely } \\
\text { decreased } \\
\end{array}$ & $30 \sim 44$ & & & \\
\hline & G4 & $\begin{array}{c}\text { Severely } \\
\text { decreased }\end{array}$ & $15 \sim 29$ & & & \\
\hline & G5 & $\begin{array}{l}\text { Kidney failure } \\
\text { (ESKD) }\end{array}$ & $<15$ & & & \\
\hline
\end{tabular}

Risks of ESKD requiring dialysis or transplantation, and risks for cardiovascular diseases such as stroke, myocardial infarction, and heart failure are coded with colors ranging from green (lowest), yellow, orange and red (highest)

$C K D$ chronic kidney disease, $C r$ creatinine, ESKD end-stage kidney disease, GFR glomerular filtration rate

Adapted from KDIGO 2012 Clinical Practice Guideline for the Evaluation and Management of Chronic Kidney Disease. Kidney Inter Suppl. 2013;3:19-62 [1], with permission from Nature Publishing Group., modified for Japanese patients

contrast radiography. However, physicians in the clinical setting should not wait for $72 \mathrm{~h}$, and should start close monitoring of SCr levels from an early stage when CIN is suspected. The incidence of CIN, and clinical characteristics such as patients' baseline kidney function, vary depending on the criteria used for diagnosis. Standardized diagnostic criteria are necessary to promote clinical research of this condition and develop preventive procedures.

\footnotetext{
Definition and Severity Classification of Acute Kidney Injury

CIN is a form of AKI. The RIFLE (Risk, Injury, Failure, Loss of kidney function and End

stage kidney disease) and AKIN (Acute Kidney Injury Network) classification are used as

the international diagnostic criteria of AKI. Both methods assess severity based on the

extent of decrease in kidney function (e.g., SCr, eGFR) and urine volume. However, most

commonly CIN manifests as a non-oliguric. For this reason, $\mathrm{CIN}$ is defined as an increase

in $\mathrm{SCr}$ levels in the present guidelines.
}

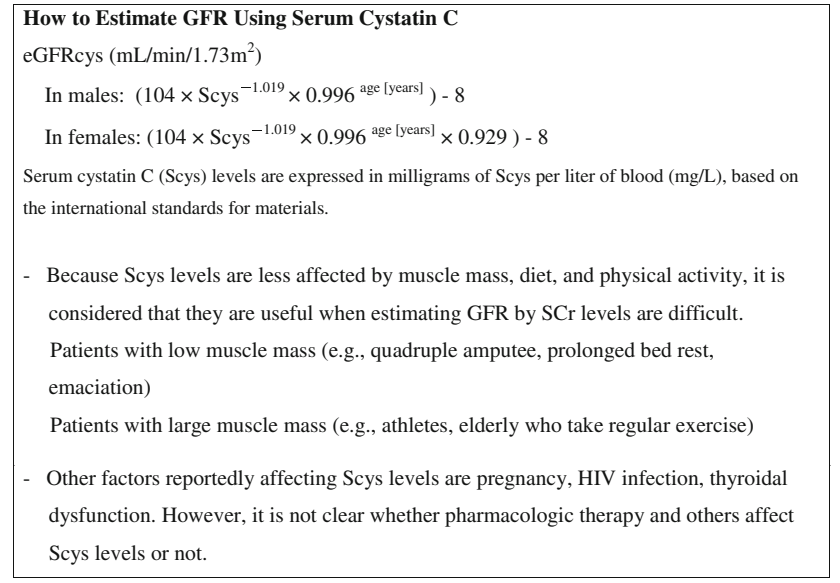




\section{Risk factors and patient assessment} 3.1 CQ3-1 Does CKD increase the risk for developing
CIN?

Answer:

CKD (GFR $<60 \mathrm{~mL} / \mathrm{min} / 1.73 \mathrm{~m}^{2}$ ) is a risk factor for the development of CIN.

\section{Level of Evidence: IVa Grade of Recommendation: Not applicable}

3.2 CQ 3-2 Does aging increase the risk for developing CIN?

\section{Answer:}

Aging is a risk factor for the development of CIN.

Level of Evidence: IVa Grade of Recommendation: Not applicable

3.3 CQ 3-3 Does diabetes increase the risk for developing CIN?

\section{Answer:}

Although diabetes associated with CKD (GFR $<60 \mathrm{~mL} /$ $\mathrm{min} / 1.73 \mathrm{~m}^{2}$ ) is a risk factor for the development of CIN, it is unclear whether diabetes not associated with CKD is a risk factor.

Level of Evidence: IVa Grade of Recommendation: Not applicable

\section{Rationale CQ3-1 3-3}

In 2006, the CIN Consensus Working Panel reported that CKD (eGFR $<60 \mathrm{~mL} / \mathrm{min} / 1.73 \mathrm{~m}^{2}$ ) is the most important risk factor to predict the risk of CIN in patients receiving iodinated contrast media [2]. In a study of CIN after percutaneous catheter interventions (PCI), the incidence of CIN was significantly lower in patients without CKD (13.1\%, $688 / 5,250$ patients) than in those with CKD (eGFR $<60 \mathrm{~mL} /$ $\min / 1.73 \mathrm{~m}^{2}, 19.2 \%, 381 / 1,980$ patients) [3]. A retrospective analysis of the Mayo Clinic PCI registry revealed that among patients with baseline SCr levels $<2.0 \mathrm{mg} / \mathrm{dL}$, the risk of AKI was higher among diabetic than nondiabetic patients, whereas among those with baseline SCr levels of $\geq 2.0 \mathrm{mg} / \mathrm{dL}$, all had a significant risk of AKI [4].

Weisbord et al. [5] reported that the risk of CIN among outpatients after computed tomography (CT) with intravenous iodinated contrast media increased significantly among those with an eGFR of $<45 \mathrm{~mL} / \mathrm{min} / 1.73 \mathrm{~m}^{2}$, and $\mathrm{Kim}$ et al. [6] reported that the incidence of CIN after contrast-enhanced $\mathrm{CT}$ was $0 \%$ among patients with a baseline eGFR of $45-59 \mathrm{~mL} / \mathrm{min} / 1.73 \mathrm{~m}^{2}, 2.9 \%$ among those with $30-44 \mathrm{~mL} / \mathrm{min} / 1.73 \mathrm{~m}^{2}$, and $12.1 \%$ among those with $<30 \mathrm{~mL} / \mathrm{min} / 1.73 \mathrm{~m}^{2}$.

The guidelines on CIN published by the Contrast Media Safety Committee of the ESUR describe that the risk for CIN is lower with intravenous than with intra-arterial imaging with iodinated contrast medium, that an eGFR of $45 \mathrm{~mL} /$ $\min / 1.73 \mathrm{~m}^{2}$ is a CIN risk threshold for the use of intravenous contrast media, and that measures to prevent CIN such as hydration with either normal saline or isotonic sodium bicarbonate are preferable for patients with an eGFR of $<45 \mathrm{~mL} / \mathrm{min} / 1.73 \mathrm{~m}^{2}$ as a measure to prevent CIN [7].

While an eGFR of $<60 \mathrm{~mL} / \mathrm{min} / 1.73 \mathrm{~m}^{2}$ is an established risk factor for the development of CIN in diabetes, diabetes is also considered to be a risk-enhancing factor. The risk for development of CIN is increased when patients with CKD also have diabetes [8].

In a study on CIN risk after coronary angiography (CAG), only patients with pre-existing CKD alone or combined with diabetes were at a higher risk for CIN [9]. In a study of CIN in patients with diabetes, CKD, or both, the risk increased in patients with both diabetes and CKD, but did not increase in patients with diabetes, or patients with CKD [10]. In a metaanalysis of pooled individual patient data $(n=2,727)$ from 16 randomized controlled trials (RCTs) in which patients received either the iso-osmolar contrast media (iodixanol) or low-osmolar contrast media, the independent predictors of CIN included CKD, CKD plus diabetes, and the use of lowosmolar contrast media [11].

Many studies have reported that aging and diabetes may increase the risk for the development of CIN. In a cohort study of 3,036 patients with baseline SCr levels $(<1.5 \mathrm{mg} /$ $\mathrm{dL}$ ) who did not receive prophylaxis while undergoing PCI, CIN occurred in $7.3 \%$ of patients [12]. Risk factors for CIN included age (odds ratio [OR] 6.4, $95 \%$ confidence interval [CI] 1.01-13.3), female sex (OR 2.0, $95 \%$ CI 1.5-2.7), an abnormal left ventricular ejection fraction (LVEF) of $<50 \%$ (OR 1.02, $95 \%$ CI 1.01-1.04), the presence of anemia with hemoglobin levels of $<11 \mathrm{mg} / \mathrm{dL}$ (OR 1.5, $95 \%$ CI 1.01-2.4), and systolic hypotension with blood pressure of $<100 \mathrm{mmHg}$ (OR 1.5, $95 \%$ CI 1.01-2.2). Patients with diabetes who were receiving insulin therapy were at the highest risk compared with similar patients receiving oral antihyperglycemic agents and diet control.

In an observational study, CIN developed in $15.44 \%$ of 136 patients who underwent CAG and measures to prevent CIN. The risk factors that seemed to display the best correlation with the risk of CIN were advanced age and heart failure ( $\mathrm{LVEF}<40 \%)$. The concomitant presence of heart failure, anemia, diabetes, previous myocardial infarction, and advanced age ( $>70$ years) was associated with a threefold increased risk of CIN [13]. 
3.4 CQ3-4 Does the use of renin-angiotensin system (RAS) inhibitors increase the risk for developing CIN?

\section{Answer:}

There is no evidence that RAS inhibitors increase the risk for developing CIN.

\section{Level of Evidence: IVa Grade of Recommendation: C2}

\section{Rationale CQ3-4}

There is no evidence that the use of RAS inhibitors increases the risk for developing CIN.

The results of observational studies on the effects of RAS inhibition on the risk of CIN have been inconsistent [14, 15], but some nephrologists have suggested that RAS inhibition may increase the incidence of CIN. In a RCT to evaluate the effect of discontinuing RAS inhibitors prior to exposure to radiographic contrast media, there was no statistically significant difference in the incidence of CIN between those patients discontinuing RAS inhibitors and those continuing treatment [16]. This finding does not support the discontinuation of RAS inhibitors prior to exposure to contrast media. The Society for Cardiovascular Angiography and Interventions (SCAI) recommended that RAS inhibitor therapy may be continued, but neither initiating treatment nor enhancing the dose should be considered [17].

3.5 CQ3-5 Does the use of diuretics increase the risk for developing CIN?

\section{Answer:}

We consider not to use diuretics, especially loop diuretics, which increases the risk for developing CIN.

\section{Level of Evidence: II Grade of Recommendation: C2}

\section{Rationale CQ3-5}

It has been reported that treatment with loop diuretics to prevent CIN increased the incidence of CIN [18]. Diuretics should be discontinued before exposure to radiographic contrast media when clinically feasible [17]. Loop diuretics increase the incidence of CIN even in patients without dehydration. In a study in which patients received hydration with $0.45 \%$ saline, or $0.45 \%$ saline plus loop diuretics, the incidence of CIN was significantly higher in those receiving loop diuretics than in those receiving saline alone [19].

Recently, two RCTs have reported that the incidence of CIN decreased significantly in patients receiving a combination of aggressive saline infusion and furosemide through devices that balanced high urine output and venous fluid infusion to maintain a urine output of $300 \mathrm{~mL} / \mathrm{h}$ (see
"Prevention of contrast-induced nephropathy: fluid therapy”) [20, 21].

3.6 CQ3-6 Does the use of non-steroidal anti-inflammatory drugs (NSAIDs) increase the risk for developing CIN?

Answer:

We consider not to use NSAIDs because NSAIDs may increase the risk for developing CIN.

\section{Level of Evidence: II Grade of Recommendation: C2}

\section{Rationale CQ3-6}

Although an observational study showed that the development of CIN is more frequently observed in patients taking NSAIDs [22], there is no direct evidence indicating an association between NSAIDs and CIN. Patients receiving NSAIDs should discontinue them $24 \mathrm{~h}$ before, and not renew treatment till $24 \mathrm{~h}$ after, contrast radiography $[17,23]$.

\subsection{CQ3-7 Does the use of iodinated contrast media} increase the risk of lactic acidosis in patients receiving biguanide antihyperglycemic drugs?

\section{Answer:}

Biguanide antihyperglycemic drugs increase the risk of developing lactic acidosis when a transient decrease in kidney function occurs after the use of iodinated contrast media. Appropriate measures, such as a temporary suspension of biguanides before the use of iodinated contrast media, are considered for most patients excluding those who undergo an emergency procedure.

\section{Level of Evidence: I Grade of Recommendation: C2}

\section{Rationale CQ3-7}

Lactic acidosis is one of the most serious adverse drug reactions to biguanide antihyperglycemic drugs. Although the incidence is very low, the prognosis of lactic acidosis is poor and mortality is high. Conditions that may lead to lactic acidosis include kidney diseases (as biguanides are excreted unchanged through the kidneys, biguanide concentration in the blood may increase in patients with kidney dysfunction), liver disease (hepatic dysfunction decreases lactic acid metabolism in the liver), heart failure, myocardial infarction, and respiratory failure (hypoxemia may occur and accelerate anaerobic glycolysis, which increases the production of lactic acid). In Japan, biguanides are contraindicated for patients with a high risk for developing lactic acidosis. Currently, the risk for lactic acidosis due to 
biguanides is very low when these drugs are used according to the approved indications.

However, when patients receiving biguanides develop AKI due to the use of iodinated contrast media, renal excretion of biguanides may decrease and lactic acidosis may develop. There have been reported cases of biguanideassociated lactic acidosis occurring after AKI due to the use of iodinated contrast media in patients with conditions known to increase the risk of lactic acidosis [24, 25]. Reviews of case series of CIN in patients receiving biguanides have been published [26-28].

Guidelines published in Western countries recommend measures be taken for patients receiving biguanides who are going to use iodinated contrast media. Although the recommended measures vary among guidelines, most guideline documents do not recommend the suspension of biguanides in patients with normal kidney function before the use of iodinated contrast media [29-31] (Table 2).

The second paragraph of the "Important Precautions" section of the package inserts for biguanides in Japan describes that "Because patients receiving biguanides may develop lactic acidosis after the use of iodinated contrast medium, treatment with biguanides should be suspended before contrast radiography (except for patients requiring emergency radiography)". Treatment with biguanides should not be resumed during the $48 \mathrm{~h}$ after the use of iodinated contrast media. Physicians should carefully observe patients when treatment with biguanides is resumed. The "Recommendations for Appropriate Use of Biguanides" published on February 1, 2012 by the committee on appropriate use of biguanides (available in Japanese at the Web sites of the Japan Diabetes Society [http://www.jds.or.jp/] and the Japan Association for Diabetes Education and Care [http://www. nittokyo.or.jp/]) describe that kidney dysfunction is common among patients with lactic acidosis associated with the use of biguanides, and attention should be given to the risk for an acute exacerbation of kidney dysfunction after the use of iodinated contrast media in patients receiving biguanides. Accordingly, the present guidelines recommend that patients using biguanides should discontinue the drugs prior to the use of iodinated contrast media, except for cases requiring emergency contrast radiography, and should undergo other appropriate measures to prevent CIN.

\subsection{CQ3-8 Does the development of CIN worsen vital prognosis of patients with CKD?}

\section{Answer:}

The development of CIN may adversely affect the vital prognosis of patients with $\mathrm{CKD}$, and the prognosis of CKD patients with CIN is poor. However, it is unclear whether CIN is a factor that defines or predicts the prognosis.

\section{Level of Evidence: IVa Grade of Recommendation: Not applicable}

\section{Rationale CQ3-8}

Although it is believed that CIN is transient and kidney function recovers in most patients, many reports described that the development of CIN affects vital prognosis [3, 32-41].

In a prospective study of 78 patients with CKD who underwent CAG, mortality at 5 years of follow-up were significantly higher among the 10 patients who developed reversible AKI (90\%) as compared with the 68 patients who had irreversible AKI (32\%) [32]. In a retrospective case-matched cohort study of 809 patients who developed CIN after CT, CT angiography (CTA), angiography, contrast venography, or cardiac catheterization $(53 \%$ of them received intravenous contrast media), and 2,427 patients who did not develop CIN after contrast exposure, 1-year mortality was significantly higher in patients with CIN (31.8\%) than in those without CIN (22.6\%) [33]. In a study of the effects of CIN after the use of ioxaglate on the morbidity and mortality of 439 patients undergoing PCI, the cumulative 1-year mortality was significantly higher in the 161 patients with CIN (37.7 \%) than in the 278 patients without CIN (19.4\%) [34]. In a study of 338 consecutive patients with acute coronary syndrome undergoing emergency PCI, the in-hospital mortality was significantly higher in the 94 patients with CIN (9.6\%) than in the 244 patients without CIN (3.3\%) [35].

Although it is believed that the incidence of CIN is lower in patients receiving contrast media intravenously than in those receiving it intra-arterially, few reports have described the incidence of CIN and its effect on vital prognosis in patients receiving intravenous contrast media, and no consensus has been achieved regarding the difference in CIN incidence by route of administration [42, 43].

In a study of 421 patients with eGFR of $<60 \mathrm{~mL} / \mathrm{min} /$ $1.73 \mathrm{~m}^{2}$ who underwent contrast- enhanced CT with intravenous iodinated contrast media, no significant correlation was observed between the incidence of CIN and the 30-day mortality [5]. In a 1-year retrospective review of 1,184 trauma patients who received intravenous contrast media, the inhospital mortality was significantly higher in the 78 patients with CIN (9.0 \%) than in those without CIN (3.2 \%), but a logistic regression analysis revealed no significant correlation between the in-hospital mortality and CIN [44]. In a study of 139 patients undergoing contrast-enhanced $\mathrm{CT}$ in an intensive care unit (ICU) setting, the ICU mortality and in-hospital mortality in the 16 patients with CIN (31 and $50 \%$, respectively) tended to be higher than those in the 123 patients without CIN (13 and $26 \%$, respectively), but no statistically significant differences in these variables were observed 
Table 2 Comparison of guidelines on the use of iodinated contrast media in patients with diabetes who are receiving biguanide antihyperglycemic drugs

\begin{tabular}{|c|c|c|c|c|c|}
\hline JDS & $\mathrm{ACR}$ & CAR & ESUR & RCR & RANZCR \\
\hline \multicolumn{6}{|c|}{ Measures of kidney function } \\
\hline No description. & SCr level & eGFR & eGFR (or SCr level) & eGFR and SCr level & eGFR (or SCr level) \\
\hline \multicolumn{6}{|c|}{ Definition of abnormal kidney function } \\
\hline No description. & $>1.5 \mathrm{mg} / \mathrm{dL}$ & $<45 \mathrm{~mL} / \mathrm{min} / 1.73 \mathrm{~m}^{2}$ & $<60 \mathrm{~mL} / \mathrm{min} / 1.73 \mathrm{~m}^{2}$ & $\begin{array}{l}\text { eGFR }<60 \\
\mathrm{~mL} / \mathrm{min} / 1.73 \mathrm{~m}^{2} \\
\text { SCr level: no } \\
\text { description. }\end{array}$ & No description. \\
\hline \multicolumn{6}{|c|}{ When should biguanide antihyperglycemic drugs be discontinued in patients with normal kidney function? } \\
\hline $\begin{array}{l}\text { Prior to contrast } \\
\text { exposure. }\end{array}$ & $\begin{array}{l}\text { Patients with normal } \\
\text { kidney function and no } \\
\text { known comorbidities: } \\
\text { there is no need to } \\
\text { discontinue metformin } \\
\text { prior to intravenous } \\
\text { contrast administration. } \\
\text { Patients with multiple } \\
\text { comorbidities who } \\
\text { apparently have normal } \\
\text { kidney function: } \\
\text { metformin should be } \\
\text { discontinued at } \\
\text { intravenous contrast } \\
\text { administration and } \\
\text { withheld for } 48 \text { hours. }\end{array}$ & $\begin{array}{l}\text { Patients with normal } \\
\text { baseline kidney function } \\
\text { who are scheduled to } \\
\text { receive normal volumes } \\
(<100 \mathrm{~mL}) \text { of contrast } \\
\text { media: it is generally } \\
\text { unnecessary to stop } \\
\text { metformin prior to } \\
\text { contrast injection and to } \\
\text { recheck kidney function, } \\
\text { but special care should } \\
\text { be taken in patients with } \\
\text { severe or acute kidney } \\
\text { injury. }\end{array}$ & $\begin{array}{l}\text { Patients with normal kidney } \\
\text { function can continue } \\
\text { metformin normally. }\end{array}$ & $\begin{array}{l}\text { Patients with normal } \\
\text { kidney function: there } \\
\text { is no need to stop } \\
\text { metformin after } \\
\text { contrast } \\
\text { administration. }\end{array}$ & $\begin{array}{l}\text { Patients with normal } \\
\text { kidney function: } \\
\text { metformin does not } \\
\text { need to be discontinued } \\
\text { providing that the } \\
\text { amount of contrast used } \\
\text { is } \leq 100 \mathrm{~mL} \text {. }\end{array}$ \\
\hline \multicolumn{6}{|c|}{ When should biguanide antihyperglycemic drugs be discontinued in patients with kidney dysfunction? } \\
\hline $\begin{array}{l}\text { Biguanide } \\
\text { antihyperglycemic } \\
\text { drugs are } \\
\text { contraindicated } \\
\text { for patients with } \\
\text { kidney } \\
\text { dysfunction. }\end{array}$ & $\begin{array}{l}\text { In patients taking } \\
\text { metformin who are } \\
\text { known to have kidney } \\
\text { dysfunction, metformin } \\
\text { should be suspended at } \\
\text { the time of contrast } \\
\text { exposure. }\end{array}$ & $\begin{array}{l}\text { Patients with an eGFR } \\
<45 \mathrm{~mL} / \mathrm{min} / 1.73 \mathrm{~m}^{2}: \\
\text { metformin should be } \\
\text { discontinued at the time } \\
\text { of contrast exposure and } \\
\text { should not be restarted } \\
\text { for } \geq 48 \text { hours. } \\
\text { Patients with an eGFR } \\
<30 \mathrm{~mL} / \mathrm{min} / 1.73 \mathrm{~m}^{2} \text { or } \\
\text { who are in acute kidney } \\
\text { injury: it would be } \\
\text { appropriate to stop } \\
\text { metformin } 48 \text { hours } \\
\text { prior to a non-urgent } \\
\text { contrast exposure. }\end{array}$ & $\begin{array}{l}\text { Patients with an eGFR } 45 \sim \\
<60 \mathrm{~mL} / \mathrm{min} / 1.73 \mathrm{~m}^{2} \text { who are } \\
\text { receiving intravenous contrast } \\
\text { medium: can continue to take } \\
\text { metformin normally. } \\
\text { Patients with an eGFR } 30 \sim< \\
59 \mathrm{~mL} / \mathrm{min} / 1.73 \mathrm{~m}^{2} \text { who are } \\
\text { receiving intra-arterial } \\
\text { contrast media, and those } \\
\text { with an eGFR } 30 \sim<44 \\
\text { mL/min/1.73 } \mathrm{m}^{2} \text { who are } \\
\text { receiving intravenous contrast } \\
\text { media: should stop metformin } \\
48 \text { hours before contrast } \\
\text { medium injection. } \\
\text { Patients with an eGFR }<30 \\
\text { mL/min/1.73 }{ }^{2}, \text { or with an } \\
\text { intercurrent illness causing } \\
\text { reduced kidney function or } \\
\text { hypoxia: metformin is } \\
\text { contraindicated and iodine- } \\
\text { based contrast media should } \\
\text { be avoided. } \\
\text { Patients with a medical } \\
\text { emergency: metformin should } \\
\text { be discontinued from the time } \\
\text { of contrast medium } \\
\text { administration. After the } \\
\text { procedure, the patient should } \\
\text { be monitored for signs of } \\
\text { lactic acidosis. }\end{array}$ & $\begin{array}{l}\text { Patients with abnormal } \\
\text { kidney function: any } \\
\text { decision to stop } \\
\text { metformin for } 48 \\
\text { hours should be made } \\
\text { in consultation with } \\
\text { the referring clinic. }\end{array}$ & $\begin{array}{l}\text { Patients with kidney } \\
\text { dysfunction: metformin } \\
\text { should be discontinued } \\
\text { for } \geq 48 \text { hours prior to } \\
\text { the contrast } \\
\text { examination. }\end{array}$ \\
\hline \multicolumn{6}{|c|}{ Timing of SCr measurements prior to contrast exposure } \\
\hline No description. & No description. & $\begin{array}{l}\text { Stable outpatients: }<6 \\
\text { months. } \\
\text { Inpatients and patients } \\
\text { with unstable or acute } \\
\text { kidney injury: }<1 \text { week. }\end{array}$ & $\begin{array}{l}\text { Determine eGFR (or } \mathrm{SCr} \\
\text { levels) within } 7 \text { days of } \\
\text { contrast medium } \\
\text { administration. }\end{array}$ & $\begin{array}{l}\text { Stable patients: }<3 \\
\text { months. } \\
\text { Patients with acute } \\
\text { illness or kidney } \\
\text { disease: }<7 \text { days. }\end{array}$ & $\begin{array}{l}\text { Stable outpatients: }<3 \\
\text { months. } \\
\text { Inpatients with stable } \\
\text { kidney function: }<7 \\
\text { days. } \\
\text { Inpatients with high SCr } \\
\text { levels: SCr level may } \\
\text { take } 7 \sim 10 \text { days to } \\
\text { stabilize after kidney } \\
\text { injury. }\end{array}$ \\
\hline
\end{tabular}


Table 2 continued

\begin{tabular}{|c|c|c|c|c|}
\hline No description. & $\begin{array}{l}\text { In patients with normal } \\
\text { kidney function and no } \\
\text { known comorbidities: } \\
\text { there is no need to check } \\
\text { creatinine levels after } \\
\text { the test or procedure. } \\
\text { In patients with multiple } \\
\text { comorbidities who } \\
\text { apparently have normal } \\
\text { kidney function: a } \\
\text { procedure for } \\
\text { reassessing kidney } \\
\text { function should be } \\
\text { established. A repeat } \\
\text { SCr measurement is not } \\
\text { mandatory. }\end{array}$ & $\begin{array}{l}\text { Patients with normal } \\
\text { kidney function: it is } \\
\text { unnecessary to recheck } \\
\text { kidney function after the } \\
\text { use of contrast media. } \\
\text { Patients with kidney } \\
\text { dysfunction who } \\
\text { discontinued metformin } \\
\text { prior to the procedure: } \\
\text { kidney function is } \\
\text { rechecked at } 48 \text { hours } \\
\text { after the procedure and } \\
\text { thereafter whenever } \\
\text { necessary. }\end{array}$ & $\begin{array}{l}\text { Restart metformin } 48 \text { hours } \\
\text { after contrast medium } \\
\text { administration. }\end{array}$ & $\begin{array}{l}\text { Patients with normal } \\
\text { kidney function: no } \\
\text { need to retest the kidney } \\
\text { function. } \\
\text { Patients with kidney } \\
\text { dysfunction: kidney } \\
\text { function should be } \\
\text { reassessed before } \\
\text { restarting metformin. }\end{array}$ \\
\hline \multicolumn{5}{|c|}{ When should biguanide antihyperglycemic drugs be restarted? } \\
\hline $\begin{array}{l}\text { Biguanides should } \\
\text { be discontinued } \\
\text { for } 2 \text { days after } \\
\text { contrast exposure. }\end{array}$ & $\begin{array}{l}\text { Procedures vary } \\
\text { depending on baseline } \\
\text { kidney function and } \\
\text { comorbidities for lactic } \\
\text { acidosis. } \\
\text { i) In patients with } \\
\text { normal kidney function } \\
\text { and no known } \\
\text { comorbidities, there is } \\
\text { no need to check SCr } \\
\text { levels after the test or } \\
\text { procedure before } \\
\text { instructing the patient to } \\
\text { resume metformin after } \\
48 \text { hours. } \\
\text { ii) In patients with } \\
\text { multiple comorbidities } \\
\text { who apparently have } \\
\text { normal kidney function, } \\
\text { metformin can be } \\
\text { restarted } 48 \text { hours after } \\
\text { the procedure without } \\
\text { repeating SCr } \\
\text { measurements } \\
\text { (undertake appropriate } \\
\text { measures when } \\
\text { clinically indicated). } \\
\text { iii) In patients who are } \\
\text { known to have kidney } \\
\text { dysfunction, cautious } \\
\text { follow-up of kidney } \\
\text { function should be } \\
\text { performed until safe } \\
\text { reinstitution of } \\
\text { metformin can be } \\
\text { assured. }\end{array}$ & $\begin{array}{l}\text { Patients with an eGFR } \\
<45 \mathrm{~mL} / \mathrm{min} / 1.73 \mathrm{~m}^{2}: \\
\text { metformin should not be } \\
\text { restarted for at least } 48 \\
\text { hours and only then if } \\
\text { kidney function remains } \\
\text { stable (less than } 25 \% \\
\text { increase compared to } \\
\text { baseline } \mathrm{Cr} \text { ). }\end{array}$ & $\begin{array}{l}\text { Patients with an eGFR } 30 \sim \\
<50 \mathrm{~mL} / \mathrm{min} / 1.73 \mathrm{~m}^{2} \text { who are } \\
\text { receiving intra-arterial } \\
\text { contrast media, and those } \\
\text { with an eGFR } 30 \sim 44 \\
\mathrm{~mL} / \mathrm{min} / 1.73 \mathrm{~m}^{2} \text { who are } \\
\text { receiving intravenous contrast } \\
\text { media should only restart } \\
\text { metformin } 48 \text { hours after } \\
\text { contrast exposure if kidney } \\
\text { function has not deteriorated. } \\
\text { Patients with a medical } \\
\text { emergency: metformin should } \\
\text { be restarted } 48 \text { hours after } \\
\text { contrast exposure if } \\
\text { SCr/eGFR ratio is unchanged } \\
\text { from the pre-imaging level. }\end{array}$ & \\
\hline
\end{tabular}

JDS Japanese Diabetes Society (Evidence-based Practice Guideline for the Treatment of Diabetes in Japan, 2010), ACR American College of Radiology (ACR Manual on Contrast Media, Version 7, 2010), CAR Canadian Association of Radiologists (Consensus Guidelines for the Prevention of Contrast Induced Nephropathy, approved: June 17, 2011), ESUR European Society of Urogenital Radiology (Contrast induced nephropathy: updated ESUR Contrast Media Safety Committee guidelines, October 2010) [7], $R C R$ The Royal College of Radiologists (Standards for intravascular contrast agent administration to adult patients, 2nd edition, 2010), RANZCR The Royal Australian and New Zealand College of Radiologists (RANZCR Guidelines for Iodinated Contrast Administration, March, 2009), eGFR estimated glomerular filtration rate, SCr serum creatinine

( $p=0.068$ and $p=0.074$, respectively) [45]. All these reports pointed out that the small sample sizes limited the statistical power. Further studies are awaited.

Although, as listed earlier, many reports have described a relationship between CIN and vital prognosis, it is unclear whether CIN defines prognosis (i.e., the occurrence of CIN worsens vital prognosis) or predicts prognosis (i.e., CIN occurs in patients with poor vital prognoses).
3.9 CQ3-9 Does the use of contrast media increase the risk of a decline of residual kidney function in patients undergoing peritoneal dialysis?

\section{Answer:}

Although the use of contrast media may be a risk factor for a decline of residual kidney function in patients undergoing peritoneal dialysis, it has been reported that radiography using 
only $100 \mathrm{~mL}$ of a contrast medium does not affect residual kidney function when urine output is maintained adequately.

\section{Level of Evidence: IVa Grade of Recommendation: Not applicable}

\section{Rationale CQ3-9}

Only a few reports have been published regarding the effect of iodinated contrast media in patients receiving peritoneal dialysis who have some residual kidney function. It has been reported that the use of approximately $100 \mathrm{~mL}$ dose of contrast media did not decrease residual kidney function in patients undergoing peritoneal dialysis with a creatinine clearance (CCr) of 4.4-7.0 mL/min/1.73 $\mathrm{m}^{2}$ compared with the control group $[46,47]$. Urine volume had a range of $1,300-1,800 \mathrm{~mL} /$ day in many patients enrolled in these studies. It is unclear why the use of contrast media did not deteriorate kidney function in these patients with severe kidney dysfunction (CKD G5). Further studies should be conducted to clarify exact reasons, e.g., maintenance of urine volume, slow removal of contrast media through peritoneal dialysis, or alkalemia frequently observed in patients undergoing peritoneal dialysis. Little evidence has been obtained regarding the effect of contrast media in patients with a urine volume of $<1,000 \mathrm{~mL} /$ day. Further studies should be conducted to investigate the effects of contrast media in patients with a CCr of $<4.0 \mathrm{~mL} / \mathrm{min} /$ $1.73 \mathrm{~m}^{2}$ or in those with less residual kidney function, and to specify the tolerable volume of contrast media for patients with different residual kidney function.

\subsection{CQ3-10 Are risk scores useful as predictors of developing CIN?}

\section{Answer:}

Although it has been reported that risk scores are useful as predictors of developing CIN, their use has not been investigated prospectively. It is inappropriate to recommend the use of risk scores at the present time.

\section{Level of Evidence: IVa Grade of Recommendation: Not applicable}

\section{Rationale CQ3-10}

A study has reported that the risk of developing severe kidney dysfunction after PCI in patients not undergoing dialysis may be predicted with a risk scoring system (Table 3) [48].

However, because this risk scoring system has not been investigated prospectively, some specialists have pointed out the inappropriateness of using this scoring system in the clinical setting [8].

It has been reported that the risk for developing CIN and the risk of requiring dialysis in patients after PCI may be predicted with a risk scoring system $[49,50]$. The risks of
Table 3 CIN risk scores: 1

\begin{tabular}{lc}
\hline Variables & Score \\
\hline Age $\geq 80$ years & 2.0 \\
Female sex & 1.5 \\
Diabetes & 3.0 \\
Urgent priority & 2.5 \\
Emergent priority & 3.5 \\
CHF history & 4.5 \\
Creatinine level $1.3-1.9 \mathrm{mg} / \mathrm{dL}$ & 5.0 \\
Creatinine level $\geq 2.0 \mathrm{mg} / \mathrm{dL}$ & 10.0 \\
IABP pre PCI & 13.0 \\
Total & 16.5 \\
\hline
\end{tabular}

Adapted from Am Heart J. 2008;155:260-266 [48], with permission from Elsevier Inc.

CHF congestive heart failure, CIN contrast-induced nephropathy, $I A B P$ intra-aortic balloon pumping, $P C I$ percutaneous catheter intervention

Table 4 CIN risk scores: 2

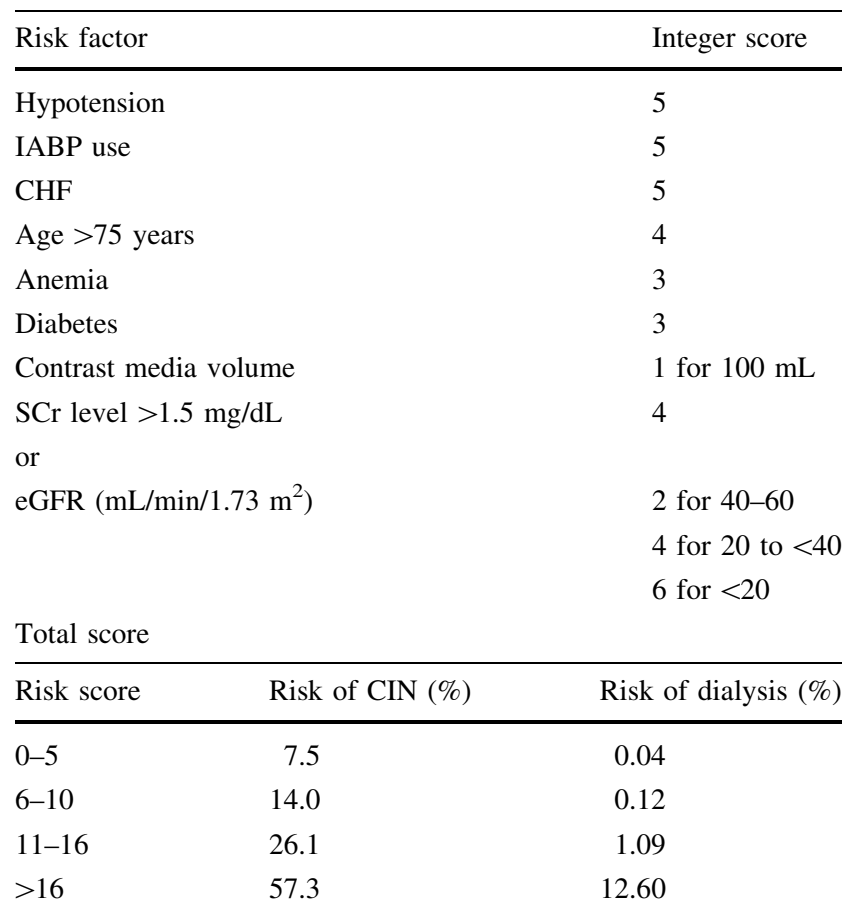

Adapted from J Am Coll Cardiol. 2004;44:1393-1399 [49], with permission from Elsevier Inc.

$C H F$ congestive heart failure, CIN contrast-induced nephropathy, $e G F R$ estimated glomerular filtration rate, IABP intra-aortic balloon pumping, $\mathrm{SCr}$ serum creatinine

CIN and of requiring dialysis reported in a study were 7.5 and $0.04 \%$ among patients with a score of $\leq 5 ; 14.0$ and $0.12 \%$ among patients with a score of $6-10 ; 26.1$ and $1.09 \%$ among those with a score of 11-16; and 57.3 and $12.6 \%$ among those with a score of $>16$, respectively (Table 4) [49]. 


\section{Type and volume of contrast media}

4.1 CQ4-1 Does the use of a smaller volume of contrast media reduce the risk for developing CIN?

(see CQ5-2)

\section{Answer:}

The volume of contrast media is a risk factor for developing CIN. We recommend that the volume of contrast media should be the minimum necessary to obtain adequate radiographs.

\section{Level of Evidence: II Grade of Recommendation: A}

\section{Rationale CQ4-1}

In a study investigating the effect of the volume of contrast media on the incidence of CIN, Cigarroa et al. [51] used the following formula to calculate a "contrast material limit" in patients with kidney disease: contrast material limit $=([5 \mathrm{~mL}$ of contrast per $1 \mathrm{~kg}] \times$ body weight $[\mathrm{kg}]) / \mathrm{SCr}(\mathrm{mg} / \mathrm{dL})$. However, the maximum volume of contrast is $300 \mathrm{~mL}$, even when the calculated limit exceeds $300 \mathrm{~mL}$. For example, the contrast material limit for a patient weighing $50 \mathrm{~kg}$ with a $\mathrm{SCr}$ of $1.0 \mathrm{mg} / \mathrm{dL}$ is $250 \mathrm{~mL}(5 \mathrm{~mL} / \mathrm{kg} \times 50 \mathrm{~kg} / \mathrm{L})$, while that for a patient weighing $70 \mathrm{~kg}$ with a $\mathrm{SCr}$ of $1.0 \mathrm{mg} / \mathrm{dL}$ is $300 \mathrm{~mL}$, rather than $350 \mathrm{~mL}(5 \mathrm{~mL} / \mathrm{kg} \times 70 \mathrm{~kg} / \mathrm{L})$.

In this study, 115 patients with kidney dysfunction underwent cardiac catheterization and angiography, and the amount of contrast media that was given adhered to the limit in 86 patients and exceeded it in 29 patients. The incidence of CIN was significantly higher in the latter patients $(21 \%, 6 / 29$ patients) than in the former patients ( $2 \%, 2 / 86$ patients).

In a study of 391 patients who underwent PCI, the independent predictors of CIN were the volume of contrast media, eGFR, LVEF, and cardiogenic shock [52]. The risk of CIN was $25 \%$ among patients with a contrast medium dose-to-eGFR ratio (gram-iodine/eGFR) of $\geq 1$, which was significantly higher than that in those with a gram-iodine/ eGFR of $<1(3 \%)$.

A study of patients undergoing PCI investigated the effects of contrast volume on the incidence of AKI, defined as $\mathrm{a} \geq 0.3 \mathrm{mg} / \mathrm{dL}$ or $\geq 50 \%$ increase in SCr levels from baseline, in subgroups of patients stratified according to categories in which 1.0 represents the "maximum allowable contrast dose" (MACD; calculated by using the formula described earlier [51]), of $<0.5$, $0.5-0.75,0.75-1.0,1.0-1.5,1.5-2.0$, and $>2.0$ [53]. The incidence of AKI did not differ significantly among subgroups with a MACD ratio of $\leq 1$, but increased in subgroups of patients with an MACD ratio of 1.0-1.5 (OR 1.60, $95 \%$ CI 1.29-1.97), 1.5-2.0 (OR 2.02, $95 \%$ CI 1.45-2.81), and $>2.0$ (OR 2.94, $95 \%$ CI 1.93-4.48).
The incremental use of contrast is associated with an increased risk of AKI.

In a study of 421 patients who underwent contrastenhanced CT with intravenous iodinated contrast media, Weisbord et al. [5] reported that the use of $>100 \mathrm{~mL}$ of contrast media was associated with an increased risk of CIN (OR: 3.3, $95 \%$ CI 1.0-11.5).

4.2 CQ4-2 Is the risk for developing CIN lower in patients receiving low- rather than high-osmolar contrast media?

\section{Answer:}

Patients with a high risk for developing CIN should receive low-osmolar contrast media, which are less associated with CIN as compared with high-osmolar contrast media. In Japan, high-osmolar contrast media are not indicated for intravascular use.

\section{Level of Evidence: II Grade of Recommendation: Not applicable}

4.3 CQ4-3 Does the risk for developing CIN differ between iso- and low-osmolar contrast media?

\section{Answer:}

There has been no definite conclusion as to whether the risk of CIN differs between iso- and low-osmolar contrast media.

\section{Level of Evidence: II Grade of Recommendation: Not applicable}

4.4 CQ4-4 Does the risk for developing CIN differ among different low-osmolar contrast media?

\section{Answer:}

There has been no definite conclusion as to whether the incidence of CIN differs among different low-osmolar contrast media.

\section{Level of Evidence: II Grade of Recommendation: Not applicable}

\section{Rationale CQ4-2 4-4}

In a meta-analysis of 31 studies, that the pooled odds of CKD (defined as a rise of SCr levels of more than $44 \mu \mathrm{mol} /$ L) with non-ionic low-osmolar contrast media was 0.61 (95\% CI 0.48-0.77) times that of ionic high-osmolar contrast media [54]. In Japan, ionic high-osmolar contrast media are no longer indicated for intravascular use since February 2001.

In a randomized double-blind prospective multicenter study comparing the nephrotoxic effects of an iso-osmolar contrast medium (iodixanol) with those of a low-osmolar contrast medium (iohexol) in 129 patients with diabetes with a SCr level of $1.5-3.5 \mathrm{mg} / \mathrm{dL}$ who underwent coronary or aortofemoral angiography, 2 of the 64 patients in 
the iodixanol group $(3.1 \%)$ had an increase in their $\mathrm{SCr}$ levels of $0.5 \mathrm{mg} / \mathrm{dL}$ or more, as compared with 17 of the 65 patients in the iohexol group $(26.2 \%)(p=0.002)$, suggesting that CIN may be less likely to develop when an iso-osmolar contrast media is used rather than when a low-osmolar contrast medium is used [55]. However, in a multicenter, randomized, double-blind comparison of the low-osmolar contrast medium (iopamidol) and the isoosmolar contrast medium (iodixanol), the incidence of CIN was not statistically different after the intra-arterial administration of iopamidol or iodixanol to high-risk patients [56]. In a meta-analysis of 25 RCTs, iso-osmolar iodixanol did not significantly reduce the risk of CIN (relative risk [RR] 0.80, $95 \%$ CI 0.61-1.04) [57]. However, in patients with intra-arterial administration and kidney dysfunction, the risk of CIN was lower for isoosmolar iodixanol than for low-osmolar iohexol (RR 0.38, $95 \%$ CI 0.21-0.68), whereas there was no difference between iodixanol and the other (non-iohexol) lowosmolar contrast media (RR 0.95, $95 \%$ CI 0.50-1.78). These findings suggest that the risk of CIN differs among low-osmolar contrast media. Alternatively, it is reported that the risk for developing CIN after coronary intervention is higher when patients at high risk for developing CIN receive iso-osmolar iodixanol compared to receiving low-osmolar ioxaglate or iohexol [58]. Table 5 lists guidelines regarding CIN published in Western countries [7, 59-61]. The ESUR Contrast Media Safety Committee guidelines updated in 2011 recommend the use of low- or iso-osmolar contrast media [7]. In the 2009 Focused Updates of ACC/AHA Guidelines for the Management of Patients With ST-Elevation Myocardial Infarction and ACC/AHA/SCAI Guidelines on Percutaneous Coronary
Intervention [59], the use of iso-osmolar contrast media or low-osmolar contrast media, other than iohexol or ioxaglate, is recommended, while the 2011 ACCF/AHA Focused Update of the Guidelines for the Management of Patients With Unstable Angina/Non-ST-Elevation Myocardial Infarction [60] and the 2011 ACCF/AHA/SCAI Guideline for Percutaneous Coronary Intervention [61] describe that current data are insufficient to justify specific recommendations about low- and iso-osmolar contrast media, and recommend that patients undergoing cardiac catheterization with receipt of contrast media should receive adequate prophylactic hydration, and calculation of the contrast volume to $\mathrm{CCr}$ ratio is useful to predict the maximum volume of contrast media that can be given without significantly increasing the risk of CIN [60].

High-osmolar contrast media have been used for a long period of time, and have caused adverse reactions due to their high osmolality. As low-osmolar contrast media became available in the 1980s and iso-osmolar contrast media were introduced thereafter, the incidence of adverse reactions to contrast media has decreased. In Japan, the intravascular use of ionic high-osmolar contrast media has not been covered by the NHI since February 2001. Although the incidence of CIN has decreased as the use of low-osmolar contrast media has become common, CIN is still a major adverse reaction to contrast media. Considerable interest has been focused on the difference in incidence of CIN among currently available low- and isoosmolar contrast media. The osmolarity of contrast media, when compared in iodine equivalent concentrations, is highest in high-osmolar contrast media followed by lowosmolar contrast media and iso-osmolar contrast media. It also should be noted that the osmotic pressure ratio of low-
Table 5 Descriptions on the selection of contrast media in CIN guidelines
$A C C(F)$ American College of Cardiology (Foundation), AHA American Heart Association, CIN contrast-induced nephropathy, ESUR European Society of Urogenital Radiology, SCAI Society for Cardiovascular Angiography and Interventions

\begin{tabular}{|c|c|c|}
\hline & Guidelines & Descriptions on the selection of contrast media \\
\hline 1 & ESUR Guidelines (2011 revision) ${ }^{7)}$ & $\begin{array}{l}\text { [1.3 Time of examination: At-risk patients] } \\
\text { - Use low- or iso-osmolar contrast media }\end{array}$ \\
\hline 2 & $\begin{array}{l}2009 \text { Focused Updates: ACC/AHA } \\
\text { Guidelines for the Management of } \\
\text { Patients With ST-Elevation Myocardial } \\
\text { Infarction }{ }^{59)}\end{array}$ & $\begin{array}{l}\text { - In patients with chronic kidney disease undergoing } \\
\text { angiography who are not undergoing chronic dialysis, either } \\
\text { an iso-osmolar contrast medium (Level of Evidence: A) or a } \\
\text { low-osmolar contrast medium other than ioxaglate or } \\
\text { iohexol is indicated. (Level of Evidence: B) }\end{array}$ \\
\hline 3 & $\begin{array}{l}2011 \text { ACCF/AHA Focused Update of } \\
\text { the Guidelines for the Management of } \\
\text { Patients With Unstable } \\
\text { Angina/Non-ST-Elevation Myocardial } \\
\text { Infarction }^{60)} \\
\text { 2011ACCF/AHA/SCAI Guidelines for } \\
\text { Percutaneous Coronary Intervention }^{61)}\end{array}$ & $\begin{array}{l}\text { - Existing evidence is not sufficient to enable a guideline } \\
\text { statement on selection among commonly used low- and } \\
\text { iso-osmolar contrast media. }\end{array}$ \\
\hline
\end{tabular}


osmolar contrast media to physiological saline ranges from $2-4$, which is a higher ratio than that of iso-osmolar contrast media (1.0).

4.5 CQ4-5 Is the risk for developing CIN higher in patients receiving contrast media via invasive (intra-arterial) administration than in those receiving contrast media via non-invasive (intravenous) administration?

\section{Answer:}

Although there is no evidence demonstrating that intraarterial administration of contrast media is an independent risk factor for developing CIN, the incidence of CIN tends to be higher in patients receiving contrast media intraarterially than in those receiving them intravenously.

\section{Level of Evidence: IVa Grade of Recommendation: Not applicable}

\section{Rationale CQ4-5}

The majority of studies on CIN have been conducted in patients receiving contract media intra-arterially, and only a few studies have investigated a possible difference in the incidence of CIN by route of administration. The incidence of CIN tends to be lower in patients receiving contrast media intravenously than in those receiving them intra-arterially (Table 6) [62-64], although this difference might be explained by other factors such as catheter techniques. In a review of 7 prospective observational studies, the overall incidence of CIN was $5.4 \%$ in patients with CKD who intravenously received low- or iso-osmolar contrast media, which suggested that intravenous administration of contrast media may pose a smaller risk of CIN as compared with that seen with intraarterial administration [42]. Table 7 lists the incidence of CIN in patients with CKD after receiving different contrast media [5, 65-70]. Table 8 summarizes currently available iodinated contrast media and their osmolar pressure [71, 72].

\section{Invasive diagnostic imaging including cardiac angiography or percutaneous catheter intervention}

5.1 CQ5-1 Does CKD increase the risk for developing CIN after CAG?

\section{Answer:}

1. It is highly likely that $\mathrm{CKD}\left(\mathrm{GFR}<60 \mathrm{~mL} / \mathrm{min} / 1.73 \mathrm{~m}^{2}\right)$ increases the risk for developing CIN after CAG. The risk for developing CIN increases as kidney function decreases.

2. We recommend that physicians explain CIN to patients with an eGFR of $<60 \mathrm{~mL} / \mathrm{min} / 1.73 \mathrm{~m}^{2}$ who are going to undergo $\mathrm{CAG}$, and that they take appropriate preventive measures such as fluid therapy before and after CAG.

\section{Level of Evidence: I Grade of Recommendation: A}

\section{Rationale CQ5-1}

Recently, CAG and catheter-based revascularization have become common procedures, and the use of contrast media has increased substantially. It has been reported that in patients with CKD the risk of CIN increases as kidney function (GFR) decreases (Fig. 1) [8]. In 2001, Shiraki et al. [73] reported that 61 of 1,920 patients (3.2\%) who underwent CAG developed CIN, and 1 of them $(0.05 \%)$ required hemodialysis. In another study, Fujisaki et al. [74] reported that CIN developed in 12 of 267 patients $(4.5 \%)$ who underwent $\mathrm{CAG}$, and hemodialysis was required in 2 patients $(0.7 \%)$. In a report from the Mayo Clinic in 2002, CIN developed in 254 of 7,586 (3.3\%) patients who underwent CAG, and 20 (7.9\%) of these required hemodialysis [4]. Mortality at 1 and 5 years were 12.1 and $44.6 \%$, respectively, in patients with CIN, which were significantly higher than those in patients without CIN (3.7 and $14.5 \%$, respectively). In a study reported in 2009, Abe et al. [75] reported that the incidence of CIN within 5 days after CAG was $4.0 \%$ in 1,157 consecutive patients who underwent $\mathrm{CAG}$, and risk factors for CIN included a baseline SCr level of $\geq 1.2 \mathrm{mg} / \mathrm{dL}$ and the use of a large volume $(\geq 200 \mathrm{~mL})$ of contrast media. In the earlier-mentioned studies, CIN was defined as an increase in SCr levels by $\geq 0.5 \mathrm{mg} / \mathrm{dL}$. The risk of CIN after CAG was 3.0-5.0 \%, and CIN developed mainly in high-risk patients such as those with diabetes, anemia, dehydration, or an underlying kidney diseases, and/or those who were elderly or were receiving nephrotoxic agents [50]. It is recommended that patients with CKD should receive appropriate preventive treatment such as fluid therapy and be closely monitored for kidney function after CAG.

5.2 CQ5-2 Does the use of a smaller volume of contrast medium decrease the risk for developing CIN?

\section{Answer:}

Because the use of a smaller volume of contrast medium decreases the risk for developing CIN in patients undergoing $\mathrm{CAG}$, we recommend that contrast medium be administered at the minimal required volume.

\section{Level of Evidence: II Grade of Recommendation: A}

\section{Rationale CQ5-2}

Because the risk for developing CIN increases as the dose of contrast medium increases, unnecessary use of contrast 


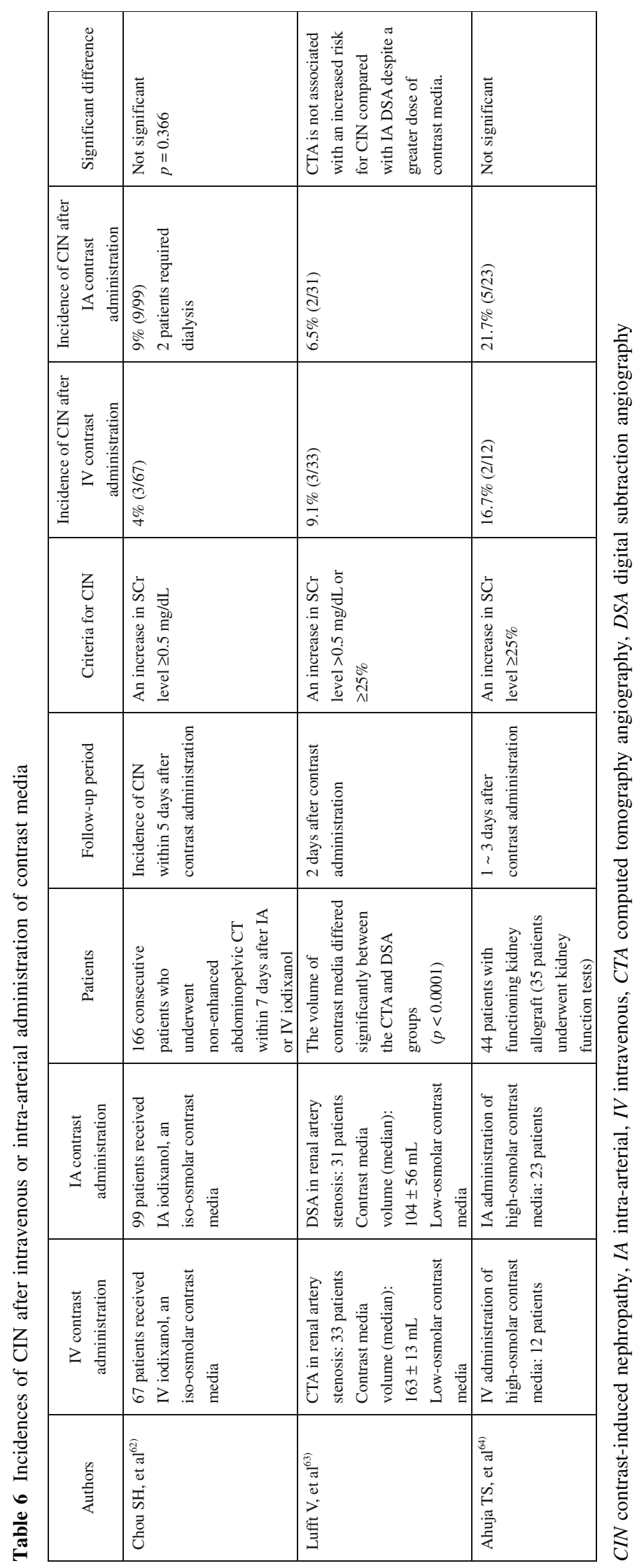


Table 7 Incidence of CIN after intravenous contrast medium administration in patients with kidney dysfunction

Adapted from Radiology. 2010;256:21-28 [42], with permission from Radiological Society of North America

CIN contrast-induced nephropathy, IOCM iso-osmolar contrast media, $L O C M$ lowosmolar contrast media, $\mathrm{SCr}$ serum creatinine level

\begin{tabular}{|c|c|c|c|c|}
\hline Authors & Contrast media & Prospective study & Criteria for CIN & Incidence of CIN \\
\hline Teplel M, et $\mathrm{al}^{65)}$ & LOCM & 0 & $\mathrm{SCr} \geq 0.5 \mathrm{mg} / \mathrm{dL}$ & $9 / 42(21 \%)$ \\
\hline Becker CR, et $\mathrm{al}^{66)}$ & IOCM & 0 & $\mathrm{SCr} \geq 0.5 \mathrm{mg} / \mathrm{dL}$ & $9 / 100(9 \%)$ \\
\hline Barrett BJ, et $\mathrm{al}^{67)}$ & LOCM, IOCM & 0 & $\mathrm{SCr} \geq 0.5 \mathrm{mg} / \mathrm{dL}$ & $2 / 153(1.3 \%)$ \\
\hline Thomsen HS, et al $\mathrm{al}^{68)}$ & LOCM, IOCM & 0 & $\mathrm{SCr} \geq 0.5 \mathrm{mg} / \mathrm{dL}$ & $5 / 148(3.4 \%)$ \\
\hline Kuhn MJ, et al ${ }^{69)}$ & LOCM, IOCM & 0 & $\mathrm{SCr} \geq 25 \%$ & $13 / 248(5.2 \%)$ \\
\hline Nguyen SA, et al $\mathrm{a}^{70)}$ & LOCM, IOCM & 0 & $\mathrm{SCr} \geq 0.5 \mathrm{mg} / \mathrm{dL}$ & $13 / 117(11.1 \%)$ \\
\hline \multirow[t]{2}{*}{ Weisbord SD, et $\mathrm{al}^{5)}$} & LOCM, IOCM & 0 & $\mathrm{SCr} \geq 0.5 \mathrm{mg} / \mathrm{dL}$ & $13 / 367(3.5 \%)$ \\
\hline & & & & $\begin{array}{l}\text { Total: } \\
64 / 1,175(5.4 \%)\end{array}$ \\
\hline
\end{tabular}

media should be avoided in all patients. Although the volume of contrast media used in CAG ranges from $50-100 \mathrm{~mL}$ in many patients, it is recommended that contrast media used for patients with CKD should be limited to the minimal required volume. In a study of 10,065 patients undergoing PCI, Brown et al. [53] reported that the incidence of AKI was significantly higher in patients receiving doses of contrast media above the minimal required volume compared to those receiving doses below it. Nyman et al. [52] suggested that the contrast medium dose-to-eGFR ratio (gram-iodine/ eGFR) should be kept under 1.0 (see CQ4-1), and Laskey et al. [76] recommended that the ratio of the volume of contrast media to $\mathrm{CCr}$ should be limited to $<3.7$. Some reports have advocated lower ratios of the volume of contrast media to $\mathrm{CCr}$. In a study of 58,957 patients undergoing PCI, the risk of CIN and nephropathy requiring dialysis (NRD) approached significance when the contrast dose to $\mathrm{CCr}$ ratio exceeded 2.0, and was dramatically elevated in patients exceeding a contrast dose to $\mathrm{CCr}$ ratio of 3.0 (Fig. 2) [77]. It is recommended, on the basis of these findings, that the volume of contrast media used during CAG or PCI be limited to the minimal required volume in patients with CKD (see CQ4-1) [8].

\subsection{CQ5-3 Does repeated CAG at short intervals} increase the risk for developing CIN?

\section{Answer:}

Because repeated CAG at short intervals may increase the risk for developing CIN, we consider not to repeat CAG within 24-48 $\mathrm{h}$ in patients with $\mathrm{CKD}\left(\mathrm{GFR}<60 \mathrm{~mL} / \mathrm{min} / 1.73 \mathrm{~m}^{2}\right)$.

\section{Level of Evidence: VI Grade of Recommendation: C2}

\section{Rationale CQ5-3}

Because it has been reported that repeated CAG within 24-48 h may increase the risk for developing CIN, patients with CKD should not undergo repeated CAG in a short time interval (24-48 h; see CQ6-3). There have been no studies investigating the effect of repeated CAG within 1 year on the risk for developing CIN.

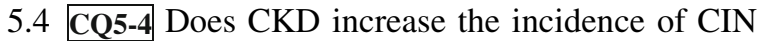 after PCI?}

\section{Answer:}

In patients with CKD (GFR $<60 \mathrm{~mL} / \mathrm{min} / 1.73 \mathrm{~m}^{2}$ ), the incidence of CIN is higher after PCI as compared with after other procedures. However, there is no evidence demonstrating that PCI itself worsens the prognosis of CKD.

\section{Level of Evidence: I Grade of Recommendation: A}

\section{Rationale CQ5-4}

PCI has been established as a revascularization procedure to treat angina and acute myocardial infarction, and has become increasingly common in recent years. The volume of contrast medica used during PCI ranges from 100-200 mL, which is larger than the volume used during CAG. More than $300 \mathrm{~mL}$ of contrast media may be used during PCI for the treatment of chronic total occlusion.

In a study of 439 patients who had baseline SCr levels of $\geq 1.8 \mathrm{mg} / \mathrm{dL}$ and underwent PCI, Gruberg et al. [34] reported that 161 patients $(36.7 \%)$ experienced CIN, and 31 patients $(7.1 \%)$ required hemodialysis. In-hospital mortality was $14 \%$ for patients with further kidney function deterioration after PCI. In a study of 208 consecutive patients with acute myocardial infarction undergoing primary PCI, Marenzi et al. [37] reported that CIN developed in 40 patients $(19.2 \%)$. Of the 160 patients with a baseline eGFR $\geq 60 \mathrm{~mL} / \mathrm{min} / 1.73 \mathrm{~m}^{2}, \mathrm{CIN}$ developed in 21 patients $(13.1 \%)$, whereas it developed in 19 patients $(39.6 \%)$ of those with eGFR $<60 \mathrm{~mL} / \mathrm{min} /$ $1.73 \mathrm{~m}^{2}$. The risk factors for CIN included age $\geq 75$ years, use of $\geq 300 \mathrm{~mL}$ of contrast media, $>6 \mathrm{~h}$ of time-toreperfusion, presence of anterior myocardial infarction, and use of an intra-aortic balloon pumping (IABP), but 
Table 8 List of currently available iodinated contrast media by osmolarity

\begin{tabular}{|c|c|c|c|c|c|}
\hline $\begin{array}{l}\text { Contrast } \\
\text { media }\end{array}$ & $\begin{array}{l}\text { Generic name } \\
\text { (product name) }\end{array}$ & $\begin{array}{l}\text { Iodine content } \\
\text { (mg iodine/mL) }\end{array}$ & $\begin{array}{l}\text { Osmotic pressure ratio } \\
\text { (to physiological saline) }\end{array}$ & $\begin{array}{l}\text { Measured osmotic } \\
\text { pressure }(\mathrm{mOsm} / \mathrm{kg} \\
\left.\mathrm{H}_{2} \mathrm{O}\right)^{\mathrm{a}}\end{array}$ & Indications \\
\hline \multirow[t]{6}{*}{$\begin{array}{l}\text { High-osmolar } \\
\text { contrast media }\end{array}$} & \multirow{2}{*}{$\begin{array}{l}\text { Amidotrizoic acid } \\
\text { (INN) diatrizoic } \\
\text { acid (USP) } \\
\text { (Urografin) }\end{array}$} & $292^{\mathrm{b}}$ & About 6 & - & $\begin{array}{l}\text { Direct cholangiography, } \\
\text { pancreatography, retrograde } \\
\text { urography, arthrography }\end{array}$ \\
\hline & & $370^{\mathrm{b}}$ & About 9 & - & Sialography \\
\hline & \multirow{3}{*}{$\begin{array}{l}\text { Iothalamic acid } \\
\text { (Conray) }\end{array}$} & $141^{\mathrm{b}}$ & About 3 & - & Retrograde urography \\
\hline & & $282^{\mathrm{b}}$ & About 5 & - & $\begin{array}{l}\text { Direct cholangiography, } \\
\text { pancreatography, retrograde } \\
\text { urography, arthrography }\end{array}$ \\
\hline & & $400^{\mathrm{b}}$ & About 8 & - & Vesiculography \\
\hline & $\begin{array}{l}\text { Iotroxic acid } \\
\quad \text { (Biliscopin) }\end{array}$ & 50 & About 1 & - & Intravenous cholangiography \\
\hline \multirow{22}{*}{$\begin{array}{l}\text { Low-osmolar } \\
\text { contrast media }\end{array}$} & \multirow{3}{*}{$\begin{array}{l}\text { Iopamidol } \\
\text { (Iopamiron) }\end{array}$} & 150 & About 1 & $340[71]$ & \multirow[t]{3}{*}{$\mathrm{CT}$, angiography, urography } \\
\hline & & 300 & About 3 & $620[71]$ & \\
\hline & & 370 & About 4 & $800[71]$ & \\
\hline & \multirow[t]{5}{*}{ Iohexol (Omnipaque) } & 140 & About 1 & - & $\mathrm{CT}$, angiography \\
\hline & & $180^{\mathrm{b}}$ & About 1 & - & $\begin{array}{l}\text { Ventriculography, cisternography, } \\
\text { myelography }\end{array}$ \\
\hline & & 240 & About 2 & $520[71]$ & $\begin{array}{l}\text { CT, angiography, urography, } \\
\text { ventriculography, cisternography, } \\
\text { myelography }\end{array}$ \\
\hline & & 300 & About 2 & $680[71]$ & $\begin{array}{l}\mathrm{CT} \text {, angiography, urography, } \\
\text { myelography }\end{array}$ \\
\hline & & 350 & About 3 & $830[71]$ & $\mathrm{CT}$, angiography, urography \\
\hline & \multirow[t]{4}{*}{ Ioversol (Optiray) } & 160 & About 1 & $350[71]$ & Angiography \\
\hline & & 240 & About 2 & $500[71]$ & $\mathrm{CT}$ \\
\hline & & 320 & About 2 & $710[71]$ & $\mathrm{CT}$, angiography, urography \\
\hline & & 350 & About 3 & $790[71]$ & Angiography \\
\hline & \multirow[t]{3}{*}{ Iomeprol (Iomeron) } & 300 & About 2 & $520[71]$ & \multirow[t]{2}{*}{$\mathrm{CT}$, angiography, urography } \\
\hline & & 350 & About 2 & $620[71]$ & \\
\hline & & 400 & About 3 & $730[71]$ & Angiography, urography \\
\hline & \multirow[t]{4}{*}{ Iopromide (Proscope) } & 150 & About 1 & $330[71]$ & \multirow[t]{4}{*}{$\mathrm{CT}$, angiography, urography } \\
\hline & & 240 & About 2 & $480[71]$ & \\
\hline & & 300 & About $2-3$ & $610[71]$ & \\
\hline & & 370 & About 3-4 & $800[71]$ & \\
\hline & \multirow[t]{2}{*}{ Ioxilan (Imagenil) } & 300 & About 2 & $570[72]$ & \multirow[t]{2}{*}{$\mathrm{CT}$, angiography, urography } \\
\hline & & 350 & About 3 & $690[72]$ & \\
\hline & $\begin{array}{c}\text { Ioxaglic acid } \\
\text { (Hexabrix) }\end{array}$ & 320 & About 2 & - & $\mathrm{CT}$, angiography, urography \\
\hline \multirow[t]{4}{*}{$\begin{array}{l}\text { Iso-osmolar } \\
\text { contrast media }\end{array}$} & \multirow[t]{2}{*}{ Iotrolan (Isovist) } & $240^{\mathrm{b}}$ & About 1 & - & $\begin{array}{l}\text { Ventriculography, cisternography, } \\
\text { myelography, arthrography }\end{array}$ \\
\hline & & $300^{\mathrm{b}}$ & About 1 & - & Hysterosalpingography, arthrography \\
\hline & \multirow[t]{2}{*}{ Iodixanol (Visipaque) } & 270 & About 1 & - & $\begin{array}{l}\text { Angiography, direct } \\
\text { cholangiography, pancreatography, } \\
\text { retrograde urography }\end{array}$ \\
\hline & & 320 & About 1 & - & Angiography \\
\hline
\end{tabular}

The package inserts for contrast media available in Japan describe osmotic pressure ratio determined using the freezing-point depression method according to the Japanese Pharmacopoeia

The osmolarity of contrast media, when compared in iodine equivalent concentrations, is highest in high-osmolar contrast media followed by low-osmolar contrast media and iso-osmolar contrast media. It also should be noted that the osmotic pressure ratio of low-osmolar contrast media to physiological saline ranges $2-4$, which is a higher ratio than that of iso-osmolar contrast media (1.0)

$C T$ computed tomography

a Actual osmolality

b Not approved for intravascular administration 


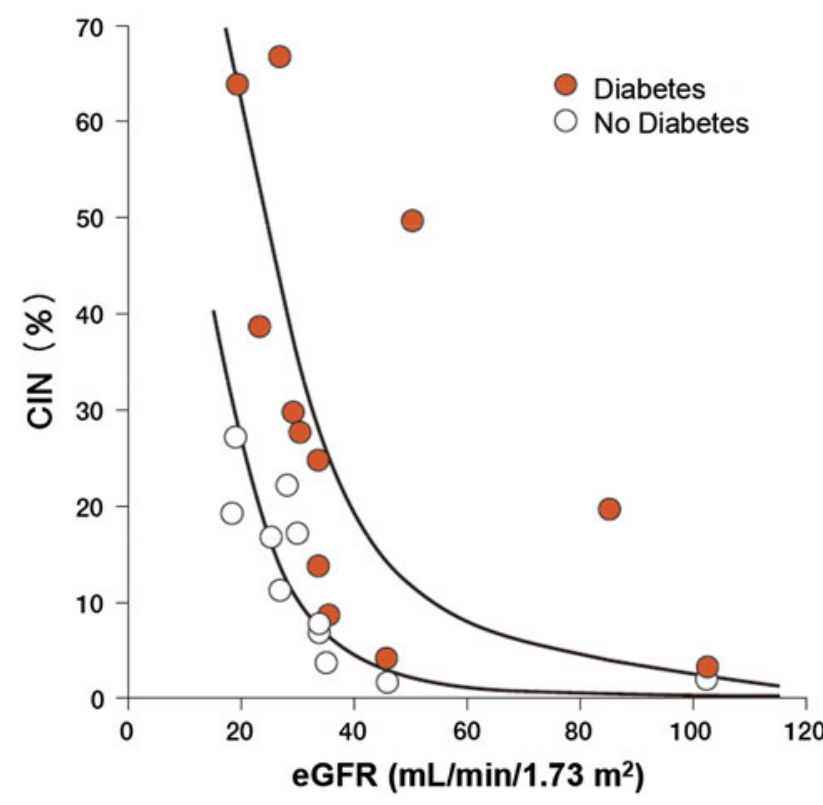

Fig. 1 Risk for developing CIN according to baseline kidney function. The incidence of CIN is higher in patients with lower baseline eGFR, and is higher in patients with diabetes than in those without diabetes. CIN contrast-induced nephropathy, $e G F R$ estimated glomerular filtration rate. Adapted from $\mathrm{J}$ Am Coll Cardiol. 2008;51:1419-1428 [8], with permission from Elsevier Inc.

CKD was not a significant risk factor for CIN. In 2005, Dangas et al. [3] investigated 7,230 patients undergoing PCI, and reported that CIN developed in 381 of 1,980 patients $(19.2 \%)$ with a baseline GFR $<60 \mathrm{~mL} / \mathrm{min} /$ $1.73 \mathrm{~m}^{2}$, and 688 of 5,250 patients $(13.1 \%)$ with a baseline GFR $\geq 60 \mathrm{~mL} / \mathrm{min} / 1.73 \mathrm{~m}^{2}$. In 2010, Chong et al. [78] investigated a cohort of 8,798 patients who underwent PCI, and reported that the incidence of CIN in patients who underwent emergency PCI for acute myocardial infarction or unstable angina was significantly higher than that in those who underwent elective PCI for stable angina (Table 9), and that the incidence of CIN was high in patients with a baseline eGFR of $<30 \mathrm{~mL} / \mathrm{min} /$ $1.73 \mathrm{~m}^{2}$ as well as in patients receiving emergency or elective PCI. These findings indicate that the incidence of $\mathrm{CIN}$ and in-hospital mortality may be higher in patients undergoing emergency PCI for the treatment of acute myocardial infarction than in patients undergoing elective PCI for the treatment of stable angina, because the former patients have cardiac failure and unstable hemodynamics due to myocardial infarction and require a larger volume of contrast media. There is no evidence indicating that PCI itself worsens the prognosis of CKD. It is recommended that patients with coronary artery disease that is indicated for CAG and PCI should have the risk of postprocedure deterioration of kidney function fully explained, receive appropriate preventive measures such
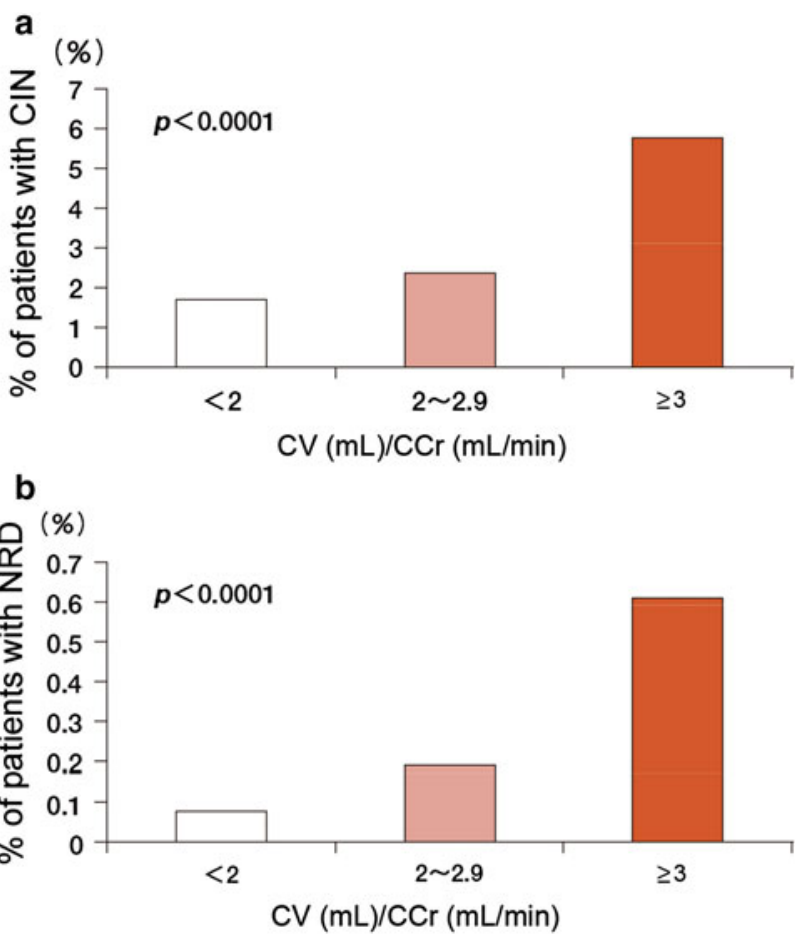

Fig. 2 Incidences of contrast-induced nephropathy (CIN) and nephropathy requiring (dialysis (NRD). Incidences of CIN and NRD increased in patients with higher $\mathrm{CV} / \mathrm{CCr}$ values (kidney function), and are especially high in patients with a $\mathrm{CV} / \mathrm{CCr}$ of $\geq 3$. $C V$ contrast volume, $\mathrm{CCr}$ calculated creatinine clearance. Adapted from J Am Coll Cardiol. 2011;58:907-914 [77], with permission from Elsevier Inc.

Table 9 Incidence of CIN in patients undergoing emergent PCI and elective PCI by kidney function $(n=8,798)$

\begin{tabular}{lclll}
\hline & $\begin{array}{l}\text { STEMI } \\
(\%)\end{array}$ & $\begin{array}{l}\text { UAP/non- } \\
\text { STEMI }(\%)\end{array}$ & $\begin{array}{l}\text { Stable } \\
\text { AP }(\%)\end{array}$ & $p$ \\
\hline $\begin{array}{l}\text { GFR }>60 \mathrm{~mL} / \mathrm{min} / \\
\quad 8.73 \mathrm{~m}^{2}\end{array}$ & 8.2 & 9.2 & 4.3 & $<0.0005$ \\
$\begin{array}{l}\text { GFR } 30-60 \mathrm{~mL} / \\
\mathrm{min} / 1.73 \mathrm{~m}^{2}\end{array}$ & 19.1 & 4.5 & 2.4 & $<0.0005$ \\
$\begin{array}{l}\text { GFR }<30 \mathrm{~mL} / \mathrm{min} / \\
\quad 3.73 \mathrm{~m}^{2}\end{array}$ & 34.4 & 40.0 & 25.9 & 0.510 \\
\hline
\end{tabular}

Adapted from J Interv Cardiol. 2010;23:451-459 [78], with permission from John Wiley and Sons

$A P$ angina pectoris, $G F R$ glomerular filtration rate, $P C I$ percutaneous catheter intervention, STEMI ST-elevation myocardial infarction, $U A P$ unstable angina pectoris

as fluid therapy, and be exposed to the minimum necessary volume of contrast media [8].

5.5 CQ5-5 How can CIN be differentiated from kidney injury due to cholesterol embolism?

\section{Answer:}

CIN may be differentiated from kidney injury due to cholesterol embolism on the basis of clinical and laboratory 
findings, although in some cases differentiation is difficult [79-86].

\section{Level of Evidence: IVb Grade of Recommendation: Not applicable}

\section{Rationale CQ5-5}

Cholesterol embolism is a disease due to the obstruction of small arteries (150-200 $\mu \mathrm{m}$ in diameter) that may cause multiple organ failure. The emboli are formed by cholesterol crystals released from ruptured atherosclerotic plaques in the aorta or other large vessels. The risk of cholesterol embolism increases during catheterization using contrast media. Kidney injury due to cholesterol embolism is believed to be caused by the microemboli of small renal arteries by cholesterol crystals, and is also associated with allergic reactions.

CIN may be differentiated from kidney injury due to cholesterol embolism, as the latter condition has the following features:

1. Prolonged and progressive kidney dysfunction that develops several days or weeks after catheterization.

2. AKI that is often irreversible and sometimes follows a progressive course.

3. Multiple organ failure that may develop in addition to AKI.

4. Systemic symptoms of embolism such as livedo reticularis of the legs, cyanosis, and blue toes may develop.

5. Vasculitis-like symptoms such as fever, arthralgia, general malaise, eosinophilia, increased CRP, decreased serum complement, and elevated sedimentation rate may develop.

6. A diagnosis must be confirmed by pathological examinations such as skin and kidney biopsies.

\section{Intravenous contrast media imaging including contrast-enhanced CT}

6.1 CQ6-1 Does CKD increase the risk for developing CIN after contrast-enhanced CT?

\section{Answer:}

1. It is highly likely that CKD (eGFR $<60 \mathrm{~mL} / \mathrm{min} /$ $1.73 \mathrm{~m}^{2}$ ) increases the risk for developing CIN after contrast-enhanced CT.

2. We suggest that physicians sufficiently explain the risk for developing CIN especially to patients with an eGFR of $<45 \mathrm{~mL} / \mathrm{min} / 1.73 \mathrm{~m}^{2}$ who are going to undergo contrast-enhanced $\mathrm{CT}$, and provide appropriate preventive measures such as fluid therapy before and after the examination.

\section{Level of Evidence: IVa Grade of Recommendation: B}

\section{Rationale CQ6-1}

In a cohort study of 539 patients (348 received a CTA) in whom the effects of CTA and the use of contrast media on the risk of kidney dysfunction were assessed, baseline GFR was an independent predictor of AKI [87]. Case series that included only patients undergoing contrast-enhanced CT have reported that baseline kidney dysfunction is a risk factor for CIN [66, 88-91]. In two cohort studies in which change over time in SCr levels was compared between patients undergoing plain and contrast-enhanced CT examinations, the incidence of an increase in SCr levels did not show statistically significant difference between the 2 groups [92, 93].

Alternatively, it has been widely believed that the risk for developing CIN after CAG or catheterization increases in patients with CKD (see CQ5-1).

It is highly likely, on the basis of these findings, that the risk for developing CIN after contrast-enhanced CT is high among patients with CKD. Because the risk for developing CIN after intravenous administration of contrast media is considered high in patients with an eGFR of $<45 \mathrm{~mL} / \mathrm{min} /$ $1.73 \mathrm{~m}^{2}$ (see CQ3-1) [5, 6], such patients should have the risk of CIN explained to them, and receive appropriate measures to prevent CIN such as fluid therapy before and after contrast-enhanced CT (see CQ7-1).

\subsection{CQ6-2 Does the use of a smaller volume of contrast media reduce the risk for developing CIN after contrast-enhanced CT?}

\section{Answer:}

We consider using minimum volume of contrast media for contrast-enhanced CT necessary to ensure an accurate diagnosis.

\section{Level of Evidence: V Grade of Recommendation: C1}

\section{Rationale CQ6-2}

The volume of contrast medium required to make an accurate diagnosis depends on the purpose of the imaging. For example, 500-600 mg iodine/kg is required to perform dynamic CT of the liver and other solid organs, while CTA for the visualization of arterial system may be performed with 180-300 mg iodine/kg of contrast medium. Accordingly, contrast-enhanced CT may be performed safely even in patients with kidney dysfunction when only a small volume of contrast medium is used.

Because in many cases CIN developed after CAG, which requires a relatively large volume of contrast media, it is believed that the use of a large volume of contrast medium increases the risk for developing CIN. 
In an analysis of 10 RCTs and 2 cohort studies that assessed the risk of CIN after cardiac catheterization, the incidence of CIN in patients with an eGFR of $30 \mathrm{~mL} / \mathrm{min} /$ $1.73 \mathrm{~m}^{2}$ who received $150,125,100$, or $75 \mathrm{~mL}$ of contrast medium containing $300 \mathrm{mg}$ iodine $/ \mathrm{mL}$ was estimated as 19.0, 14.7, 10.4, and 6.1\%, respectively [94].

In a study that investigated an association between contrast volume and CIN in patients with CKD undergoing CAG, the incidence of CIN in quartiles of contrast volume $(61,34,23,14 \mathrm{~mL})$ was $29.8,15.2,10.9$, and $4.4 \%$, respectively [95]. In a study reported in 1989 when ionic contrast media were commonly used for cardiac catheterization, a "contrast material limit" in patients with CKD was calculated by using the following formula: $([5 \mathrm{~mL}$ of contrast per $1 \mathrm{~kg}] \times$ body weight $[\mathrm{kg}]) / \mathrm{SCr}$ $(\mathrm{mg} / \mathrm{dL})$ (see CQ4-1) [51]. However, the maximum volume of contrast is $300 \mathrm{~mL}$, even when the calculated limit exceeds $300 \mathrm{~mL}$ (e.g., contrast medium containing $370 \mathrm{mg}$ iodine $/ \mathrm{mL}$ ).

Although only a few reports have described the relationship between the volume of contrast media used in contrast-enhanced CT and the risk of CIN, in a study of 421 patients undergoing contrast-enhanced CT, the use of $>100 \mathrm{~mL}$ of contrast media was associated with an increased risk of CIN defined by a rise in SCr levels $\geq 25 \%$ (OR 3.3, $95 \%$ CI 1.0-11.5) [5].

According to these findings, it is considered that the use of a small volume of contrast media may decrease the risk for developing CIN after contrast-enhanced CT, but that a safe dose of contrast media may not be determined with a simple equation. Even a small volume of contrast may induce CIN in patients with severe kidney dysfunction. Physicians must determine the volume of contrast media to be used during contrast-enhanced CT after careful consideration of the risks associated with the use of contrast media and the benefits of the examination. Patients with kidney dysfunction should undergo appropriate preventive procedures such as fluid therapy before and after contrast-enhanced CT, and should be closely followed up for kidney function and clinical condition.

According to the formula described by Nyman et al. [94], the volumes of contrast media that are associated with the 5, 10, 20, and $30 \%$ incidences of CIN in patients with different eGFRs can be calculated (Fig. 3). This formula has been validated in only 1 study by the same researchers [52], and there is no sufficient evidence supporting the formula. Readers should be aware of this, and should use these data only as a reference.
Fig. 3 Volumes of contrast media associated with the 5,10 , 20 and $30 \%$ incidences of CIN. (1) CIN was defined as an increase in $\mathrm{SCr}$ level by $44.2 \mathrm{mmol} / \mathrm{L}(0.5 \mathrm{mg} / \mathrm{dL})$ or $\geq 20-25 \%$ within $48-72 \mathrm{~h}$ after contrast exposure. (2) The formula used to calculate volume of contrast media associated with CIN has been validated in only 1 study by Nyman et al. [52], and there is no sufficient evidence supporting the formula. Readers should be aware of this, and should use these data only as a reference. The formula was developed on the basis of data of patients undergoing cardiac catheterization rather than $\mathrm{CT}$. CIN contrast-induced nephropathy, $C T$ computed tomography, $e G F R$ estimated glomerular filtration rate, $\mathrm{SCr}$ serum contrast media of $370 \mathrm{mg}$ iodine $/ \mathrm{mL}$ creatinine
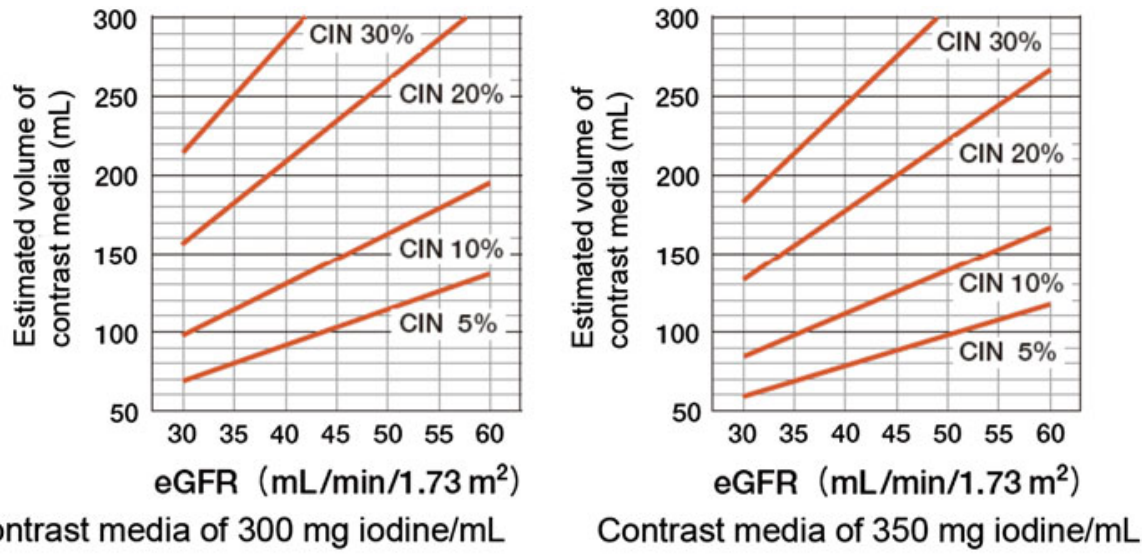

Contrast media of $370 \mathrm{mg}$ iodine $/ \mathrm{mL}$

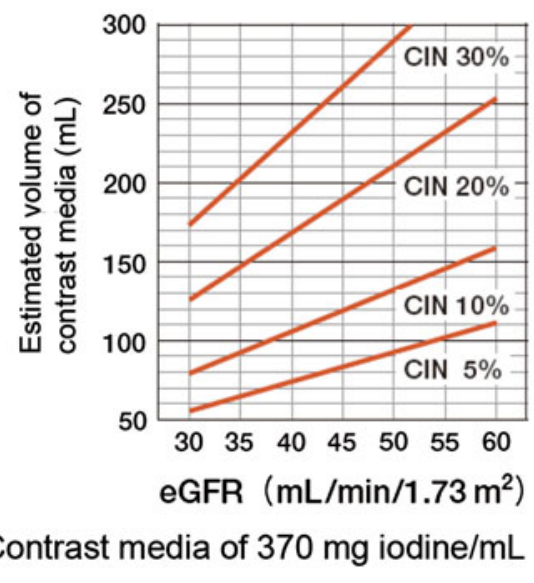


6.3 CQ6-3 Does repeated contrast-enhanced CT at short intervals increase the risk for developing CIN?

\section{Answer:}

We consider not to repeat contrast-enhanced CT within 24-48 h because repeated contrast-enhanced CT at short intervals may increase the risk for developing CIN.

\section{Level of Evidence: V Grade of Recommendation: C2}

\section{Rationale CQ6-3}

Patients with emergent conditions, such as those with ruptured cerebral aneurysm or acute myocardial infarction, may receive contrast media repeatedly within $24-48 \mathrm{~h}$ for the purposes of pre- and post-treatment assessment and intervention, among others.

In a study of 164 patients who underwent repeated contrast-enhanced CT examinations within $24 \mathrm{~h}, 21$ patients $(12.8 \%)$ developed CIN [96]. Because the incidence of CIN was higher than that reported in other studies of patients after single contrast-enhanced CT examination, it is possible that repeated contrast-enhanced CT may increase the incidence of CIN. In a study of 28 patients who underwent two contrast exposures, $\mathrm{SCr}$ levels increased and eGFR decreased statistically significantly after the second contrast exposure, and 4 of the 28 patients developed CIN [97].

In a study of 198 patients who underwent contrastenhanced CT for evaluation of acute ischemic or hemorrhagic stroke, none of 55 patients who underwent repeat contrast-enhanced CT within $24 \mathrm{~h}$ of the initial examination developed CIN (the volume of contrast media ranged from between 180-260 mL) [98]. It also has been reported that there was no correlation between the number of contrast-enhanced CT examinations and the incidence of CIN [87]; the incidence of AKI did not differ between patients receiving contrast media twice within $32 \mathrm{~h}$ and those receiving no contrast media [93]; and the incidence of CIN did not increase in patients undergoing contrast-enhanced CT followed by CAG [99]. There is no conclusive evidence demonstrating that repeated contrast-enhanced CT increases the risk of CIN.

However, because the incidence of CIN increases as the volume of contrast medium used during an examination increases, as described in CQ6-2, repeated exposure to contrast media within 24-48 h may increase the incidence of CIN [7]. Accordingly, repeated contrast-enhanced CT should be avoided in principle, and patients undergoing multiple contrast-enhanced examinations in a short period of time should be examined prior to the use of contrast medium for baseline kidney function and the risk of CIN, and should also be closely monitored for kidney function after contrast-enhanced CT.

6.4 CQ6-4 Is the risk for developing CIN after contrast-enhanced CT higher in outpatients than inpatients?

\section{Answer:}

There is no clear evidence demonstrating that the risk for developing CIN after contrast-enhanced CT is higher in outpatients than in inpatients.

\section{Level of Evidence: V Grade of Recommendation: Not applicable}

\section{Rationale CQ6-4}

Outpatients account for more than half of patients undergoing contrast-enhanced CT. There is an opinion that the incidence of CIN may be higher in outpatients than in inpatients because it is possible that preventive measures before and after the procedure and postprocedural followup are insufficient for outpatients.

In a study of 421 patients undergoing nonemergent CT, the incidence of CIN (an increase in SCr levels of $\geq 25 \%$ ) was significantly higher in inpatients $(n=127)$ than in outpatients ( $n=294$ ) (12.6 vs. $3.6 \%$ ) [5]. However, in a study of inpatients $(n=1,111)$ undergoing contrast procedures, not including coronary procedures, the incidence of CIN (increase in SCr levels of $\geq 0.5 \mathrm{mg} / \mathrm{dL}$ ) was $4.6 \%$ [91]. Conversely, in a study of outpatients undergoing contrast-enhanced CT, the incidence of CIN (an increase in SCr levels of $\geq 0.5 \mathrm{mg} / \mathrm{dL}$ or $\geq 25 \%$ ) was $11.1 \%$ (70 of 633 patients) [100].

Earlier-mentioned reports differ substantially in patient characteristics, such as disease severity, that may affect the reported incidence of CIN. There is no conclusive evidence indicating that the incidence of CIN is higher in either group. It is thought to be that the incidence of CIN differ among these reports because of non-uniformity of patient populations such as patient characteristics, disease severity.

\section{Prevention of contrast-induced nephropathy: fluid therapy}

7.1 CQ7-1 Does physiological saline hydration decrease the risk for developing CIN?

\section{Answer:}

1. We recommend using isotonic solutions such as physiological saline and sodium bicarbonate solution 
intravenously before and after contrast-enhanced examination in patients with $\mathrm{CKD}$ and a high risk for developing CIN.

\section{Level of Evidence: II Grade of Recommendation: A}

2. We recommend using isotonic solutions to prevent CIN because isotonic $0.9 \%$ sodium chloride injection (physiological saline) is superior to hypotonic $0.45 \%$ sodium chloride injection in preventing CIN.

\section{Level of Evidence: II Grade of Recommendation: A}

\section{Rationale CQ7-1}

In the 1980s, Eisenberg et al. [101, 102] demonstrated that the development of CIN in patients with CKD undergoing contrast-enhanced examination may be prevented by intravenous administration of physiological saline during the examination.

Trivedi et al. [103] conducted a RCT to assess the role of saline hydration on the development of CIN. A total of 53 patients with normal kidney function who were going to undergo nonemergency cardiac catheterization were randomized to a group of patients receiving normal saline intravenously or a group of patients allowed unrestricted oral fluids. CIN (defined as an increase in SCr levels of $\geq 0.5 \mathrm{mg} / \mathrm{dL}$ within $48 \mathrm{~h}$ of contrast exposure) developed in 1 of the 27 patients $(3.7 \%)$ receiving saline infusion and 9 of the 26 patients $(34.6 \%)$ with unrestricted oral fluids $(p=0.005)$, indicating that saline hydration significantly decreases the incidence of CIN. In the RENO Study, 111 patients with acute coronary syndrome undergoing emergency PCI were randomly assigned to receive an initial intravenous bolus of $5 \mathrm{~mL} / \mathrm{kg} / \mathrm{h}$ of alkaline saline solution with $154 \mathrm{mEq} / \mathrm{L}$ of sodium bicarbonate over $1 \mathrm{~h}$ before PCI (group A) or to receive standard hydration after PCI (group B) [104]. The incidence of CIN was $1.8 \%$ in group A and $21.8 \%$ in group $\mathrm{B}(p=0.032)$. It is recommended, according to these findings, that patients receive intravenous solutions such as physiological saline prior to contrast exposure to prevent CIN.

In a RCT comparing the effects of isotonic and hypotonic fluids on the incidence of CIN, the isotonic solution (0.9\% physiological saline) was superior to the hypotonic solution (0.45\% sodium chloride) [105]. In this study, 1,620 patients scheduled for selective or emergency coronary angioplasty were randomly assigned to receive isotonic $(n=809)$ or hypotonic $(n=811)$ hydration prior to intervention. The incidence of CIN (defined as an increase in SCr levels of $\geq 0.5 \mathrm{mg} / \mathrm{dL}$ within $48 \mathrm{~h}$ ) was significantly reduced with isotonic $(0.7 \%, 95 \%$ CI $0.1-1.4 \%)$ vs. hypotonic $(2.0 \%, 95 \%$ CI $1.0-3.1 \%)$ hydration $(p=0.04)$.
Many patients had normal kidney function at baseline, and non-ionic low-osmolar contrast media were used.

Because the earlier-mentioned findings support the efficacy of isotonic fluids, such as physiological saline, in the prevention of CIN, we recommend the use of isotonic fluids as a preventive measure for CIN. The volume of isotonic fluids infused should be adjusted according to the cardiac function and general condition of the patient. The use of isotonic fluids to prevent CIN should be considered for patients with a GFR of $<45 \mathrm{~mL} / \mathrm{min} / 1.73 \mathrm{~m}^{2}$ undergoing noninvasive contrast-enhanced examinations such as contrast-enhanced CT after intravenous administration of contrast media, and for patients with a GFR of $<60 \mathrm{~mL} /$ $\min / 1.73 \mathrm{~m}^{2}$ undergoing invasive contrast-enhanced examinations such as CAG with intra-arterial administration of contrast media.

7.2 CQ7-2 Does oral water intake decrease the risk for developing CIN as much as administration of fluid therapy does?

\section{Answer:}

There is no sufficient evidence that oral water intake is as effective as intravenous fluid therapy in preventing the development of CIN. We consider that patients receive fluid therapy or other established preventive measures rather than rely on oral water intake to prevent CIN.

\section{Level of Evidence: II Grade of Recommendation: C1}

\section{Rationale CQ7-2}

It is difficult to conduct intravenous hydration as a measure to prevent CIN in outpatients or patients undergoing emergency imaging. For such patients, oral fluid loading has been tried to prevent dehydration and promote diuresis. Trivedi et al. [103] evaluated the effects of unrestricted oral fluids and intravenous saline hydration on the incidence of CIN in patients undergoing nonemergency cardiac catheterization, and reported that saline hydration was superior to oral fluids in terms of the prevention of CIN and the severity of kidney dysfunction.

In a study of the effects of oral hydration with mineral water versus intravenous hydration with isotonic solution on kidney function in patients with diabetes undergoing elective $\mathrm{CAG}$ and PCI, 52 patients (group 1; mean $\mathrm{CCr}$ : $70.3 \mathrm{~mL} / \mathrm{min})$ were hydrated intravenously $(1 \mathrm{~mL} / \mathrm{kg} / \mathrm{h})$, during the $6 \mathrm{~h}$ before and during the $12 \mathrm{~h}$ after CABG or PCI, with isotonic solution $(0.9 \% \mathrm{NaCl})$ [106]. Fifty patients (group 2; mean $\mathrm{CCr} 79 \mathrm{~mL} / \mathrm{min}$ ) were randomized to receive oral water intake $(1 \mathrm{~mL} / \mathrm{kg} / \mathrm{h})$ during $6-12 \mathrm{~h}$ before and during the $12 \mathrm{~h}$ after CAG or PCI. At $72 \mathrm{~h}$ after the procedure, the mean $\mathrm{CCr}$ was $65.3 \mathrm{~mL} / \mathrm{min}$ in group 1 and $73.5 \mathrm{~mL} / \mathrm{min}$ in 
group 2 (not significant [NS]). The incidence of CIN was $5.77 \%$ in group 1 and $4.00 \%$ in group 2 (NS).

In the PREPARED study, 36 patients with CKD ( $\mathrm{SCr}$ levels $\geq 1.4 \mathrm{mg} / \mathrm{dL}$ ) undergoing elective cardiac catheterization were randomized to receive either an outpatient hydration protocol including precatheterization oral hydration $(1,000 \mathrm{~mL}$ oral water intake over $10 \mathrm{~h})$ followed by $6 \mathrm{~h}$ of intravenous hydration $(0.45 \%$ normal saline solution at $300 \mathrm{~mL} / \mathrm{h} ; n=18$ ) beginning just before contrast exposure, or overnight intravenous hydration $(0.45 \%$ normal saline solution at $75 \mathrm{~mL} / \mathrm{h}$ for both $12 \mathrm{~h}$ precatheterization and postcatheterization procedures; $n=18$ ) [107]. The maximal changes in $\mathrm{SCr}$ levels in the inpatient $(0.21 \pm 0.38 \mathrm{mg} / \mathrm{dL})$ and outpatient $(0.12 \pm 0.23 \mathrm{mg} / \mathrm{dL})$ groups were similar (NS). They concluded that an oral hydration strategy prior to $\mathrm{PCI} /$ CAG was similar to intravenous hydration in preventing contrast-associated changes in SCr levels. The results of the earlier-described RCT suggest that oral hydration prior to $\mathrm{PCI} / \mathrm{CAG}$ may be effective in the prevention of CIN.

A study investigated whether oral intake of sodium chloride and water exerts effects similar to that of intravenous saline hydration [108]. In this RCT of saline hydration to prevent CIN in 312 patients with CKD (mean $\mathrm{CCr} 37 \mathrm{~mL} / \mathrm{min} / 1.73 \mathrm{~m}^{2}$ ), patients were randomly assigned to 4 arms. In the first group, 76 patients received $1 \mathrm{~g} / 10 \mathrm{~kg}$ of body weight per day of sodium chloride orally for 2 days before the procedure, and in the second group, 77 patients received $0.9 \%$ saline intravenously at a rate of $15 \mathrm{~mL} / \mathrm{kg}$ for $6 \mathrm{~h}$ before the procedure. The incidence of CIN was $6.6 \%$ in the first group and $5.2 \%$ in the second group (NS). The authors concluded that oral saline hydration was as effective as intravenous saline hydration for the prevention of CIN.

Although reports have indicated that oral hydration and intravenous saline infusion are similar in terms of the prevention of CIN, there is no conclusive evidence supporting the efficacy of oral hydration at this time. Oral hydration with water cannot be recommended as an alternative to intravenous infusion of physiological saline. Further studies are needed to confirm whether CIN can be prevented by oral water intake prior to the procedure and intravenous hydration after the procedure in patients in whom preprocedural intravenous hydration is not feasible. There is no conclusive evidence regarding the equivalence of oral saline hydration and intravenous saline hydration in the prevention of CIN.

Although oral hydration is inferior to intravenous hydration as a measure to prevent CIN, oral hydration prior to contrast exposure is recommended as a measure to treat dehydration and prevent discomfort caused by contrast media.
7.3 CQ7-3 Does sodium bicarbonate-based hydration decrease the risk for developing CIN?

\section{Answer:}

Although sodium bicarbonate-based hydration may decrease the risk for developing CIN and be superior in this regard to saline hydration, currently available evidence does not support the conclusion that sodium bicarbonatebased hydration is essential in the prevention of CIN.

\section{Level of Evidence: I Grade of Recommendation: C1}

\section{Rationale CQ7-3}

The efficacy of sodium bicarbonate-based hydration in the prevention of CIN has been evaluated by using MEYLON ${ }^{\circledR}$ $(1 \mathrm{Eq} / \mathrm{L})$ at a volume of $20 \mathrm{~mL}$ and those using $154 \mathrm{mEq} / \mathrm{L}$ of sodium bicarbonate solution. In Japan, $1.26 \%$ Sodium Bicarbonate Injection (Fuso) $(152 \mathrm{mEq} / \mathrm{L})$ is commercially available.

Seven meta-analyses have been published on the comparison of sodium bicarbonate-based hydration with saline hydration in the prevention of CIN, and all but 1 analysis concluded that sodium bicarbonate-based hydration was superior to saline hydration in reducing the risk of CIN [109-115]. In 2009, Zoungas et al. [109] searched data published from 1950 to 2008, and reviewed 23 published and unpublished RCTs of intravenous sodium bicarbonate (9 peer-reviewed studies and 14 abstracts) with information on 3,563 patients. They reported that the pooled RR of CIN in patients receiving sodium bicarbonate-based hydration was 0.62 (95\% CI 0.45-0.86). Other meta-analyses yielded similar results in terms of the prevention of CIN by sodium bicarbonate-based hydration. However, no significant differences between sodium bicarbonate-based hydration and saline hydration were observed in terms of the introduction of hemodialysis, incidence of heart failure, or mortality. They concluded that sodium bicarbonatebased hydration may decrease the incidence of CIN, but does not differ from saline hydration in terms of kidney function and vital prognoses. Researchers have pointed out that studies included in these meta-analyses differ substantially in design, and that sodium bicarbonate-based hydration was reported effective in many published articles, and was concluded to be ineffective in other studies published as abstracts only.

In a meta-analysis of 14 studies (3 large and 11 small studies) of 2,290 patients, there was no evidence of a benefit for hydration with sodium bicarbonate compared with sodium chloride for the prevention of CIN among the large trials [116]. The report pointed out that including studies of lower methodological quality in the analysis may have led to a false conclusion. In this report, the researchers performed an analysis limited to 8 studies meeting the quality criteria, including 
$>100$ patients enrolled, and a similar dose and route between treatment groups if $\mathrm{N}$-acetylcysteine (NAC) use was permitted. The RR for sodium bicarbonate $(n=945)$ compared with that for sodium chloride $(n=945)$ was $0.71(95 \%$ CI 0.41-1.03), which was not a statistically significant difference, but suggested a superior efficacy of the sodium bicarbonate-based hydration.

Readers of these meta-analyses should be aware that a typical protocol of sodium bicarbonate-based hydration consists of a 1-h infusion of about $150 \mathrm{mEq} / \mathrm{L}$ solution at $3 \mathrm{~mL} / \mathrm{kg} / \mathrm{h}$ for $1 \mathrm{~h}$ before contrast exposure and a 6-h infusion of the solution at $1 \mathrm{~mL} / \mathrm{kg} / \mathrm{h}$ for $6 \mathrm{~h}$ after contrast exposure, and is different in duration from a typical protocol of saline hydration with a 6-12 h infusion at $1 \mathrm{~mL} /$ $\mathrm{kg} / \mathrm{h}$ before and after contrast exposure. In these metaanalyses, data were not adjusted for the difference in the duration of infusion. Also, preprocedural hemofiltration has been reported to be effective for preventing CIN, and alkalinization of body fluids is also considered effective in the prevention of CIN (see CQ9-2). However, in a study of patients randomized to receive either sodium chloride or sodium bicarbonate administered at the same rate $(3 \mathrm{~mL} / \mathrm{kg}$ for $1 \mathrm{~h}$ before $\mathrm{CAG}$, decreased to $1.5 \mathrm{~mL} / \mathrm{kg} / \mathrm{h}$ during the procedure and for $4 \mathrm{~h}$ after the completion of the procedure), the incidence of CIN did not differ between the 2 groups [117].

Since 2009, 7 reports have been published on the use of sodium bicarbonate-based hydration. These 7 studies differ in design, and sodium bicarbonate-based hydration was concluded to be effective in 3 studies [118-120] and ineffective in 4 studies [121-124]. The 4 studies that concluded that the sodium bicarbonate-based hydration was ineffective included 2 studies conducted in the same institution around the same time. These 2 studies may contain duplicated data. There are 3 reports on sodium bicarbonate-based hydration in Japan. Ueda et al. [118] compared bolus saline infusion with bolus sodium bicarbonate infusion immediately before emergency PCI, and reported that sodium bicarbonate infusion significantly decreased the incidence of CIN by $88 \%$ (RR: $0.128,95 \%$ CI: $0.016 \sim 0.91, p=0.01$ ). In a RCT of 144 patients with mild CKD undergoing an elective CAG, Tamura et al. [119] reported that the incidence of CIN was lower in patients receiving standard saline hydration $(12 \mathrm{~h}$ before contrast exposure) plus a single-bolus intravenous administration of $20 \mathrm{mEq} / \mathrm{L}$ sodium bicarbonate (MEY$\mathrm{LON}^{\circledR} 20 \mathrm{~mL}$ ) immediately before contrast exposure than in patients receiving standard saline hydration alone ( $p=0.017)$. Motohiro et al. [120] conducted a RCT in 155 patients and reported that the incidence of CIN in patients undergoing CAG was significantly lower in 78 patients who received $3 \mathrm{~h}$ of saline hydration followed by $3 \mathrm{~h}$ of sodium bicarbonate-based hydration at $1 \mathrm{~mL} / \mathrm{kg} / \mathrm{h}$ prior to $\mathrm{CAG}$ and
$6 \mathrm{~h}$ of sodium bicarbonate-based hydration after CAG than in 77 patients receiving saline hydration alone $(p=0.012)$. In the PREVENT study conducted in Korea, 382 patients with diabetes and CKD were randomly assigned to receive saline hydration at $1 \mathrm{~mL} / \mathrm{kg} / \mathrm{h}$ for $12 \mathrm{~h}$ before and after CAG or PCI (saline group, $n=189$ ), or sodium bicarbonate at $3 \mathrm{~mL} / \mathrm{kg} / \mathrm{h}$ for $1 \mathrm{~h}$ before contrast exposure and at $1 \mathrm{~mL} / \mathrm{kg} /$ $\mathrm{h}$ from the initiation of the procedure to $6 \mathrm{~h}$ after the procedure (bicarbonate group, $n=193$ ) [121]. All patients received oral NAC $1,200 \mathrm{mg}$ twice daily for 2 days. The incidence of CIN was $5.3 \%$ in the saline group and $9.0 \%$ in the bicarbonate group, but the difference was not significant $(p=0.17)$.

These findings suggest that sodium bicarbonate is superior to saline in the prevention of CIN in patients who have only a limited time to receive intravenous infusion (e.g., patients requiring emergency care). However, sodium bicarbonate-based hydration does not significantly decrease the risks of hemodialysis and death, and is not concluded to be necessary.

\subsection{CQ7-4 Is short-term intravenous hydration as effective as standard intravenous hydration in preventing CIN?}

\section{Answer:}

Although there is no conclusive evidence on the efficacy of short-term intravenous hydration, we consider not to use short-term intravenous hydration because the incidence of CIN may be higher in those patients receiving short-term intravenous hydration than in those receiving standard intravenous hydration.

\section{Level of Evidence: II Grade of Recommendation: C2}

\section{Rationale CQ7-4}

It is difficult to conduct RCTs comparing short-term intravenous hydration (e.g., 1-h intravenous hydration before contrast exposure) with standard intravenous hydration because short-term intravenous hydration is required only for patients undergoing emergency PCI.

In a RCT of 63 patients with CKD who received either 12-h intravenous hydration at $1 \mathrm{~mL} / \mathrm{kg} / \mathrm{h}$ or bolus hydration at a volume of $250 \mathrm{~mL}$ over $1 \mathrm{~h}$ immediately before procedure, the incidence of CIN was $0 \%$ in patients receiving overnight hydration and $10.8 \%$ in patients receiving bolus hydration [125]. Meanwhile, in a study comparing intravenous administration of $\geq 2,000$ $\mathrm{mL} /$ day within $12 \mathrm{~h}$ before and after contrast exposure, and volume expansion with $300 \mathrm{~mL}$ saline immediately before the administration of contrast media, the incidence of CIN did not differ between the groups [126]. 
Among 4 RCTs comparing 1-h sodium bicarbonate hydration at $3 \mathrm{~mL} / \mathrm{kg} / \mathrm{h}$ with $6-12 \mathrm{~h}$ saline hydration at $1 \mathrm{~mL} / \mathrm{kg} / \mathrm{h}, 3 \mathrm{RCTs}$ did not show a difference in the incidence of CIN between the groups [121, 124, 127]. These findings suggest that short-term sodium bicarbonate-based hydration is as effective as standard saline hydration in preventing CIN.

In 2 RCTs, patients received furosemide in addition to saline hydration to achieve a urine flow of $\geq 300 \mathrm{~mL} / \mathrm{h}$ before contrast exposure and to maintain it for $4 \mathrm{~h}$ after contrast exposure to prevent CIN in high-risk patients [20, 21]. In the REMEDIAL II study, 292 patients with CKD and a GFR of $<30 \mathrm{~mL} / \mathrm{min} / 1.73 \mathrm{~m}^{2}$ were randomized to receive sodium bicarbonate solution and NAC ( $n=146$ ), or aggressive saline hydration, NAC, and furosemide $(n=146)$ [20]. In the group of patients receiving saline infusion and furosemide with keeping urine volume more than $300 \mathrm{~mL} / \mathrm{h}$, a $53 \% \mathrm{RR}$ reduction was observed as compared with that seen in patients receiving sodium bicarbonate-based hydration (OR 0.47, $95 \%$ CI 0.24-0.92). In patients with a higher risk of heart failure, the initial bolus administration of saline was reduced to $\leq 150 \mathrm{~mL}$. No patients experienced adverse drug reactions to furosemide, but acute pulmonary edema due to volume overload developed in 3 patients. According to these findings, administration of a large amount of saline and furosemide may be effective in the prevention of CIN after contrast exposure in patients with a GFR of $<30 \mathrm{~mL} / \mathrm{min} / 1.73 \mathrm{~m}^{2}$. However, patients should be closely observed to prevent the occurrence of pulmonary edema.

Only a few studies have investigated the efficacy of hydration within $1 \mathrm{~h}$ before contrast exposure as compared with intravenous hydration over $12 \mathrm{~h}$, and no sufficient evidence has been obtained. Further studies should be done in this area.

\section{Prevention of contrast-induced nephropathy: pharmacologic therapy}

It has been suggested that renal injury due to reactive oxygen species, renal vascular constriction, and renal ischemia may play important roles in the development of CIN. Accordingly, vasodilating drugs and antioxidants have been expected to prevent or alleviate CIN, and many clinical studies of these drugs have been conducted. However, there have been no established pharmacological measures to prevent CIN. Almost all studies of drugs to prevent CIN have been conducted in patients undergoing $\mathrm{CAG}$, and few studies have included patients undergoing CT using intravenous contrast enhancement.
8.1 CQ8-1 Does NAC decrease the risk for developing CIN?

\section{Answer:}

We consider not to use NAC for prevention of CIN.

\section{Level of Evidence: I Grade of Recommendation: C2}

\section{Rationale CQ8-1}

It has been suggested that a decrease in renal blood flow and hypoxia of the renal medulla due to vascular constriction, and kidney injury due to reactive oxygen species, may play important roles in the development of CIN. Accordingly, it has been expected that CIN may be prevented with drugs exerting anti-oxidant action such as NAC, ascorbic acid, sodium bicarbonate, and statins, as well as drugs that dilate blood vessels and increase renal blood flow such as human atrial natriuretic peptide (hANP), dopamine, fenoldopam, prostaglandin, and theophylline, and many clinical studies of these drugs have been conducted. However, no conclusive evidence has been obtained for any of these drugs.

NAC, an antioxidant with vasodilative properties [23], has been proven effective in the treatment of hepatic injury due to acetaminophen, and is indicated for the treatment of this condition in Japan and other countries, including the United States. Because animal studies have indicated that NAC may protect the myocardium and preserve kidney function [128], it was expected to prevent CIN in humans. After the report by Tepel et al. [65] on the effect of NAC (600 mg twice daily, orally) in preventing CIN, many RCTs and meta-analyses were conducted [129-139].

In a meta-analysis on the effects of NAC and other drugs on preventing CIN, Kelly et al. [133] analyzed the results of 26 RCTs of oral NAC, and concluded that NAC reduced the risk for CIN more than did saline hydration alone (RR: 0.62). However, in a comment on the meta-analysis performed by Kelly et al., Trivedi [140] pointed out the diverse designs of the included studies, and questioned the validity of the conclusion. Although this meta-analysis concluded that NAC was more renoprotective than was saline hydration alone, the sample sizes of the studies analyzed and the quality of sample calculation methods used in the meta-analysis were questioned. In another meta-analysis of 22 RCTs, Gonzales et al. [138] used a modified L'Abbé plot to divide the data into cluster 1 (18 studies, 2,445 patients) and cluster 2 (4 studies, 301 patients), and reported that cluster 1 studies showed no benefit, while cluster 2 studies indicated that NAC was highly beneficial. However, cluster 2 studies were published earlier, and were of lower quality as measured by Jadad scores $(<3$, three study characteristics combined) $[138,139]$. At the present time, oral NAC treatment has not 
been demonstrated to be sufficiently effective in the prevention of CIN. In a meta-analysis of 6 studies on the effect of intravenous NAC in the prevention of CIN, no conclusive evidence has shown that intravenous NAC is safe and effective in preventing CIN [139]. Subsequently, a multicenter RCT of NAC in about 2,300 patients was conducted to compare NAC 1,200 mg with placebo, and it was concluded that NAC does not reduce the risk of CIN, improve 30-day mortality, or reduce the need for dialysis at 30 days [132].

The absence of an increase in SCr levels after the administration of NAC does not always indicate that NAC is effective in preventing CIN. NAC is known to increase the activity of creatinine kinase and the excretion of creatinine from the renal tubules [141, 142]. Accordingly, it cannot be concluded that NAC may preserve kidney function even when no increase in $\mathrm{SCr}$ levels is observed after treatment with NAC, because NAC may maintain the patient's baseline SCr level by increasing excretion of SCr.

Although the use of NAC is not recommended for a measure to prevent CIN, some specialists recommend it for high risk patients because of the low cost and low incidence of adverse drug reactions [8, 143].

\subsection{CQ8-2 Does hANP decrease the risk for developing CIN?}

\section{Answer:}

We consider not to use hANP to prevent CIN.

\section{Level of Evidence: II Grade of Recommendation: C2}

\section{Rationale CQ8-2}

An intrinsic peptide, hANP exerts a natriuretic action, afferent arteriole dilatation [144], anti-renin and antialdosterone actions [145], and has been reported to be beneficial in the treatment of AKI after cardiac surgery [146]. Although several reports have denied the efficacy of hANP in preventing CIN [147-149], the decrease in blood pressure by hANP might have affected the incidence of CIN in these reports. A study in Japan has reported that hANP at a low dose that does not decrease blood pressure is beneficial in the prevention of CIN [150]. However, there is no conclusive evidence supporting the efficacy of hANP in preventing CIN, and at the present time, hANP is not recommended as a standard measure to prevent CIN. Further studies are awaited to investigate the indications of hANP in the prevention of CIN in high risk patients. B-type natriuretic peptide (BNP) is also expected to be effective in the prevention of CIN, and further studies are awaited to evaluate its efficacy [151].
8.3 CQ8-3 Does ascorbic acid decrease the risk for developing CIN?

\section{Answer:}

We consider not to use ascorbic acid to prevent CIN.

\section{Level of Evidence: II Grade of Recommendation: C2}

\section{Rationale CQ8-3}

Ascorbic acid exerts an anti-oxidant action against reactive oxygen species, and potentiates the effects of other antioxidants [152, 153]. Spargias et al. [152] have reported the efficacy of ascorbic acid in preventing CIN. In the REMEDIAL study in which 326 patients with CKD were randomly assigned to prophylactic administration of $0.9 \%$ saline infusion plus NAC, sodium bicarbonate infusion plus NAC, or $0.9 \%$ saline plus ascorbic acid plus NAC, ascorbic acid was not effective in the prevention of CIN [154]. At the present time, the use of ascorbic acid is not recommended as a standard measure to prevent CIN.

\subsection{CQ8-4 Do statins decrease the risk for developing} CIN?

\section{Answer:}

We consider not to use statins to prevent CIN.

\section{Level of Evidence: I Grade of Recommendation: C2}

\section{Rationale CQ8-4}

Because statins exert many different actions, including anti-oxidant and anti-inflammatory actions [155], they are expected to be effective in preventing CIN. Observational studies have reported that statins may preserve kidney function [156, 157]. However, meta-analyses have yielded inconsistent conclusions. A meta-analysis of 6 cohort studies and 6 RCTs concluded that current data are not conclusive as to whether statins are protective for CIN [158], while another meta-analysis of data on 1,251 patients from 7 RCTs concluded that periprocedural shortterm statin treatment is likely effective in the prevention of CIN [159]. At the present time, we consider not to use statins to prevent CIN.

\section{Prevention of contrast-induced nephropathy: dialysis}

9.1 CQ9-1 Does hemodialysis conducted after contrast exposure as a measure to prevent CIN decrease the risk for developing CIN?

\section{Answer:}

Because there is no evidence indicating that hemodialysis decreases the risk for developing CIN, we recommend not 
to use hemodialysis after contrast exposure for this purpose.

\section{Level of Evidence: I Grade of Recommendation: D}

9.2 CQ9-2 Is hemofiltration superior to hemodialysis in decreasing the risk for developing CIN?

Answer:

We consider not to use hemofiltration as a measure to prevent CIN.

\section{Level of Evidence: II Grade of Recommendation: C2}

\section{Rationale CQ9-1 and CQ9-2}

Contrast media can be removed from the blood by hemodialysis. It has been reported that $60-90 \%$ of the contrast medium is removed during 1 session of hemodialysis. Clinical studies have been conducted on the basis of these findings to investigate the efficacy of hemodialysis, hemodiafiltration, and hemofiltration in the prevention of CIN [160-169]. However, most studies could not demonstrate the efficacy of these procedures in the prevention of CIN. A few studies have reported a lower risk of CIN, but some others have reported an increased risk of CIN. The risk of CIN was not changed in a majority of studies. Accordingly, there is no scientific evidence that supports the use of hemodialysis as a measure to prevent CIN.

Although studies have been conducted to investigate the efficacy of hemofiltration in preventing CIN, there has been no conclusive evidence that hemofiltration prevents CIN by removing the contrast medium from the blood.

However, in the clinical setting, hemodialysis may be conducted after contrast exposure to prevent heart failure or for other purposes.

\section{Treatment of contrast-induced nephropathy}

\subsection{CQ10-1 Does the treatment of CIN with loop diuretics improve the recovery from AKI?}

\section{Answer:}

We recommend not using loop diuretics for the treatment of CIN because it does not improve the recovery from AKI.

\section{Level of Evidence: I Grade of Recommendation: D}

\section{Rationale CQ10-1}

Most clinical studies on the effects of loop diuretics in the treatment of AKI, including CIN, have concluded that loop diuretics are ineffective in the treatment of AKI [170-174]. In a RCT of 338 patients with AKI requiring dialysis therapy who received either loop diuretics (furosemide) or placebo, furosemide showed no significant improvement for any endpoints tested [173]. In 2 meta-analyses published in 2006 [175] and 2007 [176], loop diuretics were not associated with improved kidney function, rate of hemodialysis, or mortality. In a cohort study, the use of diuretics in critically ill patients with AKI was associated with an increased risk of death [172]. Accordingly, the use of loop diuretics for the treatment of CIN is not recommended. Loop diuretics may be effective in restoring fluid balance through diuresis $[173,176]$, but may negatively affect the outcome of AKI [172]. In the treatment of CIN, physicians should keep appropriate body fluid volume and consider hemodialysis whenever necessary.

10.2 CQ10-2 Does fluid therapy prevent the progression of kidney dysfunction in patients with CIN?

\section{Answer:}

Because an excessive increase in body fluid volume after the development of CIN is a risk factor for the progression of kidney dysfunction and an increase in mortality, we consider that the volume of fluid therapy may be determined after careful evaluation of body fluid volume.

\section{Level of Evidence: IVa Grade of Recommendation: C2}

\section{Rationale CQ10-2}

Fluid therapy is an essential procedure to improve and maintain circulatory hemodynamics in patients with sepsis or shock, but multicenter collaborative studies of critically ill patients with AKI, including those with sepsis and CIN, have shown that an excessive increase in body fluid volume is an independent risk factor for in-hospital mortality [177, 178]. An early introduction of hemodialysis to restore fluid balance resulted in a decrease in mortality. On the other hand, no significant relationship was observed between body fluid volume and an improvement of kidney function. Accordingly, keeping patients appropriate body fluid should be monitored carefully to ensure that they are receiving appropriate fluid therapy based on the correct volume for the patient because an excessive increase in body fluid volume may increase the risk of death.

10.3 CQ10-3 Does the low-dose dopamine prevent the progression of kidney dysfunction in patients with CIN?

\section{Answer:}

We recommend not using low-dose dopamine for the treatment of CIN because it does not improve recovery from AKI.

\section{Level of Evidence: I Grade of Recommendation: D}

\section{Rationale CQ10-3}


In a RCT, patients with AKI after PCI (assumed to include many patients with CIN) were randomized to receive lowdose dopamine or saline alone, and the peak SCr level and the percentage of patients requiring hemodialysis were significantly higher in the group receiving low-dose dopamine [179]. In a subsequent RCT of patients with AKI, including those with CIN, there was no difference between the low-dose dopamine and placebo groups in $\mathrm{SCr}$ levels and percentages of patients requiring hemodialysis [180]. In 2 meta-analyses and a systematic review of studies addressing the use of dopamine in the prevention and/or treatment of kidney dysfunction, including studies on the use of low-dose dopamine for the prevention of AKI, low-dose dopamine was not effective in preventing the development and exacerbation of AKI and decreasing the percentages of patients requiring hemodialysis [181183]. A sub-analysis of patients with CIN revealed similar results [183].

In a cross-over study of patients with mild non-oliguric AKI, the effects of low-dose dopamine (increases in GFR and sodium excretion) disappeared in a short period of time [184]. It has been pointed out that low-dose dopamine reduced renal resistance indices in healthy individuals, but it increased renal resistance indices and may worsen kidney perfusion in patients with AKI [185].

In a small RCT of patients, many of whom were considered to have CIN, low-dose dopamine had a deleterious effect on the severity of kidney dysfunction [179]. In conclusion, low-dose dopamine is not recommended for patients with CIN as it does not prevent the progression of kidney dysfunction.

\subsection{CQ10-4 Does the treatment of CIN with hANP improve recovery from AKI?}

\section{Answer:}

We recommend not using hANP for the treatment of CIN because it does not prevent the progression of kidney dysfunction.

\section{Level of evidence: I Grade of Recommendation: D}

\section{Rationale CQ10-4}

In a RCT of critically ill patients with AKI, including patients with CIN, the dialysis-free survival for 21 days after treatment, percentage of patients undergoing dialysis by day 14 , and all-cause mortality by day 21 did not differ significantly between patients receiving high-dose hANP at $0.2 \mu \mathrm{g} / \mathrm{kg} / \mathrm{min}$ for $24 \mathrm{~h}$ or those receiving placebo [186]. In a RCT of critically ill patients with oliguric AKI, the dialysisfree survival through day 21 , percentage of patients undergoing dialysis by day 14 , and mortality through day 60 did not differ significantly between patients receiving hANP and placebo [187]. On the other hand, in a small RCT of patients with AKI associated with cardiac surgery who started to receive a continuous infusion of low-dose hANP $(50 \mathrm{ng} / \mathrm{kg}$ / min) or placebo immediately after the onset of AKI ( $\mathrm{SCr}$ levels increased by $>50 \%$ from baseline), there was no significant difference in the incidence of hypotensive episodes between the low-dose hANP and placebo groups, but the need for hemodialysis was significantly lower in the low-dose hANP group [188]. In a meta-analysis published in 2009, high-dose hANP did not significantly decrease mortality or the percentages of patients requiring hemodialysis, and was associated with an increased incidence of hypotension [189]. Alternatively, low-dose hANP did not increase the incidence of hypotension, or decrease the percentages of patients requiring hemodialysis. In summary, we recommend not using hANP for the treatment of CIN because it does not prevent the progression of kidney dysfunction. However, lowdose hANP may be effective in the treatment of CIN. Further studies are awaited.

10.5 CQ10-5 Does early renal replacement therapy (RRT) improve the outcome of kidney function in patients with CIN?

\section{Answer:}

1. There is no evidence demonstrating that early RRT improves the outcome of kidney function in patients with CIN.

2. We suggest that prompt initiation of early RRT for patients with AKI due to different causes, including critically ill patients with oliguric CIN, as it may decrease mortality and the incidence of major complications including kidney dysfunction.

\section{Level of Evidence: I Grade of Recommendation: B}

\section{Rationale CQ10-5}

In a small RCT of 106 patients with oliguric AKI, including those with CIN, who underwent early high-volume continuous venovenus hemofiltartion (CVVH), early low-volume CVVH, or late low-volume CVVH, survival and recovery of kidney function were not improved significantly in patients undergoing early continuous hemofiltration (started $7 \mathrm{~h}$ after inclusion in the early group) as compared with those receiving late CVVH (started $42 \mathrm{~h}$ after inclusion in the later group) [190]. In a cohort study in which data were analyzed according to the blood urea nitrogen (BUN) concentration at the start of dialysis, Liu et al. [191] reported that initiation of dialysis at a BUN of $>76 \mathrm{mg} / \mathrm{dL}$ was associated with an increased mortality. In a meta-analysis of studies including the study reported by Liu et al., early initiation of dialysis may lower mortality 
according to the results of cohort studies, although the criteria for initiating dialysis was not clearly described [192]. However, there was no significant difference in the recovery of kidney function by the timing of the initiation of dialysis. Similar results were obtained in a recent cohort study [193]. In a large-scale cohort study of critically ill patients with severe AKI in whom RRT was initiated on the basis of BUN and SCr levels, there was no significant difference in mortality between patients undergoing early (BUN $<67.76 \mathrm{mg} / \mathrm{dL}$ ) and late (BUN $\geq 67.76 \mathrm{mg} / \mathrm{dL}$ ) RRT, and late RRT was associated with a longer duration of RRT [194]. The mortality was significantly lower in patients undergoing late ( $\mathrm{SCr}$ level $>3.49 \mathrm{mg} / \mathrm{dL}$ ) RRT than early ( $\mathrm{SCr}$ level $\leq 3.49 \mathrm{mg} / \mathrm{dL}$ ) RRT, but late RRT was also associated with a longer duration of RRT. In a cohort study of patients with AKI after major abdominal surgery who underwent early or late start of RRT defined by the simplified RIFLE classification, mortality was significantly lower in patients undergoing early RRT (RIFLE: 0 or Risk) than in those undergoing late RRT (RIFLE: Injury or Failure) [195]. In another study of patients with AKI after elective open-heart surgery, the incidence of major complications was significantly lower in patients with early RRT [196].

In summary, there is no evidence demonstrating the efficacy of RRT in patients with non-oliguric CIN. How- ever, early RRT may decrease mortality and the incidence of major complications including kidney dysfunction in critically ill patients with oliguric CIN [192, 194].

\section{Appendix}

Essence of the guidelines on the use of iodinated contrast media in patients with kidney disease 2012.

Developed in collaboration with the Japanese Society of Nephrology, the Japan Radiological Society, and the Japanese Circulation Society.

\section{Definition of Contrast-Induced Nephropathy (CIN)}

CIN is defined as an increase in serum creatinine ( $\mathrm{SCr}$ ) levels by $\geq 0.5 \mathrm{mg} / \mathrm{dL}$ or $\geq 25 \%$

from baseline within 72 hours after a contrast examination using iodinated contrast medium.

- Baseline kidney function should be evaluated on the basis of the latest $\mathrm{SCr}$ levels prior to contrast examination.

- Glomerular filtration rate (GFR) should be evaluated using estimated GFR (eGFR).

- Physicians should start close monitoring of SCr levels over time from an early stage when CIN is suspected.

See Tables 10, 11, 12, 13, and 14. 
Table 10 Risk factors and patient assessment

\begin{tabular}{|c|c|c|c|}
\hline Clinical question (CQ) & Answer & $\begin{array}{c}\text { Grade of } \\
\text { recommendation }\end{array}$ & Level of evidence \\
\hline CKD & Chronic kidney disease (CKD) is a risk factor for CIN. & \multirow[b]{3}{*}{ Not applicable } & \multirow[b]{3}{*}{ IVa } \\
\hline Aging & Aging is a risk factor for CIN. & & \\
\hline Diabetes & $\begin{array}{l}\text { Although diabetes associated with CKD is a risk factor for } \\
\text { CIN, it is unclear whether diabetes not associated with CKD } \\
\text { is a risk factor. }\end{array}$ & & \\
\hline Use of RAS inhibitors & $\begin{array}{l}\text { There is no evidence that renin-angiotensin system (RAS) } \\
\text { inhibitors increase the risk for developing CIN. }\end{array}$ & \multirow{4}{*}{$\mathrm{C} 2$} & IVa \\
\hline Use of diuretics & $\begin{array}{l}\text { The use of diuretics, especially loop diuretics, is not } \\
\text { considered. }\end{array}$ & & \multirow{2}{*}{ II } \\
\hline Use of NSAIDs & $\begin{array}{l}\text { The use of non-steroidal anti-inflammatory drugs (NSAIDs) } \\
\text { is not considered. }\end{array}$ & & \\
\hline $\begin{array}{l}\text { Biguanide } \\
\text { antihyperglycemic drugs }\end{array}$ & $\begin{array}{l}\text { Biguanide antihyperglycemic drugs increase the risk of } \\
\text { developing lactic acidosis. }\end{array}$ & & I \\
\hline $\begin{array}{l}\text { Does the development of } \\
\text { CIN worsen vital } \\
\text { prognosis of patients with } \\
\text { CKD? }\end{array}$ & $\begin{array}{l}\text { The vital prognosis is poor for CKD patients who developed } \\
\text { CIN. }\end{array}$ & \multirow{3}{*}{ Not applicable } & \multirow{3}{*}{ IVa } \\
\hline $\begin{array}{l}\text { Patients undergoing } \\
\text { peritoneal dialysis }\end{array}$ & $\begin{array}{l}\text { The use of contrast media may be a risk factor for a decline } \\
\text { of residual kidney function in patients undergoing peritoneal } \\
\text { dialysis. }\end{array}$ & & \\
\hline $\begin{array}{l}\text { Are risk scores useful as } \\
\text { predictors of developing } \\
\text { CIN? }\end{array}$ & It is inappropriate to recommend the use of risk scores. & & \\
\hline
\end{tabular}

Table 11 Type and volume of contrast media

\begin{tabular}{|c|c|c|c|}
\hline CQ & Answer & $\begin{array}{c}\text { Grade of } \\
\text { recommendation }\end{array}$ & $\begin{array}{l}\text { Level of } \\
\text { evidence }\end{array}$ \\
\hline $\begin{array}{l}\text { Use of a smaller volume } \\
\text { of contrast media }\end{array}$ & $\begin{array}{l}\text { The volume of contrast media should be the minimum } \\
\text { necessary to obtain adequate radiographs. }\end{array}$ & A & \multirow{4}{*}{ II } \\
\hline $\begin{array}{l}\text { Low- and high-osmolar } \\
\text { contrast media }\end{array}$ & The use of low-osmolar contrast media is recommended.* & \multirow{4}{*}{ Not applicable } & \\
\hline $\begin{array}{l}\text { Iso- and low-osmolar } \\
\text { contrast media }\end{array}$ & $\begin{array}{l}\text { There has been no definite conclusion as to the superiority of } \\
\text { the two. }\end{array}$ & & \\
\hline $\begin{array}{l}\text { Comparison among low- } \\
\text { osmolar contrast media }\end{array}$ & $\begin{array}{l}\text { There has been no definite conclusion indicated that a } \\
\text { particular contrast media is superior to the others. }\end{array}$ & & \\
\hline $\begin{array}{l}\text { Intra-arterial vs. } \\
\text { intravenous } \\
\text { administration }\end{array}$ & $\begin{array}{l}\text { The incidence of CIN tends to be higher in patients receiving } \\
\text { contrast media intra-arterially than those receiving them } \\
\text { intravenously. }\end{array}$ & & IVa \\
\hline
\end{tabular}

* In Japan, high-osmolar contrast media are not indicated for intravascular use. Care should be taken not to use high-osmolar contrast media for intravascular use 
Table 12 Invasive diagnostic imaging including cardiac angiography or percutaneous catheter intervention

\begin{tabular}{|c|c|c|c|}
\hline CQ & Answer & $\begin{array}{c}\text { Grade of } \\
\text { recommendation }\end{array}$ & $\begin{array}{l}\text { Level of } \\
\text { evidence }\end{array}$ \\
\hline CKD & $\begin{array}{l}\text { CKD is a risk factor for CIN. } \\
\text { Appropriate preventive measures should be given especially } \\
\text { for patients with an eGFR of }<60 \mathrm{~mL} / \mathrm{min} / 1.73 \mathrm{~m}^{2} \text {. }\end{array}$ & \multirow[t]{2}{*}{ A } & I \\
\hline Volume of contrast media & $\begin{array}{l}\text { Contrast media should be administered at the minimal } \\
\text { required dose. }\end{array}$ & & II \\
\hline $\begin{array}{l}\text { Repeated coronary } \\
\text { angiography (CAG) at } \\
\text { short intervals }\end{array}$ & Not considered. & $\mathrm{C} 2$ & VI \\
\hline $\begin{array}{l}\text { Does CKD increase the } \\
\text { incidence of CIN after } \\
\text { PCI? }\end{array}$ & $\begin{array}{l}\text { Percutaneous catheter intervention (PCI) itself doesn't } \\
\text { worsen the prognosis of CKD. }\end{array}$ & A & I \\
\hline $\begin{array}{l}\text { Differentiation between } \\
\text { CIN and cholesterol } \\
\text { embolism }\end{array}$ & Differentiation is usually possible. & Not applicable & $\mathrm{IVb}$ \\
\hline
\end{tabular}

Table 13 Intravenous contrast media imaging including contrast-enhanced CT

\begin{tabular}{|c|c|c|c|}
\hline CQ & Answer & $\begin{array}{c}\text { Grade of } \\
\text { recommendation }\end{array}$ & $\begin{array}{l}\text { Level of } \\
\text { evidence }\end{array}$ \\
\hline CKD & $\begin{array}{l}\text { CKD is a risk factor for CIN. } \\
\text { Appropriate preventive measures should be given especially } \\
\text { for patients with an eGFR of }<45 \mathrm{~mL} / \mathrm{min} / 1.73 \mathrm{~m}^{2} \text {. }\end{array}$ & B & IVa \\
\hline Volume of contrast media & $\begin{array}{l}\text { Contrast media may be administered at the minimal required } \\
\text { dose. }\end{array}$ & $\mathrm{C} 1$ & V \\
\hline $\begin{array}{l}\text { Repeated contrast- } \\
\text { enhanced CT at short } \\
\text { intervals }\end{array}$ & Not considered. & $\mathrm{C} 2$ & V \\
\hline $\begin{array}{l}\text { Incidence of CIN in } \\
\text { inpatients vs. outpatients }\end{array}$ & $\begin{array}{l}\text { It is not unclear whether the risk for developing CIN is higher } \\
\text { in outpatients than in inpatients. }\end{array}$ & Not applicable & V \\
\hline
\end{tabular}

Table 14 Prevention of CIN: fluid therapy

\begin{tabular}{|c|c|c|c|}
\hline CQ & Answer & $\begin{array}{c}\text { Grade of } \\
\text { recommendation }\end{array}$ & $\begin{array}{l}\text { Level of } \\
\text { evidence }\end{array}$ \\
\hline \multirow{2}{*}{$\begin{array}{l}\text { Isotonic solutions such as } \\
\text { physiological saline }\end{array}$} & Intravenous hydration before and after contrast examination. & & \multirow[b]{3}{*}{ II } \\
\hline & $\begin{array}{l}\text { Isotonic solutions rather than hypotonic saline }(0.45 \%) \text { are } \\
\text { recommended. }\end{array}$ & A & \\
\hline Oral hydration & $\begin{array}{l}\text { Insufficient evidence to demonstrate that oral hydration is as } \\
\text { effective as intravenous hydration. } \\
\text { Intravenous hydration rather than oral hydration alone is } \\
\text { considered. }\end{array}$ & \multirow[t]{2}{*}{$\mathrm{C} 1$} & \\
\hline $\begin{array}{l}\text { Sodium bicarbonate- } \\
\text { based hydration }\end{array}$ & $\begin{array}{l}\text { Sodium bicarbonate-based hydration may be better than } \\
\text { physiological saline hydration. }\end{array}$ & & I \\
\hline $\begin{array}{l}\text { Short-term intravenous } \\
\text { hydration }\end{array}$ & $\begin{array}{l}\text { The incidence of CIN may be higher in patients receiving } \\
\text { short-term intravenous hydration than in those receiving } \\
\text { standard intravenous hydration. }\end{array}$ & $\mathrm{C} 2$ & II \\
\hline
\end{tabular}




\section{Fluid Therapy to Prevent CIN}

1. Administer physiological saline intravenously at $1 \mathrm{mg} / \mathrm{kg} / \mathrm{h} 6$ hours before and $6 \sim 12$ hours after the contrast examination.

2. Administer sodium bicarbonate solution $(1.26 \%, 152 \mathrm{mEq} / \mathrm{L})$ at $3 \mathrm{~mL} / \mathrm{kg} / \mathrm{h}$ for 1 hour before and at $1 \mathrm{~mL} / \mathrm{kg} / \mathrm{h}$ for 4 6 hours after the contrast examination.

Grade of Recommendation: A

Physicians should consider adjusting fluid volume for See Tables 15 and 16. patients in whom fluid therapy may cause heart failure.

Table 15 Prevention of CIN: pharmacologic therapy and dialysis

\begin{tabular}{|c|c|c|c|c|}
\hline & CQ & Answer & $\begin{array}{c}\text { Grade of } \\
\text { recommendation }\end{array}$ & $\begin{array}{l}\text { Level of } \\
\text { evidence }\end{array}$ \\
\hline \multirow{4}{*}{$\begin{array}{l}\text { Pharmacologic } \\
\text { Therapy }\end{array}$} & $\mathrm{N}$-acetylcysteine & Not considered. & \multirow{4}{*}{$\mathrm{C} 2$} & I \\
\hline & $\begin{array}{l}\text { Human atrial } \\
\text { natriuretic peptide } \\
\text { (hANP) }\end{array}$ & Not considered. & & II \\
\hline & Ascorbic acid & Not considered. & & \\
\hline & Statins & Not considered. & & I \\
\hline \multirow[t]{2}{*}{ Dialysis } & Hemodialysis & Not recommended. & D & I \\
\hline & Hemofiltration & Not considered. & $\mathrm{C} 2$ & II \\
\hline
\end{tabular}

Table 16 Treatment of CIN: pharmacologic therapy and dialysis

\begin{tabular}{|l|l|l|c|c|}
\hline & \multicolumn{1}{|c|}{ CQ } & \multicolumn{1}{|c|}{ Answer } & $\begin{array}{c}\text { Grade of } \\
\text { recommendation }\end{array}$ & \multicolumn{1}{c|}{$\begin{array}{c}\text { Level of } \\
\text { evidence }\end{array}$} \\
\hline \multirow{2}{*}{$\begin{array}{l}\text { Pharmacologic } \\
\text { Therapy }\end{array}$} & Loop diuretics & Not recommended. & D & I \\
\cline { 2 - 6 } & Fluid therapy & Not considered. & C2 & IVa \\
\cline { 2 - 6 } & Low-dose dopamine & Not recommended. & D & I \\
\cline { 2 - 6 } & hANP & Not recommended. & B & I \\
\hline Dialysis & $\begin{array}{l}\text { Early renal } \\
\text { replacement therapy }\end{array}$ & $\begin{array}{l}\text { Suggested for critically ill patients with } \\
\text { oliguric CIN. }\end{array}$ & & \\
\hline
\end{tabular}

Grade A: A given treatment or procedure is recommended based on robust scientific evidence.

Grade B: A given treatment or procedure is suggested based on scientific evidence.

Grade C1: A given treatment or procedure may (/might) be considered although scientific evidence is not available.

Grade C2: A given treatment or procedure may (/might) be not considered because scientific evidence is not available.

Grade D: A given treatment or procedure is not recommended because scientific evidence indicating the inefficacy or harm of the treatment/procedure is available. 


\section{References}

1. Kidney Disease: Improving Global Outcomes (KDIGO) CKD Work Group. KDIGO 2012 clinical practice guideline for the evaluation and management of chronic kidney disease. Kidney Int Suppl. 2013;2013(3):19-62.

2. Lameire N, Adam A, Becker CR, Davidson C, McCullough PA, Stacul F, CIN Consensus Working Panel, et al. Baseline renal function screening. Am J Cardiol. 2006;98:21K-6K [VI].

3. Dangas G, Iakovou I, Nikolsky E, Aymong ED, Mintz GS, Kipshidze NN, et al. Contrast-induced nephropathy after percutaneous coronary interventions in relation to chronic kidney disease and hemodynamic variables. Am J Cardiol. 2005;95: 13-9 [IVb].

4. Rihal CS, Textor SC, Grill DE, Berger PB, Ting HH, Best PJ, et al. Incidence and prognostic importance of acute renal failure after percutaneous coronary intervention. Circulation. 2002; 105:2259-64 [IVb].

5. Weisbord SD, Mor MK, Resnick AL, Hartwig KC, Palevsky PM, Fine MJ. Incidence and outcomes of contrast-induced AKI following computed tomography. Clin J Am Soc Nephrol. 2008;3:1274-81 [IVa].

6. Kim SM, Cha RH, Lee JP, Kim DK, Oh KH, Joo KW, et al. Incidence and outcomes of contrast-induced nephropathy after computed tomography in patients with CKD: a quality improvement report. Am J Kidney Dis. 2010;55:1018-25 [IVb].

7. Stacul F, van der Molen AJ, Reimer P, Webb JA, Thomsen HS, Morcos SK, Contrast Media Safety Committee of European Society of Urogenital Radiology (ESUR), et al. Contrast induced nephropathy: updated ESUR Contrast Media Safety Committee guidelines. Eur Radiol. 2011;21:2527-41 [VI].

8. McCullough PA. Contrast-induced acute kidney injury. J Am Coll Cardiol. 2008;51:1419-28 [I].

9. Rudnick MR, Goldfarb S, Wexler L, Ludbrook PA, Murphy MJ, Halpern EF, et al. Nephrotoxicity of ionic and nonionic contrast media in 1196 patients: a randomized trial. The Iohexol Cooperative Study. Kidney Int. 1995;47:254-61 [II].

10. Parfrey PS, Griffiths SM, Barrett BJ, Paul MD, Genge M, Withers $\mathrm{J}$, et al. Contrast material-induced renal failure in patients with diabetes mellitus, renal insufficiency, or both. A prospective controlled study. N Engl J Med. 1989;320:143-9 [III].

11. McCullough PA, Bertrand ME, Brinker JA, Stacul F. A metaanalysis of the renal safety of isosmolar iodixanol compared with low-osmolar contrast media. J Am Coll Cardiol. 2006;48:692-9 [I].

12. Chong E, Poh KK, Liang S, Tan HC. Risk factors and clinical outcomes for contrast-induced nephropathy after percutaneous coronary intervention in patients with normal serum creatinine. Ann Acad Med Singapore. 2010;39:374-80 [IVa].

13. La Manna G, Pancaldi LG, Capecchi A, Maska E, Comai G, Cappuccilli ML, et al. Risk for contrast nephropathy in patients undergoing coronarography. Artif Organs. 2010;34:E193-9 [IVb].

14. Kiski D, Stepper W, Brand E, Breithardt G, Reinecke H. Impact of renin-angiotensin-aldosterone blockade by angiotensin-converting enzyme inhibitors or AT-1 blockers on frequency of contrast medium-induced nephropathy: a post hoc analysis from the Dialysis-versus-Diuresis (DVD) trial. Nephrol Dial Transplant. 2010;25:759-64 [IVb].

15. Saudan P, Muller H, Feraille E, Martin PY, Mach F. Reninangiotensin system blockade and contrast-induced renal toxicity. J Nephrol. 2008;21:681-5 [IVa].

16. Rosenstock JL, Bruno R, Kim JK, Lubarsky L, Schaller R, Panagopoulos G, et al. The effect of withdrawal of ACE inhibitors or angiotensin receptor blockers prior to coronary angiography on the incidence of contrast-induced nephropathy. Int Urol Nephrol. 2008;40:749-55 [IVa].

17. Schweiger MJ, Chambers CE, Davidson CJ, Blankenship J, Bhalla NP, Block PC, et al. Prevention of contrast induced nephropathy: recommendations for the high risk patient undergoing cardiovascular procedures. Catheter Cardiovasc Interv. 2007;69:135-40.

18. Majumdar SR, Kjellstrand CM, Tymchak WJ, Hervas-Malo M, Taqylor DA, Teo KK. Forced euvolemic diuretic with mannitol and furosecemide for prevention of contrast-induced nephropathy in patients with CKD undergoing coronary angiography: a randomized controlled trial. Am J Kidney Dis. 2009;54:602-9 [I].

19. Solomon R, Wener C, Mann D, D'Elia J, Silva P. Effects of saline, mannitol, and furosemide to prevent acute decrease in renal function induced by radiocontrast agents. $\mathrm{N}$ Engl $\mathrm{J}$ Med. 1994;331:1416-20 [II].

20. Briguori C, Visconti G, Focaccio A, Airoldi F, Valgimigli M, Sangiorgi GM, REMEDIAL II Investigators, et al. Renal Insufficiency After Contrast Media Administration Trial II (REMEDIAL II): RenalGuard System in high-risk patients for contrast-induced acute kidney injury. Circulation. 2011;124:1260-9 [II].

21. Marenzi G, Ferrari C, Marana I, Assanelli E, De Metrio M, Teruzzi G, et al. Prevention of contrast nephropathy by furosemide with matched hydration: the MYTHOS (Induced Diuresis With Matched Hydration Compared to Standard Hydration for Contrast Induced Nephropathy Prevention) trial. JACC Cardiovasc Interv. 2012;5:90-7 [II].

22. Schneider V, Lévesque LE, Zhang B, Hutchinson T, Brophy JM. Association of selective and conventional nonsteroidal antiinflammatory drugs with acute renal failure: a population-based, nested case-control analysis. Am J Epidemiol. 2006;164:881-9 [IVb].

23. Barrett BJ, Parfrey PS. Clinical practice. Preventing nephropathy induced by contrast medium. N Engl J Med. 2006;354:379-86 [V].

24. Jain V, Sharma D, Prabhakar H, Dash HH. Metformin-associated lactic acidosis following contrast media-induced nephrotoxicity. Eur J Anaesthesiol. 2008;25:166-7 [V].

25. Safadi R, Dranitzki-Elhalel M, Popovtzer M, Ben-Yehuda A. Metformin-induced lactic acidosis associated with acute renal failure. Am J Nephrol. 1996;16:520-2 [V].

26. Stades AM, Heikens JT, Erkelens DW, Holleman F, Hoekstra JB. Metformin and lactic acidosis: cause or coincidence? A review of case reports. J Intern Med. 2004;255:179-87 [V].

27. McCartney MM, Gilbert FJ, Murchison LE, Pearson D, McHardy K, Murray AD. Metformin and contrast media-a dangerous combination? Clin Radiol. 1999;54:29-33 [I].

28. Rasuli P, Hammond DI. Metformin and contrast media: where is the conflict? Can Assoc Radiol J. 1998;49:161-6 [VI].

29. Goergen SK, Rumbold G, Compton G, Harris C. Systematic review of current guidelines, and their evidence base, on risk of lactic acidosis after administration of contrast medium for patients receiving metformin. Radiology. 2010;254:261-9 [I].

30. Khurana R, Malik IS. Metformin: safety in cardiac patients. Heart. 2010;96:99-102 [VI].

31. Holstein A, Stumvoll M. Contraindications can damage your health—is metformin a case in point? Diabetologia. 2005;48: 2454-9 [VI].

32. Goldenberg I, Chonchol M, Guetta V. Reversible acute kidney injury following contrast exposure and the risk of long-term mortality. Am J Nephrol. 2009;29:136-44 [IVa].

33. From AM, Bartholmai BJ, Williams AW, Cha SS, McDonald FS. Mortality associated with nephropathy after radiographic contrast exposure. Mayo Clin Proc. 2008;83:1095-100 [IVa].

34. Gruberg L, Mintz GS, Mehran R, Gangas G, Lansky AJ, Kent $\mathrm{KM}$, et al. The prognostic implications of further renal function 
deterioration within $48 \mathrm{~h}$ of interventional coronary procedures in patients with pre-existent chronic renal insufficiency. J Am Coll Cardiol. 2000;36:1542-8 [IVa].

35. Senoo T, Motohiro M, Kamihata H, Yamamoto S, Isono T, Manabe $\mathrm{K}$, et al. Contrast-induced nephropathy in patients undergoing emergency percutaneous coronary intervention for acute coronary syndrome. Am J Cardiol. 2010;105:624-8 [IVa].

36. Sadeghi HM, Stone GW, Grines CL, Mehran R, Dixon SR, Lansky AJ, et al. Impact of renal insufficiency in patients undergoing primary angioplasty for acute myocardial infarction. Circulation. 2003;108:2769-75 [IVa].

37. Marenzi G, Lauri G, Assanelli E, Campodonico J, De Metrio M, Marana I, et al. Contrast-induced nephropathy in patients undergoing primary angioplasty for acute myocardial infarction. J Am Coll Cardiol. 2004;44:1780-5 [IVa].

38. McCullough PA, Wolyn R, Rocher LL, Levin RN, O’Neill WW. Acute renal failure after coronary intervention: incidence, risk factors, and relationship to mortality. Am J Med. 1997;103: 368-75 [IVa].

39. Marenzi G, Assanelli E, Campodonico J, Lauri G, Marana I, De Metrio M, et al. Contrast volume during primary percutaneous coronary intervention and subsequent contrast-induced nephropathy and mortality. Ann Intern Med. 2009;150:170-7 [IVa].

40. Heitmeyer C, Hölscher B, Fobker M, Breithardt G, Hausberg M, Reinecke $\mathrm{H}$. Prognostic value of different laboratory measures of renal function for long-term mortality after contrast mediaassociated renal impairment. Clin Cardiol. 2010;33:E51-9 [IVa].

41. Jujo K, Yamaguchi J, Obayashi K, Suzuki K, Sekiguchi H, Nagashima M, et al. Clinical impact of nephropathy induced by contrast medium in patients with acute myocardial Infarction undergoing emergent coronary angiography. $\mathrm{J}$ Cardiol. 2006;48:9-16 (in Japanese) [IVa].

42. Katzberg RW, Newhouse JH. Intravenous contrast mediuminduced nephrotoxicity: is the medical risk really as great as we have come to believe? Radiology. 2010;256:21-8 [IVa].

43. Solomon R. Contrast-induced acute kidney injury: is there a risk after intravenous contrast? Clin J Am Soc Nephrol. 2008;3:1242-3 [VI].

44. Matsushima K, Peng M, Schaefer EW, Pruitt JH, Kashuk JL, Frankel HL. Posttraumatic contrast-induced acute kidney injury: minimal consequences or significant threat? J Trauma. 2011;70:415-9 [IVa]

45. Rashid AH, Brieva JL, Stokes B. Incidence of contrast-induced nephropathy in intensive care patients undergoing computerised tomography and prevalence of risk factors. Anaesth Intensive Care. 2009;37:968-75 [IVa].

46. Moranne O, Willoteaux S, Pagniez D, Dequiedt P, Boulanger E. Effect of iodinated contrast agents on residual renal function in PD patients. Nephrol Dial Transplant. 2006;21:1040-5 [IVa].

47. Dittrich E, Puttinger H, Schillinger M, Lang I, Stefenelli T, Hörl $\mathrm{WH}$, et al. Effect of radio contrast media on residual renal function in peritoneal dialysis patients-a prospective study. Nephrol Dial Transplant. 2006;21:1334-9 [IVa].

48. Brown JR, DeVries JT, Piper WD, Robb JF, Hearne MJ, Ver Lee PM, Northern New England Cardiovascular Disease Study Group, et al. Serious renal dysfunction after percutaneous coronary interventions can be predicted. Am Heart J. 2008; 155:260-6 [IVa].

49. Mehran R, Aymong ED, Nikolsky E, Lasic Z, Iakovou I, Fahy M, et al. A simple risk score for prediction of contrast-induced nephropathy after percutaneous coronary intervention: development and initial validation. J Am Coll Cardiol. 2004;44:1393-9 [II].

50. Mehran R, Nikolsky E. Contrast-induced nephropathy: definition, epidemiology, and patients at risk. Kidney Int Suppl. 2006;100:S11-5 [VI].
51. Cigarroa RG, Lange RA, Williams RH, Hillis LD. Dosing of contrast material to contrast nephropathy in patients with renal disease. Am J Med. 1989;86:649-52 [IVb].

52. Nyman U, Bjork J, Aspelin P, Marenzi G. Contrast medium dose-to-GFR ratio: a measure of systemic exposure to predict contrast-induced nephropathy after percutaneous coronary intervention. Acta Radiol. 2008;49:658-67 [V].

53. Brown JR, Robb JF, Block CA, Schoolwerth AC, Kaplan AV, O'Connor GT, et al. Does safe dosing of iodinated contrast prevent contrast-induced acute kidney injury? Circ Cardiovasc Interv. 2010;3:346-50 [II].

54. Barrett BJ, Carlisle EJ. Metaanalysis of the relative nephrotoxicity of high- and low-osmolality iodinated contrast media. Radiology. 1993;188:171-8 [I].

55. Aspelin P, Aubry P, Fransson SG, Strasser R, Willenbrock R, Berg KJ, Nephrotoxicity in High-Risk Patients Study of IsoOsmolar and Low-Osmolar Non-Ionic Contrast Media Study Investigators. Nephrotoxic effects in high-risk patients undergoing angiography. N Engl J Med. 2003;348:491-9 [II].

56. Solomon RJ, Natarajan MK, Doucet S, Sharma SK, Staniloae CS, Katholi RE, Investigators of the CARE Study, et al. Cardiac Angiography in Renally Impaired Patients (CARE) study: a randomized double-blind trial of contrast-induced nephropathy in patients with chronic kidney disease. Circulation. 2007;115:3189-96 [II].

57. Heinrich MC, Häberle L, Müller V, Bautz W, Uder M. Nephrotoxicity of iso-osmolar iodixanol compared with nonionic low-osmolar contrast media: meta-analysis of randomized controlled trials. Radiology. 2009;250:68-86 [I].

58. Liss P, Persson PB, Hansell P, Lagerqvist B. Renal failure in 57 925 patients undergoing coronary procedures using iso-osmolar or low-osmolar contrast media. Kidney Int. 2006;70:1811-7 [IVb].

59. Kushner FG, Hand M, Smith SC Jr, King SB 3rd, Anderson JL, Antman EM, American College of Cardiology Foundation/ American Heart Association Task Force on Practice Guidelines, et al. Focused updates: ACC/AHA Guidelines for the Management of Patients With ST-Elevation Myocardial Infarction (updating the 2004 Guideline and 2007 Focused Update) and ACC/AHA/SCAI Guidelines on Percutaneous Coronary Intervention (updating the 2005 Guideline and 2007 Focused Update): a report of the American College of Cardiology Foundation/American Heart Association Task Force on Practice Guidelines. Circulation. 2009;2009(120):2271-306.

60. Wright RS, Anderson JL, Adams CD, Bridges CR, Casey DE, Ettinger SM, et al. 2011 ACCF/AHA Focused Update of the Guidelines for the Management of Patients With Unstable Angina/Non-ST-Elevation Myocardial Infarction (Updating the 2007 Guideline): a report of the American College of Cardiology Foundation/American Heart Association Task Force on Practice Guidelines. Circulation. 2011;123:2022-60.

61. Levine GN, Bates ER, Blankenship JC, Bailey SR, Bittl JA, Cercek B, et al. 2011 ACCF/AHA/SCAI Guideline for Percutaneous Coronary Intervention: a report of the American College of Cardiology Foundation/American Heart Association Task Force on Practice Guidelines and the Society for Cardiovascular Angiography and Interventions. Circulation. 2011;124: e574-651.

62. Chou SH, Wang ZJ, Kuo J, Cabarrus M, Fu Y, Aslam R, et al. Persistent renal enhancement after intra-arterial versus intravenous iodixanol administration. Eur J Radiol. 2011;80:378-86 [IVb].

63. Lufft V, Lufft LH, Fels LM, Baiyee DE, Tusch G, Galanski M, et al. Contrast media nephropathy: intravenous $\mathrm{CT}$ angiography versus intraarterial digital subtraction angiography in renal artery stenosis: a prospective randomized trial. Am J Kidney Dis. 2002;40:236-42 [II]. 
64. Ahuja TS, Niaz N, Agraharkar M. Contrast-induced nephrotoxicity in renal allograft recipients. Clin Nephrol. 2000;54:11-4 [IVb].

65. Tepel M, van der Geit M, Schwarzfeld C, Laufer U, Liermann D, Zidek W. Prevention of radiographic-contrast-agent-induced reductions in renal function by acetylcysteine. N Engl J Med. 2000;343:180-4 [II].

66. Becker CR, Reiser MF. Use of iso-osmolar nonionic dimeric contrast media in multidetector row computed tomography angiography for patients with renal impairment. Invest Radiol. 2005;40:672-5 [IVa].

67. Barrett BJ, Katzberg RW, Thomsen HS, Chen N, Sahani D, Soulez G, et al. Contrast-induced nephropathy in patients with chronic kidney disease undergoing computer tomography: a double-blind comparison of iodixanol and iopamidol. Invest Radiol. 2006;41:815-21 [II].

68. Thomsen HS, Morcos SK, Earley CM, Grazioli L, Bonomo L, Ni Z, Investigators in the Abdominal Computed Tomography: IOMERON 400 Versus VISIPAQUE 320 Enhancement (ACTIVE) Study, et al. The ACTIVE Trial: comparison of the effects on renal function of iomeprol-400 and iodixanol-320 in patients with chronic kidney disease undergoing abdominal computed tomography. Invest Radiol. 2008;43:170-8 [II].

69. Kuhn MJ, Chen N, Sahani DV, Reimer D, van Beek EJ, Heiken JP, et al. The PREDICT study: a randomized double-blind comparison of contrast-induced nephropathy after low- or isoosmolar contrast agent exposure. Am J Roentgenol. 2008;191:151-7 [II].

70. Nguyen SA, Suranyi P, Ravenel JG, Randall PK, Romano PB, Strom KA, et al. Iso-osmolality versus low-osmolality iodinated contrast medium at intravenous contrast-enhanced CT: effect on kidney function. Radiology. 2008;248:97-105 [II].

71. Gallotti A, Uggeri F, Favilla A, Cabrini M, de Haën C. The chemistry of iomeprol and physico-chemical properties of its aqueous solutions and pharmaceutical formulations. Eur $\mathbf{J}$ Radiol. 1994;18(Suppl 1):S1-12 [VI].

72. Sovak M. The need for improved contrast media. Ioxilan: updating design theory. Invest Radiol. 1988;23(Suppl 1):S79-83 [VI].

73. Shiraki K, Otani H, Ohno Z, Takeuchi R, Hirai M, Murata K, et al. Case study of contrast-induced nephropathy using cardiac catheterization. Jpn Circ J. 2001;65(Suppl III):750 (in Japanese) [IVb].

74. Fujisaki K, Nakayama M, Yoshimitsu T, Doi T, Tanaka R, Yamada $\mathrm{A}$, et al. Incidence of contrast-induced nephropathy using cardiac catheterization: a case report. Jpn J Nephrol. 2002;44:315 (in Japanese) [IVb].

75. Abe M, Kimura T, Morimoto T, Furukawa Y, Kita T. Incidence of and risk factors for contrast-induced nephropathy after cardiac catheterization in Japanese patients. Circ J. 2009;73: 1518-22 [IVb].

76. Laskey WK, Jenkins C, Selzer F, Marroquin OC, Wilensky RL, Glaser R, NHLBI Dynamic Registry Investigators, et al. Volumeto-creatinine clearance ratio: a pharmacokinetically based risk factor for prediction of early creatinine increase after percutaneous coronary intervention. J Am Coll Cardiol. 2007;50:584-90 [IVb].

77. Gurm HS, Dixon SR, Smith DE, Share D, Lalonde T, Greenbaum A, BMC2 (Blue Cross Blue Shield of Michigan Cardiovascular Consortium) Registry, et al. Renal function-based contrast dosing to define safe limits of radiographic contrast media in patients undergoing percutaneous coronary interventions. J Am Coll Cardiol. 2011;58:907-14 [IVb].

78. Chong E, Poh KK, Liang S, Soon CY, Tan HC. Comparison of risks and clinical predictors of contrast-induced nephropathy in patients undergoing emergency versus nonemergency percutaneous coronary interventions. J Interv Cardiol. 2010;23:451-9 [IVa].
79. Machino-Ohtsuka T, Seo Y, Ishizu T, Sekiguchi Y, Sato A, Tada H, et al. Combined assessment of carotid vulnerable plaque, renal insufficiency, eosinophilia, and hs-CRP for predicting risky aortic plaque of cholesterol crystal embolism. Circ J. 2010;74:51-8 [IVb].

80. Fukumoto Y, Tsutsui H, Tsuchihashi M, Masumoto A, Takeshita A, Cholesterol Embolism Study (CHEST) Investigators. The incidence and risk factors of cholesterol embolization syndrome, a complication of cardiac catheterization: a prospective study. J Am Coll Cardiol. 2003;42:211-6 [IVb].

81. Funabiki K, Masuoka H, Shimizu H, Emi Y, Mori T, Ito M, et al. Cholesterol crystal embolization (CCE) after cardiac catheterization: a case report and a review of 36 cases in the Japanese literature. Jpn Heart J. 2003;44:767-74 [IVb].

82. Modi KS, Rao VK. Atheroembolic renal disease. J Am Soc Nephrol. 2001;12:1781-7 [IVb].

83. Scolari F, Tardanico R, Zani R, Pola A, Viola BF, Movilli E, et al. Cholesterol crystal embolism: a recognizable cause of renal disease. Am J Kidney Dis. 2000;36:1089-109 [IVb].

84. Belenfant X, Meyrier A, Jacquot C. Supportive treatment improves survival in multivisceral cholesterol crystal embolism. Am J Kidney Dis. 1999;33:840-50 [IVb].

85. Thadhani RI, Camargo CA Jr, Xavier RJ, Fang LS, Bazari H. Atheroembolic renal failure after invasive procedures. Natural history based on 52 histologically proven cases. Medicine (Baltimore). 1995;74:350-8 [IVb].

86. Fine MJ, Kapoor W, Falanga V. Cholesterol crystal embolization: a review of 221 cases in the English literature. Angiology. 1987;38:769-84 [IVb].

87. Oleinik A, Romero JM, Schwab K, Lev MH, Jhawar N, Delgado Almandoz JE, et al. CT angiography for intracerebral hemorrhage does not increase risk of acute nephropathy. Stroke. 2009;40:2393-7 [IVa].

88. Herts BR, Schneider E, Obuchowski N, Poggio E, Jain A, Baker ME. Probability of reduced renal function after contrastenhanced CT: a model based on serum creatinine level, patient age, and estimated glomerular filtration rate. AJR Am J Roentgenol. 2009;193:494-500 [IVb].

89. Hipp A, Desai S, Lopez C, Sinert R. The incidence of contrastinduced nephropathy in trauma patients. Eur J Emerg Med. 2008;15:134-9 [IVa].

90. Lencioni R, Fattori R, Morana G, Stacul F. Contrast-induced nephropathy in patients undergoing computed tomography (CONNECT) - a clinical problem in daily practice? A multicenter observational study. Acta Radiol. 2010;51:741-50 [IVa].

91. Shema L, Ore L, Geron R, Kristal B. Contrast-induced nephropathy among Israeli hospitalized patients: incidence, risk factors, length of stay and mortality. Isr Med Assoc J. 2009;11:460-4 [IVb].

92. Cramer BC, Parfrey PS, Hutchinson TA, Baran D, Melanson $\mathrm{DM}$, Ethier RE, et al. Renal function following infusion of radiologic contrast material. A prospective controlled study. Arch Intern Med. 1985;145:87-9 [IVa].

93. Langner S, Stumpe S, Kirsch M, Petrik M. No increased risk for contrast-induced nephropathy after multiple CT perfusion studies of the brain with a nonionic, dimeric, iso-osmolal contrast medium. AJNR Am J Neuroradiol. 2008;29:1525-9 [IVa].

94. Nyman U, Almen T, Aspelin P, Hellstrom M, Kristiansson M, Sterner G. Contrast-medium-induced nephropathy correlated to the ratio between dose in gram iodine and estimated GFR in $\mathrm{mL} /$ min. Acta Radiol. 2005;46:830-42 [I].

95. Kane GC, Doyle BJ, Lerman A, Barsness GW, Best PJ, Rihal CS. Ultra-low contrast volumes reduce rates of contrast-induced nephropathy in patients with chronic kidney disease undergoing coronary angiography. J Am Coll Cardiol. 2008;51:89-90 [V].

96. Abujudeh HH, Gee MS, Kaewiai R. In emergency situations, should serum creatinine be checked in all patients before 
performing second contrast CT examinations within 24 hours? J Am Coll Radiol. 2009;6:268-73 [V].

97. Trivedi H, Foley WD. Contrast-induced nephropathy after a second contrast exposure. Ren Fail. 2010;32:796-801 [V].

98. Hopyan JJ, Gladstone DJ, Mallia G, Schiff J, Fox AJ, Symons $\mathrm{SP}$, et al. Renal safety of CT angiography and perfusion imaging in the emergency evaluation of acute stroke. AJNR Am J Neuroradiol. 2008;29:1826-30 [V].

99. Lima FO, Lev MH, Levy RA, Silva GS, Ebril M, de Camargo EC, et al. Functional contrast-enhanced CT for evaluation of acute ischemic stroke does not increase the risk of contrast-induced nephropathy. AJNR Am J Neuroradiol. 2010;31:817-21 [IVa].

100. Mitchell AM, Jones AE, Tumlin JA, Kline JA. Incidence of contrast-induced nephropathy after contrast-enhanced computed tomography in the outpatient setting. Clin J Am Soc Nephrol. 2010;5:4-9 [V].

101. Eisenberg RL, Bank WO, Hedgock MW. Renal failure after major angiography. Am J Med. 1980;68:43-6 [V].

102. Eisenberg RL, Bank WO, Hedgock MW. Renal failure after major angiography can be avoided with hydration. AJR Am J Roentgenol. 1981;136:859-61 [V].

103. Trivedi HS, Moore H, Nasr S, Aggarwal K, Agrawal A, Goel P, et al. A randomized prospective trial to assess the role of saline hydration on the development of contrast nephrotoxicity. Nephron Clin Pract. 2003;93:C29-34 [II].

104. Recio-Mayoral A, Chaparro M, Prado B, Cózar R, Méndez I, Banerjee D, et al. The reno-protective effect of hydration with sodium bicarbonate plus $\mathrm{N}$-acetylcysteine in patients undergoing emergency percutaneous coronary intervention: the RENO Study. J Am Coll Cardiol. 2007;49:1283-8 [II].

105. Mueller C, Buerkle G, Buettner HJ, Petersen J, Perruchoud AP, Eriksson U, et al. Prevention of contrast media-associated nephropathy: randomized comparison of 2 hydration regimens in 1620 patients undergoing coronary angioplasty. Arch Intern Med. 2002;162:329-36 [II].

106. Wróbel W, Sinkiewicz W, Gordon M, Woźniak-Wiśniewska A. Oral versus intravenous hydration and renal function in diabetic patients undergoing percutaneous coronary interventions. Kardiol Pol. 2010;68:1015-20 [II].

107. Taylor AJ, Hotchkiss D, Morse RW, McCabe J. PREPARED: Preparation for Angiography in Renal Dysfunction: a randomized trial of inpatient vs outpatient hydration protocols for cardiac catheterization in mild-to-moderate renal dysfunction. Chest. 1998;114:1570-4 [II].

108. Dussol B, Morange S, Loundoun A, Auquier P, Berland Y. A randomized trial of saline hydration to prevent contrast nephropathy in chronic renal failure patients. Nephrol Dial Transplant. 2006;21:2120-6 [II].

109. Zoungas S, Ninomiya T, Huxley R, Cass A, Jardine M, Gallagher M, et al. Systematic review: sodium bicarbonate treatment regimens for the prevention of contrast-induced nephropathy. Ann Intern Med. 2009;151:631-8 [I].

110. Meier P, Ko DT, Tamura A, Tamhane U, Gurm HS. Sodium bicarbonate-based hydration prevents contrast-induced nephropathy: a meta-analysis. BMC Med. 2009;7:23 [I].

111. Kanbay M, Covic A, Coca SG, Turgut F, Akcay A, Parikh CR. Sodium bicarbonate for the prevention of contrast-induced nephropathy: a meta-analysis of 17 randomized trials. Int Urol Nephrol. 2009;41:617-27 [I].

112. Hogan SE, L'Allier P, Chetcuti S, Grossman PM, Nallamothu BK, Duvernoy C, et al. Current role of sodium bicarbonate-based preprocedural hydration for the prevention of contrast-induced acute kidney injury: a meta-analysis. Am Heart J. 2008;156:414-21 [I].

113. Joannidis M, Schmid M, Wiedermann CJ. Prevention of contrast media-induced nephropathy by isotonic sodium bicarbonate: a meta-analysis. Wien Klin Wochenschr. 2008;120:742-8 [I].
114. Navaneethan SD, Singh S, Appasamy S, Wing RE, Sehgal AR. Sodium bicarbonate therapy for prevention of contrast-induced nephropathy: a systematic review and meta-analysis. Am J Kidney Dis. 2009;53:617-27 [I].

115. Trivedi H, Nadella R, Szabo A. Hydration with sodium bicarbonate for the prevention of contrast-induced nephropathy: a meta-analysis of randomized controlled trials. Clin Nephrol. 2010;74:288-96 [I].

116. Brar SS, Shen AY, Jorgensen MB, Kotlewski A, Aharonian VJ, Desai N, et al. Sodium bicarbonate vs sodium chloride for the prevention of contrast medium-induced nephropathy in patients undergoing coronary angiography: a randomized trial. JAMA. 2008;300:1038-46 [II].

117. Brar SS, Hiremath S, Dangas G, Mehran R, Brar SK, Leon MB. Sodium bicarbonate for the prevention of contrast induced-acute kidney injury: a systematic review and meta-analysis. Clin J Am Soc Nephrol. 2009;4:1584-92 [I].

118. Ueda H, Yamada T, Masuda M, Okuyama Y, Morita T, Furukawa Y, et al. Prevention of contrast-induced nephropathy by bolus injection of sodium bicarbonate in patients with chronic kidney disease undergoing emergent coronary procedures. Am J Cardiol. 2011;107:1163-7 [II].

119. Tamura A, Goto Y, Miyamoto K, Naono S, Kawano Y, Kotoku $\mathrm{M}$, et al. Efficacy of single-bolus administration of sodium bicarbonate to prevent contrast-induced nephropathy in patients with mild renal insufficiency undergoing an elective coronary procedure. Am J Cardiol. 2009;104:921-5 [II].

120. Motohiro M, Kamihata H, Tsujimoto S, Seno T, Manabe K, et al. A new protocol using sodium bicarbonate for the prevention of contrast-induced nephropathy in patients undergoing coronary angiography. Am J Cardiol. 2011;107:1604-8 [II].

121. Lee SW, Kim WJ, Kim YH, Park SW, Park DW, Yun SC, et al. Preventive strategies of renal insufficiency in patients with diabetes undergoing intervention or arteriography (the PREVENT Trial). Am J Cardiol. 2011;107:1447-52 [II].

122. Vasheghani-Farahani A, Sadigh G, Kassaian SE, Khatami SM, Fotouhi A, Razavi SA, et al. Sodium bicarbonate plus isotonic saline versus saline for prevention of contrast-induced nephropathy in patients undergoing coronary angiography: a randomized controlled trial. Am J Kidney Dis. 2009;54:610-8 [II].

123. Vasheghani-Farahani A, Sadigh G, Kassaian SE, Khatami SM, Fotouhi A, Razavi SA, et al. Sodium bicarbonate in preventing contrast nephropathy in patients at risk for volume overload: a randomized controlled trial. J Nephrol. 2010;23:216-23 [II].

124. Shavit L, Korenfeld R, Lifschitz M, Butnaru A, Slotki I. Sodium bicarbonate versus sodium chloride and oral $\mathrm{N}$-acetylcysteine for the prevention of contrast-induced nephropathy in advanced chronic kidney disease. J Interv Cardiol. 2009;22:556-63 [II]

125. Krasuski RA, Beard BM, Geoghagan JD, Thompson CM, Guidera SA. Optimal timing of hydration to erase contrast-associated nephropathy: the OTHER CAN study. J Invasive Cardiol. 2003;15:699-702 [II].

126. Bader BD, Berger ED, Heede MB, Silberbaur I, Duda S, Risler $\mathrm{T}$, et al. What is the best hydration regimen to prevent contrast media-induced nephrotoxicity? Clin Nephrol. 2004;62:1-7 [II].

127. Maioli M, Toso A, Leoncini M, Gallopin M, Tedeschi D, Micheletti C, et al. Sodium bicarbonate versus saline for the prevention of contrast-induced nephropathy in patients with renal dysfunction undergoing coronary angiography or intervention. J Am Coll Cardiol. 2008;52:599-604.

128. DiMari J, Megyesi J, Udvarhelyi N, Price P, Davis R, Safirstein R. $N$-acetylcysteine ameliorates ischemic renal failure. Am J Physiol. 1997;272:F292-8 [VI].

129. Webb JG, Pate GE, Humphries KH, Buller CE, Shalansky S, Al Shamari A, et al. A randomized controlled trial of intravenous 
$\mathrm{N}$-acetylcysteine for the prevention of contrast-induced nephropathy after cardiac catheterization: lack of effect. Am Heart J. 2004;148:422-9 [II].

130. Azmus AD, Gottschall C, Manica A, Manica J, Duro K, Frey M, et al. Effectiveness of acetylcysteine in prevention of contrast nephropathy. J Invasive Cardiol. 2005;17:80-4 [II].

131. Marenzi G, Assanelli E, Marana I, Lauri G, Campodonico J, Grazi $\mathrm{M}$, et al. $N$-acetylcysteine and contrast-induced nephropathy in primary angioplasty. N Engl J Med. 2006;354:2773-82 [II].

132. Investigators ACT. Acetylcysteine for prevention of renal outcomes in patients undergoing coronary and peripheral vascular angiography: main results from the randomized Acetylcysteine for Contrast-induced nephropathy Trial (ACT). Circulation. 2011;124:1250-9 [II].

133. Kelly AM, Dwamena B, Cronin P, Bernstein SJ, Carlos RC. Meta-analysis: effectiveness of drugs for preventing contrastinduced nephropathy. Ann Intern Med. 2008;148:284-94 [I].

134. Trivedi H, Daram S, Szabo A, Bartorelli AL, Marenzi G. Highdose $N$-acetylcysteine for the prevention of contrast-induced nephropathy. Am J Med. 2009;122(874):e9-15 [I].

135. Zagler A, Azadpour M, Mercado C, Hennekens CH. $N$-acetylcysteine and contrast-induced nephropathy: a meta-analysis of 13 randomized trials. Am Heart J. 2006;151:140-5 [I].

136. Pannu N, Manns B, Lee H, Tonelli M. Systematic review of the impact of $\mathrm{N}$-acetylcysteine on contrast nephropathy. Kidney Int. 2004;65:1366-74 [I].

137. Kshirsagar AV, Poole C, Mottl A, Shoham D, Franceschini N, Tudor $\mathrm{G}$, et al. $\mathrm{N}$-acetylcysteine for the prevention of radiocontrast induced nephropathy: a meta-analysis of prospective controlled trials. J Am Soc Nephrol. 2004;15:761-9 [I].

138. Gonzales DA, Norsworthy KJ, Kern SJ, Banks S, Sieving PC, Star RA, et al. A meta-analysis of $N$-acetylcysteine in contrastinduced nephrotoxicity: unsupervised clustering to resolve heterogeneity. BMC Med. 2007;5:32 [I]

139. Anderson SM, Park ZH, Patel RV. Intravenous $N$-acetylcysteine in the prevention of contrast media-induced nephropathy. Ann Pharmacother. 2011;45:101-7 [I].

140. Trivedi $\mathrm{H}$. Is there enough evidence to support use of $N$-acetylcysteine in contrast-induced nephropathy? Ann Intern Med. 2008;149:213 (author reply 215-216 [VI]).

141. Hoffmann U, Fischereder M, Krüger B, Drobnik W, Krämer BK. The value of $N$-acetylcysteine in the prevention of radiocontrast agent-induced nephropathy seems questionable. J Am Soc Nephrol. 2004;15:407-10 [VI].

142. Poletti PA, Saudan P, Platon A, Mermillod B, Sautter AM, Vermeulen B, et al. I.v. $N$-acetylcysteine and emergency CT: use of serum creatinine and cystatin $\mathrm{C}$ as markers of radiocontrast nephrotoxicity. AJR Am J Roentgenol. 2007;189:687-92 [VI].

143. Goldfarb S, McCullough PA, McDermott J, Gay SB. Contrastinduced acute kidney injury: specialty-specific protocols for interventional radiology, diagnostic computed tomography radiology, and interventional cardiology. Mayo Clin Proc. 2009;84:170-9 [VI].

144. Lanese DM, Yuan BH, Falk SA, Conger JD. Effects of atriopeptin III on isolated rat afferent and efferent arterioles. Am J Physiol. 1991;261:F1102-9 [VI].

145. Meyer-Lehnert H, Bayer T, Predel HG, Glanzer K, Kramer HJ. Effects of atrial natriuretic peptide on systemic and renal hemodynamics and renal excretory function in patients with chronic renal failure. Klin Wochenschr. 1991;69:895-903 [VI].

146. Valsson F, Ricksten SE, Hedner T, Lundin S. Effects of atrial natriuretic peptide on acute renal impairment in patients with heart failure after cardiac surgery. Intensive Care Med. 1996;22:230-6 [IVa].

147. Kurnik BR, Weisberg LS, Cuttler IM, Kurnik PB. Effects of atrial natriuretic peptide versus mannitol on renal blood flow during radiocontrast infusion in chronic renal failure. J Lab Clin Med. 1990;116:27-36 [II].

148. Weisberg LS, Kurnik PB, Kurnik BR. Risk of radiocontrast nephropathy in patients with and without diabetes mellitus. Kidney Int. 1994;45:259-65 [II].

149. Kurnik BR, Allgren RL, Genter FC, Solomon RJ, Bates ER, Weisberg LS. Prospective study of atrial natriuretic peptide for the prevention of radiocontrast-induced nephropathy. Am J Kidney Dis. 1998;31:674-80 [II].

150. Morikawa S, Sone T, Tsuboi H, Mukawa H, Morishima I, Uesugi $\mathrm{M}$, et al. Renal protective effects and the prevention of contrast-induced nephropathy by atrial natriuretic peptide. J Am Coll Cardiol. 2009;53:1040-6 [II].

151. Zhang J, Fu X, Jia X, Fan X, Gu X, Li S, et al. B-type natriuretic peptide for prevention of contrast-induced nephropathy in patients with heart failure undergoing primary percutaneous coronary intervention. Acta Radiol. 2010;6:641-8 [II].

152. Spargias K, Alexopoulos E, Kyrzopoulos S, Iokovis P, Greenwood DC, Manginas A, et al. Ascorbic acid prevents contrastmediated nephropathy in patients with renal dysfunction undergoing coronary angiography or intervention. Circulation. 2004;110:2837-42 [II].

153. Naidu KA. Vitamin $C$ in human health and disease is still a mystery? An overview. Nutr J. 2003;2:7-16 [II].

154. Briguori C, Airoldi F, D'Andrea D, Bonizzoni E, Morici N, Focaccio A, et al. Renal Insufficiency Following Contrast Media Administration Trial (REMEDIAL): a randomized comparison of 3 preventive strategies. Circulation. 2007;115:1211-7 [II].

155. Agarwal R. Effects of statins on renal function. Mayo Clin Proc. 2006;82:1381-90 [VI].

156. Khanal S, Attallah N, Smith DE, Kline-Rogers E, Share D, O'Donnell MJ, et al. Statin therapy reduces contrast-induced nephropathy: an analysis of contemporary percutaneous interventions. Am J Med. 2005;118:843-9 [IVa].

157. Patti G, Nusca A, Chello M, Pasceri V, D'Ambrosio A, Vetrovec $\mathrm{GW}$, et al. Usefulness of statin pretreatment to prevent contrast-induced nephropathy and to improve long-term outcome in patients undergoing percutaneous coronary intervention. Am J Cardiol. 2008;101:279-85 [IVa].

158. Zhang T, Shen LH, Hu LH, He B. Statins for the prevention of contrast-induced nephropathy: a systematic review and metaanalysis. Am J Nephrol. 2011;33:344-51 [I].

159. Takagi $\mathrm{H}$, Umemoto $\mathrm{T}$. A meta-analysis of randomized trials for effects of periprocedural atorvastatin on contrast-induced nephropathy. Int J Cardiol. 2011;153:323-5 [I].

160. Vogt B, Ferrari P, Schönholzer C, Marti HP, Mohaupt M, Wiederkehr M, et al. Prophylactic hemodialysis after radiocontrast media in patients with renal insufficiency is potentially harmful. Am J Med. 2001;111:692-8 [I].

161. Sterner G, Frennby B, Kurkus J, Nyman U. Does post-angiographic hemodialysis reduce the risk of contrast-medium nephropathy? Scand J Urol Nephrol. 2000;34:323-6 [I].

162. Lehnert T, Keller E, Gondolf K, Schäffner T, Pavenstädt H, Schollmeyer P. Effect of haemodialysis after contrast medium administration in patients with renal insufficiency. Nephrol Dial Transplant. 1998;13:358-62 [I].

163. Frank H, Werner D, Lorusso V, Klinghammer L, Daniel WG, Kunzendorf U, et al. Simultaneous hemodialysis during coronary angiography fails to prevent radiocontrast-induced nephropathy in chronic renal failure. Clin Nephrol. 2003;60:176-82 [I].

164. Reinecke H, Fobker M, Wellmann J, Becke B, Fleiter J, Heitmeyer $\mathrm{C}$, et al. A randomized controlled trial comparing hydration therapy to additional hemodialysis or $N$-acetylcysteine for the prevention of contrast medium-induced nephropathy: the Dialysis-versus-Diuresis (DVD) Trial. Clin Res Cardiol. 2007;96:130-9 [I]. 
165. Shiragami K, Fujii Z, Sakumura T, Shibuya M, Takahashi N, Yano M, et al. Effect of a contrast agent on long-term renal function and the efficacy of prophylactic hemodiafiltration. Circ J. 2008;72:427-33 [I].

166. Lee PT, Chou KJ, Liu CP, Mar GY, Chen CL, Hsu CY, et al. Renal protection for coronary angiography in advanced renal failure patients by prophylactic hemodialysis. A randomized controlled trial. J Am Coll Cardiol. 2007;50:1015-20 [I].

167. Marenzi G, Marana I, Lauri G, Assanelli E, Grazi M, Campodonico $\mathrm{J}$, et al. The prevention of radiocontrast-agent-induced nephropathy by hemofiltration. N Engl J Med. 2003;349: $1333-40[\mathrm{I}]$

168. Marenzi G, Lauri G, Campodonico J, Marana I, Assanelli E, De Metrio M, et al. Comparison of two hemofiltration protocols for prevention of contrast-induced nephropathy in high-risk patients. Am J Med. 2006;119:155-62 [I].

169. Song K, Jiang S, Shi Y, Shen H, Shi X, Jing D. Renal replacement therapy for prevention of contrast-induced acute kidney injury: a meta-analysis of randomized controlled trials. Am J Nephrol. 2010;32:497-504 [II].

170. Hager B, Betschart M, Krapf R. Effect of postoperative intravenous loop diuretic on renal function after major surgery. Schweiz Med Wochenschr. 1996;126:666-73 [II].

171. Shilliday IR, Quinn KJ, Allison ME. Loop diuretics in the management of acute renal failure: a prospective, double-blind, placebo-controlled, randomized study. Nephrol Dial Transplant. 1997;12:2592-6 [II].

172. Mehta RL, Pascual MT, Soroko S, Chertow GM. Diuretics, mortality, and nonrecovery of renal function in acute renal failure. JAMA. 2002;288:2547-53 [IVa].

173. Cantarovich F, Rangoonwala B, Lorenz H, Verho M, Esnault VL, High-Dose Furosemide in Acute Renal Failure Study Group. High-dose furosemide for established ARF: a prospective, randomized, double-blind, placebo-controlled, multicenter trial. Am J Kidney Dis. 2004;44:402-9 [II].

174. Uchino S, Doig GS, Bellomo R, Morimatsu H, Morgera S, Schetz M, et al. Diuretics and mortality in acute renal failure. Crit Care Med. 2004;32:1669-77 [IVa].

175. Ho KM, Sheridan DJ. Meta-analysis of frusemide to prevent or treat acute renal failure. BMJ. 2006;333:420 [I].

176. Bagshaw SM, Delaney A, Haase M, Ghali WA, Bellomo R. Loop diuretics in the management of acute renal failure: a systematic review and meta-analysis. Crit Care Resusc. 2007;9:60-8 [I]

177. Payen D, de Pont AC, Sakr Y, Reinhart K, Vincent JL. A positive fluid balance is associated with a worse outcome in patients with acute renal failure. Crit Care. 2008;12:R74 [IVb].

178. Bouchard J, Soroko SB, Chertow GM, Himmelfarb J, Ikizler TA, Paganini EP, et al. Fluid accumulation, survival and recovery of kidney function in critically ill patients with acute kidney injury. Kidney Int. 2009;76:422-7 [IVa].

179. Abizaid AS, Clark CE, Mintz GS, Dosa S, Popma JJ, Pichard $\mathrm{AD}$, et al. Effects of dopamine and aminophylline on contrastinduced acute renal failure after coronary angioplasty in patients with preexisting renal insufficiency. Am J Cardiol. 1999;83: 260-3 [II].

180. Bellomo R, Chapman M, Finfer S, Hickling K, Myburgh J. Lowdose dopamine in patients with early renal dysfunction: a placebocontrolled randomised trial. Lancet. 2000;356:2139-43 [II].
181. Kellum JA, Decker JM. Use of dopamine in acute renal failure: a meta-analysis. Crit Care Med. 2001;29:1526-31 [I].

182. Friedrich JO, Adhikari N, Herridge MS, Beyene J. Meta-analysis: low-dose dopamine increases urine output but does not prevent renal dysfunction or death. Ann Intern Med. $2005 ; 142: 510-24[\mathrm{I}]$.

183. Marik PE. Low-dose dopamine: a systematic review. Intensive Care Med. 2002;28:877-83 [I]

184. Ichai C, Passeron C, Carles M, Bouregba M, Grimaud D. Prolonged low-dose dopamine infusion induces a transient improvement in renal function in haemodynamically stable, critically ill patients: a single-blind, prospective, controlled study. Crit Care Med. 2000;28:1329-35 [II].

185. Lauschke A, Teichgraber UK, Frei U, Eckardt KU. Low-dose dopamine worsens renal perfusion in patients with acute renal failure. Kidney Int. 2006;69:1669-74 [II].

186. Allgren RL, Marbury TC, Rahman SN, Weisberg LS, Fenves AZ, Lafayette RA, et al. Anaritide in acute tubular necrosis. N Engl J Med. 1997;336:828-34 [II].

187. Lewis J, Salem MM, Chertow GM, Weisberg LS, McGrew F, Marbury TC, et al. Atrial natriuretic factor in oliguric acute renal failure. Am J Kidney Dis. 2000;36:767-74 [II].

188. Swaerd K, Valsson F, Odencrants P, Samuelsson O, Ricksten SE. Recombinant human atrial natriuretic peptide in ischemic acute renal failure: a randomized placebo-controlled trial. Crit Care Med. 2004;32:1310-5 [II].

189. Nigwekar SU, Navaneethan SD, Parikh CR, Hix JK. Atrial natriuretic peptide for management of acute kidney injury: a systematic review and meta-analysis. Clin J Am Soc Nephrol. 2009;4:261-72 [I].

190. Bouman CS, Oudemans-Van Straaten HM, Tijssen JG, Zandstra DF, Kesecioglu J. Effects of early high-volume continuous venovenous hemofiltration on survival and recovery of renal function in intensive care patients with acute renal failure: a prospective, randomized trial. Crit Care Med. 2002;30:2205-11 [II].

191. Liu KD, Himmelfarb J, Paganini E, Ikizler TA, Soroko SH, Mehta RL, et al. Timing of initiation of dialysis in critically ill patients with acute kidney injury. Clin J Am Soc Nephrol. 2006;1:915-9 [IVa].

192. Seabra VF, Balk EM, Liangos O, Sosa MA, Cendoroglo M, Jabber BL. Timing of renal replacement therapy initiation in acute renal failure: a meta-analysis. Am J Kidney Dis. 2008;52:272-84 [I].

193. Carl DE, Grossman C, Behnke M, Sessler CN, Gehr TW. Effect of timing of dialysis on mortality in critically ill, septic patients with acute renal failure. Hemodial Int. 2010;14:11-7 [IVa].

194. Bagshaw SM, Uchino S, Bellomo R, Morimatsu H, Morgera S, Schetz M, et al. Timing of renal replacement therapy and clinical outcomes in critically ill patients with severe acute kidney injury. J Crit Care. 2009;24:129-40 [IVa].

195. Shiao CC, Wu VC, Li WY, Lin YF, Hu FC, Young GH, National Taiwan University Surgical Intensive Care UnitAssociated Renal Failure Study Group, et al. Late initiation of renal replacement therapy is associated with worse outcomes in acute kidney injury after major abdominal surgery. Crit Care. 2009; 13:R171 [IVa].

196. Iyem H, Tavli M, Akcicek F, Bueket S. Importance of early dialysis for acute renal failure after an open-heart surgery. Hemodial Int. 2009;13:55-61 [IVa]. 